\title{
"Beyond the Veil": Queering Epistemologies, Imperial Anxieties, and the Quest for Forbidden Knowledge in Late-Victorian Gothic Literature
}

Kristen J. Davis

Follow this and additional works at: https://researchrepository.wvu.edu/etd

\section{Recommended Citation}

Davis, Kristen J., "'Beyond the Veil": Queering Epistemologies, Imperial Anxieties, and the Quest for Forbidden Knowledge in Late-Victorian Gothic Literature" (2017). Graduate Theses, Dissertations, and Problem Reports. 5446.

https://researchrepository.wvu.edu/etd/5446

This Dissertation is protected by copyright and/or related rights. It has been brought to you by the The Research Repository @ WVU with permission from the rights-holder(s). You are free to use this Dissertation in any way that is permitted by the copyright and related rights legislation that applies to your use. For other uses you must obtain permission from the rights-holder(s) directly, unless additional rights are indicated by a Creative Commons license in the record and/ or on the work itself. This Dissertation has been accepted for inclusion in WVU Graduate Theses, Dissertations, and Problem Reports collection by an authorized administrator of The Research Repository @ WVU.

For more information, please contact researchrepository@mail.wvu.edu. 
"Beyond the Veil": Queering Epistemologies, Imperial Anxieties, and the Quest for Forbidden Knowledge in Late-Victorian Gothic Literature

Kristen J. Davis

\author{
Dissertation submitted \\ to the Eberly College of Arts and Sciences \\ at West Virginia University
}

in partial fulfillment of the requirements for the degree of

Doctor of Philosophy in

English

Dennis Allen, $\mathrm{PhD}$, Chair

John Lamb, PhD

Adam Komisaruk, PhD

Lisa Weihman, $\mathrm{PhD}$

Lisa DiBartolomeo, $\mathrm{PhD}$

Department of English

Morgantown, West Virginia

2017

Keywords: epistemology, gothic, imperialism, knowledge, queer, sexuality, Victorian, Henry Rider Haggard, Arthur Machen, Richard Marsh, Bram Stoker

Copyright 2017 Kristen J. Davis 


\begin{abstract}
"Beyond the Veil": Queering Epistemologies, Imperial Anxieties, and the Quest for Forbidden Knowledge in Late-Victorian Gothic Literature
\end{abstract}

Kristen J. Davis

This dissertation analyzes four late-Victorian imperial gothic novels which focus on the British search for forbidden knowledge held by foreign and ancient Others. I demonstrate how the devastating outcomes of these tales illustrate the crisis of epistemology and undecidability felt by Victorians (often subconsciously) in relation to medico-legal policies like the colonial Contagious Diseases Acts and imperial campaigns such as the military intervention in 1880s Egypt to secure control of the Suez Canal. A chapter on Rider Haggard's She (1886-7) highlights the use of an (ultimately effective) Egyptian curse against the seemingly superior power of the imperialist; the ostensibly immortal Ayesha believes she has mastered the secret knowledge of the Other only to find herself destroyed by her arrogance and ignorance. This narrative of Egyptian, Arab, and British characters serves as a metaphor for the 1880s Egyptian Questionone in which Haggard advises wariness. A chapter on Richard Marsh's The Beetle (1897) examines concerns about sexual knowledge, contamination, and the fear of the colonial prostitute. I reveal how the novel supports the continuation of the colonial Contagious Diseases Acts as it portrays syphilitic contagion and the psychological, as well as physical, breakdown into irrational states from exposure to the colonial woman. A chapter on Bram Stoker's The Jewel of Seven Stars (1903) argues that the novel portrays hybridity as a force of menacing mimicry upon Victorian tomb-raiding Egyptologists. The ambiguity espoused in both the dissimilar 1903 and 1912 editions of the novel attest to the inability to truly know anything for certain and cautions against the flawed arrogance of such assuredness, particularly when it relies on the exploitation of archeological artefacts from colonized lands. The final chapter on Arthur Machen's The Great God Pan (1894) reveals that the search for forbidden knowledge can expose one to a terrifying world beyond language, rationality, and epistemology into a queered phenomenology. The fundamental anxiety underlying all these texts is not merely the potential fallibility of Western knowledge and Europeans' ability to coopt the knowledge of the Other, but also the terrifying encounter with the Real — the traumatic kernel outside epistemology and symbolization itself. 


\section{Dedication}

To: Ron and Gail Davis

and in memory of Dorothy Davis and Varonia Levy 


\section{Acknowledgements}

This project's completion would not have been possible without the guidance and support of several people. First and foremost, Dennis Allen has been an incredible chair. His great attitude, sense of humor, and optimism are infectious and I always left his office feeling better than I did before I entered it. He has provided me with excellent feedback and ideas over the years. He has given me advice on everything from theorists to investigate for the dissertation, to job search and publishing advice, to coping with the stressful demands of being a teacher and doctoral student. For his encouragement and limitless patience, I will always be grateful.

The other members of my committee have also been invaluable. John Lamb has provided astute critiques and asked thought-provoking questions; thank you for your excellent ideas and for challenging me intellectually. Adam Komisaruk has been very helpful, not only as an enthusiastic and thoughtful committee member, but also as a graduate program director and mentor. Additionally, Lisa Weihman has asked compelling questions and pushed my thinking outside the box. I really appreciate her encouragement and our chats (online and in person) about the various challenges of academia. Finally, I want to thank Lisa DiBartolomeo for her advice and painstaking comments on my dissertation. I am recognizing some bad writing habits and am actively working to improve them!

I also want to thank the faculty and staff I have had the privilege to work with over the years at WVU. I especially appreciate Donald Hall, who was instrumental in my developing ideas and early work that evolved into my dissertation. I enjoyed our courses and independent studies together. Katy Ryan has also been a wonderful professor and mentor; thank you for your inspiring work both in and out of the classroom.

Additional thanks go to my friends and colleagues here at WVU. I treasure the friendships I've made with officemates, including Lindsey Joyce Tuggle, Doug Terry, Lisa Detweiler Miller, Jamie Kegg, and Jessica Queener. I've enjoyed sharing ideas (and sometimes commiserating) about scholarship and teaching and I've cherished our social outings together. I also appreciate my friendships with Cara Snider Williams, Courtney Novosat, Christina Rothenbeck, Kayla Krueger McKinney, Sarah Einstein, and Angela Hanlin. I am thankful to Lisa Panico for her enduring friendship through good times and bad; we've come a long way! Our offroading adventures with the dogs to the river have been particularly therapeutic.

I would be remiss not to mention my dogs, Kaley (Boo) and Aroha. They have been my constant companions and loyal friends for many years. Whether they are listening to my ideas while hiking, lying at my feet as I work at the computer, or cuddling close on the couch while I read or relax, they are constant, patient, loving, and loyal friends. I truly treasure our time together.

Finally, I am most grateful to my parents for their enduring love and support throughout my lifetime. They have been incredible role models who exhibit compassion, service, generosity, and love for others. They have patiently listened to me talk about my academic work over the years, no matter the topic, and have provided continual encouragement. I cannot thank them enough for everything they have done for me. They are my best friends and I am truly blessed to have them in my life. 


\section{Table of Contents}

Chapter 1: Introduction: Late-Victorian Epistemological Doubt..........................

Chapter 2: The Egyptian Curse and Failed Reverse Mimicry: Epistemological Anxiety and

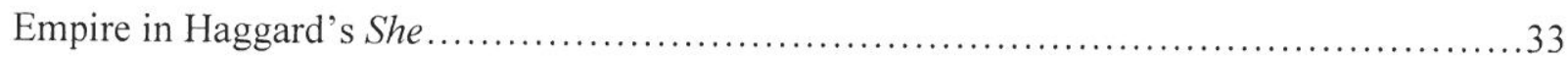

Chapter 3: Competing Epistemologies and Irrational States: Sexual Terror and Contamination

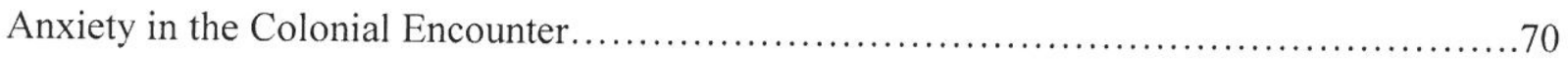

Chapter 4: "A New and Strange World": Dangerous Hybridity in Stoker's The Jewel of Seven

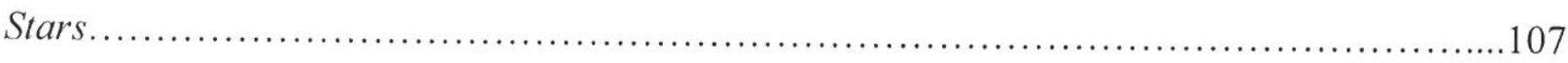

Chapter 5: "I couldn't define it to you, I only know I felt queer": The Great God Pan, Queer Knowledge, and the Horrors of a World Beyond Epistemology

Works Cited. 


\section{Chapter 1}

Introduction: Late-Victorian Epistemological Doubt

The latter half of the $19^{\text {th }}$-century displayed unprecedented self-doubt in British belief and knowledge systems. Scientific advances in geology, paleontology, and especially Darwin's theory of evolution were fundamentally at odds with Christian beliefs, particularly concerning the origins of human society and God as Creator through intelligent design. The authority of Christianity and the Bible were undermined by scientific and rationalistic Victorian discoveries and theories. Paradoxically, Victorians did not respond by merely disregarding epistemologies that lay outside the scientific method; instead, they often sought to validate esoteric, occult, and "supernatural" phenomena through a scientific approach. "Rejecting the anthropological orthodoxy that science necessarily superseded religion in the evolution of cultures," asserts Kelly Hurley, "late-Victorian occultists brought scientific methods to bear on their topic and argued that magical phenomena could be rationally demonstrated and validated" ("Victorian Mummy" 191). This is well-illustrated by the Society for Psychical Research (SPR), founded in 1882 . The SPR attempted to develop a "science of the supernatural" which replaced terms such as "ghosts" with "phastasms of the living" or "haunted houses" with "phantasmogenetic centres" in an attempt to re-categorize supernatural phenomena as "supernormal" (Luckhurst, "Knowledge" 197). The shift toward legitimizing occult knowledge is represented through the evolution of Victorian psychical detective fiction, for example; L. Anne Delgado's work on late $19^{\text {th }}$-century British literature and the occult explains that while earlier tales construct the occult as a kind of "Orientalized threat" needing scientific rationalism to solve the mystery, many later stories required working knowledge of the occult for the detectives to resolve the crimes (197-198). Characters such as Dracula's Van Helsing would fall into this category. 
Other Victorians laid aside traditional scientific methods altogether in their pursuit of knowledge and answers. This is evidenced by the incredibly popular movement of Spiritualism - communication with the dead via mediums - practiced or witnessed by much of the British intelligentsia. In Reading the Sphinx, Lynn Parramore notes that the discrediting of Biblical and classical texts during the 1860 s prompted researchers to look to "nonwestern societies for insights into human prehistory" (104), seen through the popularity of such movements as Theosophy, the Order of the Golden Dawn, and Rosicrucianism, especially among British educated and elite. The interest in nonwestern traditions also relates to new social sciences emerging during this time such as archeology, sociology, and anthropology, which were often linked with imperial projects. While not intentionally, disciplines such as Egyptology tended to blur myth, occult, and science. For example, while archeology attempted to quell superstitions surrounding ancient cultures, Roger Luckhurst argues that the "official discourses only fed rumours of a body of hidden or shadow knowledges" and it was "difficult to police the boundaries of Egyptological legitimacy, particularly in the traffic of archeological artefacts and the stories about those artefacts" ("Mummy's Curse" 123). In a way, then, disciplines were always already hybrid and perhaps the Victorian attempts to solidify distinct, positivist, sciencebased epistemologies - even as others attempted to queer such forms of knowledge by combining them with various other epistemological approaches, particularly in relation to the occult and supernatural — was an attempt to disguise that underlying hybridity. Competing knowledges or epistemologies challenged and subverted one another, especially in the "wild and wordless wastes of colonial India, Africa, the Caribbean," the "dark unruly spaces of the earth" (Bhabha 144, 149). Such subversions happened rather frequently during the $19^{\text {th }}$-century as Britain was the center of an extensive global empire comprised of more than 400 million 
subjects. By 1900, nearly one quarter of the world's land surface was part of the British Empire (Greenblatt 1636). Vast numbers of Britons permanently emigrated to the colonies; about 15 million people left Britain to settle overseas during the $19^{\text {th }}$-century (Judd). There were also myriad travelers, tourists, missionaries, artists, scholars, and military personnel who regularly experienced colonial contact in nearly every part of the globe.

A critical aspect of the Victorian imperial project was not only to conquer and exploit various parts of the world but also to know them; the colonial impulse mirrors the impulse for knowledge. Edward Said argues that Orientalism is an exercise in power exerted through knowledge: the West authors the East, becomes its authority, and this "knowledge" works to legitimize imperial control. But can we truly "know" the mysteries of the Other? Are there limits or dangers in seeking such knowledge? Late Victorian anxieties concerning such questions become evident in the literature of the period. While the British wished to believe that they were effectively pushing their modern scientific approach onto colonial subjects to "enlighten" and "civilize" them, mysterious and often powerful knowledge held by the foreign Other inevitably pushed back. The prejudice that knowledge emerged from Europe and ignorance from subject races is thus much more complicated than the binary suggests.

Given the cultural context of late imperialism and the scientizing of the occult and foreign myths of knowledge, how did popular literature respond to the anxieties engendered by the British attempt to know and master the Other? And why were these responses often linked to dangerous or terrifying sexuality? The idea that there are things we cannot (and should not) know about foreign or ancient ${ }^{1}$ cultures is exemplified with nightmarish results in late $19^{\text {th }}$.

\footnotetext{
' This may seem problematic since "antiquity" relates to diverse cultures such as Roman, Egyptian, and Far Eastern; however, the tales reveal that even cultures which are often respected and largely imitated by the West are sources for anxiety. This is seen especially well in the horrifying tale of Roman paganism haunting bourgeois Londoners in The Great God Pan.
} 
century Gothic literature. Such literature took occult elements that pervaded popular Victorian culture or myths of secret ancient knowledge (reanimation, telepathy, psychic activity, reincarnation, mesmerism ${ }^{2}$ ) and combined them with imperial settings and characters to produce cautionary tales about the negative repercussions of trying to master such knowledge. While a few critics have considered the occult and imperial Gothic in terms of atavism (Brantlinger, Rule of Darkness) or the real-life use of occult in imperial settings (Luckhurst, "Knowledge"), this analysis will examine a variety of late-Victorian Gothic tales and the recurring intersections between forbidden knowledge, empire, sexual anxiety and contamination. Westerners believed that their "superior" abilities would enable them to employ native knowledge more effectively and efficiently than the natives themselves (just as colonists knew "best" how to utilize native lands, resources, bodies, and so on). Fiction of the period, however, suggests that Europeans failed disastrously in such attempts at "reverse" mimicry and thus reveal the anxiety of undecidability created through competing epistemologies in the colonial encounter.

The time period (1887-1903) of this analysis's chosen texts occurs during a crucial era of transition. In their anxious pessimism, the novels play a role in the cultural movement away from Victorian optimism toward Modernist doubt and undecidability as every major cultural certainty was undermined by major thinkers of the $19^{\text {th }}$ - and early $20^{\text {th }}$-centuries, including Darwin, Nietzsche, Marx, and Freud. While the British empire was vast during this time (the "age of empire" occurred between 1880 and World War I), anxieties were nevertheless increasing as "new imperialism" and jingoism took over from the ideologies of free-trade imperialism (Brantlinger, Victorian 5); these anxieties about empire are well displayed in Victorian and

\footnotetext{
${ }^{2}$ While mesmerism officially began with eighteenth-century European Franz Mesmer's work with animal magnetism, it became a pseudo-science used among colonial natives (and may have existed earlier in similar forms, such as hypnosis). For example, Roger Luckhurst explains that during the late $19^{\text {th }}$-century there was a "long established culture of mesmerism in India, away from its marginal and abject status in England" ("Knowledge" 200).
} 
imperial Gothic literature, though public debate about empire also certainly existed. The late $19^{\text {th }}$ - and early $20^{\text {th }}$-centuries produced a Gothic revival in which the Gothic became more "domesticated"- - set in contemporary settings in Britain or abroad in the empire. They exhibit the influence of Realism (as opposed to Romanticism) in their approach and were often presented as scientific, medical, historical, or criminal case studies and included scientists, doctors, and archeologists. The paradoxical term "Victorian Gothic" well-illustrates the competing epistemologies of positivist, empirical science and supernatural, non-Western or occult knowledges. The authors discussed in this study approach the underlying anxiety of undecidability through various approaches: She utilizes an Egyptian curse; The Beetle emphasizes contamination and irrational states; The Jewel of the Seven Stars focuses on reanimation and hybridity; and The Great God Pan exposes a terrifying world beyond epistemology itself. All these texts display the persistent epistemological anxiety about the impossibility of transcendental truths and thus challenge British superiority and the imperialist project.

\section{Challenging Western Ideologies: Undecidability}

The problems and complexities arising from imperialism interrogated British belief systems, authority, and superiority on a fundamental level. Homi Bhabha discusses European cultural rule in colonial spaces via the role of the "English Book" (the Bible or other canonical European text). The English book ostensibly represents the authority of imperialism and Western beliefs in general. It "figures those ideological correlatives of the Western sign-empiricism, idealism, mimeticism, monoculturalism (to use Edward Said's term) - that sustain a tradition of English 'national' authority" (Bhabha 147). Bhabha references a particular colonial situation involving the Christian Bible, translated into the native tongues of India (as it was elsewhere). 
The natives respond with challenging questions ("How can this book be from God if it was created and given to us by the British?") as well as their decision only to adhere to certain aspects of the scriptures. This is Bhabha's central example of how authoritative texts are challenged and subverted by colonial natives.

Critic Benjamin Graves explains that while the English book is supposed to glorify the "epistemological centrality and permanence of European dominance, [it] paradoxically is an emblem of 'colonial ambivalence' that suggests the weakness of colonial discourse and its susceptibility to "mimetic subversion"' (1). Instead of the notion of silent, faceless native servants controlled by an all-powerful, authoritative empire, Bhabha complicates this idea by his concepts of mimicry and hybridity. Colonized subjects often imitate their colonizers, but such repetitions are never exactly like the original—whether purposefully or not—and thus the authority of the original is undermined by the imitation. Competing epistemologies among European and Other cultures actually destabilize Western authority. The notion of Western ideologies as self-evident and universal is questioned when the colonized exhibit "flaws" in their European mimicry. This is not merely the specific failure of a "primitive" group of people. The fact that such "universal" ideologies are not quickly adopted and easily replicated by the (now "enlightened") colonized peoples disrupts the power and legitimacy of the imperial approach.

Rather than embodying the supposedly self-evident and universal authority of European rule, the English book and Western ideologies are recognized as cultural constructions and enunciations by colonized peoples. Their response is hybridity, new transcultural forms generated by encounters of various cross-cultural exchange. If Western ideologies are appropriated variously in colonial contexts, the symbols of "truth" held by Europeans are deconstructed to become mere signs, causing the "dominant discourse to split along the axis of 
its power to be representative, authoritative" (Bhabha 155). Graves notes that "the colonized subject's repetition of the English book invariably involves a changing of its nuances-a subversion, in other words, that translates eventually into political insurgence" (1). These repetitions and resulting hybridity expose British universals as culturally constructed and create an epistemological anxiety in ruling authorities. According to Bhabha, hybridity "unsettles the mimetic or narcissistic demands of colonial power but reimplicates its identifications in strategies of subversion that turn the gaze of the discriminated back upon the eye of power" (154). If colonial power leads to hybridization, the "ambivalence at the source of traditional discourses on authority enables a form of subversion, founded on the undecidability that turns the discursive conditions of dominance into the grounds of intervention" (Bhabha 154). Imperialists were forced to question their Western epistemology and ultimately the morality and efficacy of their civilizing mission.

\section{Blurring Epistemologies: Subjugated, Traditional, and Heterodox Knowledges}

In addition to the (often subtle) subversion of Western epistemologies through mimicry, European imperialists also encountered mysterious centuries-old belief systems and "subjugated knowledges" throughout the empire. In "Knowledge, Belief and the Supernatural at the Imperial Margin," Luckhurst discusses various accounts of Victorian occult experience (such as from the SPR) which he calls "doxai, a shadow-record of beliefs and semi-legitimate knowledges" that circulated outside orthodox epistemology (199). He considers doxai to be subjugated knowledges, defined by Michel Foucault as "a whole set of knowledges that have been disqualified as nonconceptual," "insufficiently elaborated" or "below the required level of erudition or scientificity" (qtd. Luckhurst, "Mummy's Curse" 123-124). Luckhurst's research suggests that doxai held a different status in colonial spaces; narratives describing occult 
experiences, telepathic and other uncanny methods of communication were commonplace.

Science, order, and rationalism were emphasized in official imperialist discourse, but especially in the hinterland "where the writ of modernity reached the limits of Western power, leaving behind the supports of governmental, military or scientific institutions, and technologies of communication, doxai became a more locally responsive discourse, and the line between positive knowledge and folkloric belief became blurred" (Luckhurst, "Knowledge" 200).

This blurring of epistemologies is well displayed through the study of Egyptian history and folklore which rose to great popularity during this time. In the West, ancient Egypt was largely revered for its early development of modern civilization, culture, and power as well as rich spiritual/religious/mythological aspects that appealed to many literary and elite Victorians. A crucial aspect of Egyptology was the artifacts being "discovered" (or stolen) by nascent European archeologists during the $19^{\text {th }}$-century. Napoleon invaded Egypt in 1798 and found the Rosetta Stone shortly after; the British seized the Stone after Napoleon's defeat in 1801. The Stone was, of course, the key to solving the riddle of hieroglyphics for a written language that had been "dead" for almost 2,000 years. The interest in Egyptian relics and ancient culture continued to flourish through the century and by the 1880 s, tomb-hunting had gained widespread popularity among both experts and amateurs. In 1881 , a cache of royal mummies was discovered (including Rameses the Second, then considered the Pharaoh of the Biblical Jewish exodus) which led to what Luckhurst calls the "golden-age of tomb-hunting in the Valley of the Kings" ("Mummy's Curse" 133). He notes that "unofficial and undisciplined knowledge" such as rumor, gossip, and folklore played a major role in discourse surrounding Egypt even though the Western institutionalized discourse of Egyptology attempted to establish a "cohesive authority" that would subjugate superstitions about ancient Egyptian sites and objects (123). Interestingly, this 
hybridization of epistemologies is repeatedly alluded to in Egyptian Gothic ${ }^{3}$ narratives of the period, especially through the commonly portrayed scene at a museum where the limitations of European knowledge are tested through ancient curses and reanimated mummies.

Outside archeology and literature, Egypt also influenced the "spiritual movement of the age," what Victorian contemporaries called the new upsurge of occult-related interests. In The Place of Enchantment: British Occultism and the Culture of the Modern, Alex Owen describes this "spiritual movement" as revealing an "interest in medieval and Renaissance Christian mysticism, heterodox inspirational neo-Christianity, and, most notably, a nondenominationalsometimes non-Christian-interest in 'esoteric philosophy,' or occultism" (4). The movement included the Hermetic Order of the Golden Dawn, an elite secret society founded in the 1880s which gained the membership (or alleged membership) of famous people such as Bram Stoker, Arthur Conan Doyle, H. Rider Haggard, Florence Farr, Aleister Crowley, Arthur Machen, W.B. Yeats, and Maud Gonne. With a focus on esotericism, "authentic" canonical texts, and practices of magic, leaders found inspiration in "centuries-old Rosicrucian tradition with its roots in JudeoChristian mysticism and the 'Egyptian' esotericism of Hermes Trismegistus”4 (Owen 3). This adaptation of ancient beliefs for a new alternative system dependent on "secret knowledge" reveals the hybridization of epistemologies affecting Victorians on the home front.

The quest for secret knowledge and alternative belief systems was in fact widely popular among Victorians. What is known as Modern Spiritualism was imported from the U.S. in the 1860s, flourished until well after World War I, and reemerged during World War II. The level of

\footnotetext{
${ }^{3}$ Luckhurst notes that the widespread interest in — and anxieties about-ancient Egypt formed a trend in literature and popular culture especially from the 1880s to the 1930s ("Mummy's Curse," 123).

${ }^{4}$ Hermetic occult knowledge was based on what were believed to be texts written by an ancient Egyptian magician and scribe, Hermes. They were actually composed by Greeks living in Egypt in the $2^{\text {nd }}$ and $3^{\text {rd }}$ centuries, however (Thompson 129).
} 
seriousness varied greatly as some Spiritualists and observers understood the practice as entertainment while many others believed whole-heartedly in the ability to communicate with the dead through mediums, automatic writing, and séances, providing knowledge of life beyond the grave. Delgado explains that the doubts of the modern age (and great losses from war) led many people to a serious investment in Spiritualism as it "realigned faith in the unknown by establishing contact with those who were once known" (4). Spiritualism also could be an empowering space for women as they were believed to have heightened emotions that were more sensitive to spirits than men's, allowing them to establish authority in the field. In this way, Spiritualism was subversive and "facilitated oppositional discourses that countered more orthodox narratives of belief" and gave women more autonomy over "their own bodies and bodies of knowledge" (Delgado 4). The relatively passive "feminine" role as medium was denigrated by active "masculine" adepts, however.

Growing out of Spiritualism was the Theosophical Movement, also founded in the U.S. in 1875 by the infamous Helena Petrovna Blavatsky and Henry Steel Olcott. This movement was more elite and active: whereas Spiritualist mediums were seen as passive recipients of supernatural communications with the dead — over which they had no power or understandingTheosophists nurtured members into "adepts" who were able to manipulate occult/magical powers because they had been initiated into its secret knowledge. Religion scholar Stephen Prothero explains that Theosophy sought to reform Spiritualism "by 'uplifting' its masses out of their supposed philosophical and moral vulgarities - to transform the masses of prurient ghostseeking Spiritualists into ethically exemplary theorists of the astral plane" (qtd. in Burdett 224). Indeed, the Theosophical Society added a moral, educational, elite, religious, and investigative approach to Spiritualism. Carolyn Burdett's contribution to The Victorian 
Supernatural explains that Theosophists' aims were threefold: "to form a universal brotherhood of humanity free from distinctions of race, creed, sex, caste or colour; to support and encourage the study of comparative religion, philosophy and science; and to investigate occult laws" (224225). Such comparative and eclectic studies led to (Blavatsky's successor) Annie Besant's notion of Theosophy as an "evolutionary science" where reincarnation represents how civilization or "evolved life, is the product of rebirths" and that karma plays a crucial role in individuals" moral accountability (Burdett 225). While the new Darwinian lens challenged traditional/orthodox belief systems, alternative or heterodox spiritualities "accommodated and even integrated such world views into their own stories of origin" and "produced a type of knowledge that was ostensibly legitimized by scientific certainty yet endowed with an aura of mystery and otherworldliness" (Delgado 4-5). As Theosophy drew from Eastern philosophy as well as scientific and esoteric Western traditions, it serves as another example of late-Victorian negotiations of competing epistemologies.

The vast Victorian Empire brought myriad Westerners into contact with many nonWestern religions, as well. Arthur Conan Doyle reveals the fascination with the wisdom and power of the "East" in The Mystery of Cloomber (1889). In the story, a Major-General who killed a Buddhist holyman during the Afghan war is thereafter haunted until three "chela" disciples arrive in Scotland and convince him to commit suicide. The narrator suggests that if skeptical Europeans "will look to the East, from which all great movements come, he will find there a school of philosophers and of savants, who working on different lines from his own, are many thousand years ahead of him in all the essentials of knowledge" (qtd. in Brantlinger, Victorian 49). Colonists, travelers, and missionaries made frequent contact with major religions such as Hindu, Buddhism, and Islam. Their reactions varied from blatant disrespect and 
animosity (as evidenced in Cloomber and a variety of other stories by authors such as Kipling) to conversion (seen through real-life famous examples such as Richard Burton). Remnants of ancient religions were also sometimes found close to home, such as Roman pagan relics in Wales. While more modern Western belief systems were still generally favored among the British, the literature of the period portrays the mysterious attraction to alternate spiritualities and provided cautionary tales about respect for such traditions and in many cases, suggested Britons keep their distance. Such narratives reveal Western anxieties about the power (and potential vengeance) of the non-Westerner and thus call into question the imperial project itself.

\section{Subconscious Anxieties: Undecidability and Pessimism in Literature}

Many Victorian authors used fiction as a means to express the nation's increasing anxieties regarding the imperial enterprise. Bhabha's work in postcolonial studies outlines the ways in which the colonial encounter and undecidability undermine Western authority and superiority, though discussing such doubts seemed difficult for many Britons to voice overtly. Psychoanalysis explains that humans have difficulty confronting anxieties directly as our unconscious is continuously "sliding" to keep such things repressed; in this way, it is apparent that Victorian authors often used the Gothic narrative to encode doubts about global exploitation and whether imperialists truly know what is "best" for the colonized. Such authors often invoked the past into contemporary settings where the non-European characters are representatives of a world that is gone and thus not a threat. The narratives then suggest that the places Britain colonized were merely earlier stages of civilization - that such cultures are destined to die out anyway — and Britain has transcended them, and so in a sense, imperialism is justified. However, the authors' deep-seated anxieties are reflected in the way that hauntings, curses, contamination, psychological trauma, injury, and death come back from the "past" or the "empire" to harm 
British subjects at home and abroad. The doubt and undecidability seen in fiction exhibits the epistemological crisis affecting so many Britons.

A recurring theme of late-Victorian writers was the quest for hidden or forbidden knowledge. Sometimes these pursuits took place abroad in the empire or "unknown" parts of the world; sometimes they happened at home in London after experience and "expertise" were gathered from ancient cultural world centers such as Egypt or India; other times, they occurred domestically, with only second-hand or ancient information available with which to seek occult knowledge. In any of these scenarios, however, such tales did not usually lead to a positive or fruitful endeavor. Many narratives feature British or European characters of certainty and arrogance-mirroring British ethnocentric imperialists—who undertake expeditions or experiments to attain forbidden/occult knowledge but ultimately meet disastrous results. Usually the sought-after secret knowledge is not uncovered and death and terror ensue; if such knowledge is discovered, it led to insanity or horrific and haunting results.

This trope relates to Patrick Brantlinger's characterization of "imperial Gothic" in Rule of Darkness: British Literature and Imperialism, 1830-1914. Such tales represent Europeans regressing or "going native," forces of barbarism invading civilization, and diminished opportunities for "adventure and heroism in the modern world" (230). The quest for hidden/forbidden knowledge initially appears to be a great adventure-sometimes involving the search for ancient tombs, lost cities, and powerful and supernaturally beautiful rulers, other times in attempting to perform occult activities such as reanimation of mummies or achieving immortality. Such adventures, however, are physically and psychologically threatening and devastating; they repeatedly portray the dangerous nature of alternative epistemologies to Westerners who never really comprehend or control such powers. 
The four texts discussed in this analysis critique certainty/decidability and are cautionary for both imperial and unorthodox or occult endeavors. H. Rider Haggard's She (1887) features two Cambridge fellows who seek a mythical, immortal female empress in central Africa to appropriate her secret knowledge and thus the potential power to rule the world. They are entranced by her incredible beauty, however, and in a twist of an ancient Egyptian curse, witness Queen Ayesha's (apparently limited) knowledge of immortality graphically reversed. Ayesha dies and the fellows barely survive the ordeal with their lives. In Richard Marsh's The Beetle (1897), a young British tourist in Cairo enters a dangerous native quarter out of curiosity (and his lust for the beautiful and sensual "Woman of Songs"), is seduced, and held captive by a sadistic religious cult of Isis who practice rape and human sacrifice. When he finally escapes, his past follows him back to London for more supernatural horrors, irrational states, mayhem, and death. In Stoker's 1903 novel The Jewel of the Seven Stars, an Egyptologist uses his knowledge of the ancient Egyptian Queen Tera and, after raiding her mummified remains and an assortment of jewels and artifacts from a forbidden tomb in Egypt, attempts to reanimate her in Britain. His daughter becomes possessed by the spirit of the queen, creating a dangerous hybridity. The reanimation goes horribly awry and leads to the death of all involved (except the narrator) and the disappearance of the mummy. The Great God Pan (1894) by Arthur Machen, though positioned last, is part of a logical (rather than chronological) order; it represents a limit case in queer/ing epistemology. Pan tells the story of a doctor whose occult interest in "transcendental medicine" leads him to an experiment on a young woman's brain that will supposedly allow her to see beyond the veil of "dreams and shadows" of ordinary life into its secret forces and knowledge, known as seeing the "god Pan" (Machen 184). Though the girl immediately goes insane, she is also infernally impregnated by the devil-like Pan and gives birth to demi-god 
Helen who corrupts the minds, bodies, and souls of respectable young men in London.

Pan/Helen's queering force exposes those she encounters to a horrific, queer knowledge beyond rationality, language, and epistemology itself and instead introduces a queer phenomenology.

Rather than affirming the superiority of European epistemology or illustrating the useful power of alternate/non-European knowledges, these texts reveal the undecidability of competing epistemologies seen in the colonial encounter. Such narratives exacerbate the anxiety surrounding this undecidability by portraying failed "reverse" mimicry in which Europeans attempt to appropriate doxai knowledges for empowerment, only to find they cannot truly master it. While Bhabha's concept of mimicry focuses on imperialism's effects on the colonized, what I call "reverse mimicry" considers epistemological mimicry's effects on the colonizers. In "reverse mimicry," the colonizer fails to properly enact or imitate the knowledge and rituals of the colonized. Mimicry and reverse mimicry represent the complex colonial exchange that was more of an interpenetrating, mutual osmosis between cultures rather than one culture subsuming or completely dominating another. Self-assuredness led Europeans to believe they could acquire and exploit doxai knowledge of the Other in much the same way they had acquired and exploited native bodies, lands, and resources; Gothic literature, however, reveals that this may not be as simple as it seems. A pertinent example of reverse mimicry is the Victorian attempt to "scientize" occult and supernatural phenomena stemming from ancient and foreign cultures; such epistemological "hybridity" is a motif utilized frequently in late-Victorian Gothic fiction. European reverse mimicry of powerful secret/occult knowledge typically led to dire and tragic circumstances that could have been avoided if not for Western hubris and arrogance. European mimicry is not purposefully subversive like the colonized's often was-Western authority was maintained throughout $19^{\text {th }}$-century colonization and such subversion was largely unnecessary. 
This mimicry, rather, seemed to be closer to ineptitude and hubris as Europeans did not generally question their actions or the consequences of trifling with foreign and ancient secret knowledge. While reverse mimicry is not a deliberate attempt to subvert the authority of the West but rather to bolster it, the consistently failed attempts portrayed in late-Victorian Gothic nonetheless undermine the ostensible superiority of the West in a critique of the imperialist agenda. In Victorian Gothic fiction, the characters experimenting with forbidden knowledge are not merely amateurs or triflers; they are well-educated and respected doctors, academics, politicians, scientists, researchers. Their failures imply that even the best and brightest of England cannot understand or master such queer knowledge. The idea that the knowledge/power of the Other can supersede Western rationality and authority heightened epistemological undecidability and doubt. And if Europeans cannot master foreign cultures' doxai knowledges, it could mean that the power does not lie simply in the acquisition of secret knowledge but perhaps in the Other herself.

\section{Genre: The Utility of the Gothic}

The fiction analyzed in this project can all be categorized within the mode of the Gothic - the genre most useful in illustrating and attempting to negotiate cultural anxieties, including epistemological ones. By its very nature, Gothic also focuses on horror, terror, and anxiety as techniques to elicit fear, disgust, desire, frisson, and other visceral responses in the reader. The supernatural elements that often accompany the genre suspend the reader in a space beyond Western rationality and yield more extreme and exaggerated tales to give the author greater imaginative opportunities for social critique.

While initially marginalized both as a fictional genre and in literary criticism, the Gothic has become a crucial area of study and discourse for academic scholars throughout a wide 
variety of fields, including literature, history, and the social sciences. Initially, during the Renaissance, the term "Gothic" was used in contrast to classically styled architecture. Where the classical was considered simple, pure, rational, civilized, and practical, Gothic was ornate, excessive, convoluted, irrational, and barbaric. Because the Goths were one of the Germanic tribes that led to the downfall of the Roman Empire in the fifth century, they were viewed as opposing classical Roman style — even as destroyers of it. The Dark Ages following the fall of Rome became known as the medieval period generally and extended into the 1600s; Gothic soon became associated with all things medieval. Gothic scholars David Punter and Glennis Byron note that Renaissance art historians first used the term aesthetically and "erroneously attributed a style of architecture to those Germanic tribes that sacked Rome, and identified this style as barbaric, disordered and irrational in opposition to the classical style" (4). Dr. Johnson's 1775 Dictionary defined a Goth as "one not civilised, one deficient in general knowledge, a barbarian" (qtd. in Punter and Byron 4). The (mis)conception of Gothic had an ideological purpose which attempted to establish the superiority of the rational, orderly, and civilized world based on Greco-Roman attitudes and style.

In literature, the Gothic is far from medieval-it was, in fact, established as a selfconscious literary genre well after the Renaissance period in the 1760s. Literary Gothic, considered at its height between the 1790s and 1820s, maintains many of the earlier associations with architecture, including excessive, barbaric, and irrational characteristics. While the definitions of Gothic have changed over the years, several important aspects stand out: an emphasis on transgression and decay, the returning past, challenging or dissolving boundaries, and an aesthetics of fear. ${ }^{5}$ Judith Halberstam also notes the important role desire plays in most

\footnotetext{
${ }^{5}$ See the Routledge Companion to the Gothic (ed. Spooner and McEvoy) and Blackwell's Companion to the Gothic (ed. Byron).
} 
Gothic texts, arguing that the Gothic "may be loosely defined as the rhetorical style and narrative structure designed to produce fear and desire within the reader" (Skin Shows 2). Gothic excesses, fascination with transgression, and anxiety over cultural limits and boundaries continue to produce ambivalent emotions and meanings in tales of darkness, desire, and power. David Punter's Literature of Terror notes the characteristics of traditional Gothic such as the portrayal of terror, archaic settings, presence of the supernatural, stereotyped characters, and techniques of literary suspense.

In certain ways, the Gothic recaptured history, used a style of self-conscious un-realism (something that changed significantly for Victorian Gothic), revealed a connection with the primitive, barbaric, and taboo, and, above all, had an emphasis on terror $(1,5)$. Punter reminds us that fear is not merely a theme or an attitude but also "has consequences in terms of form, style, and social relations of the texts"; by exploring Gothic, we explore fear and see the various ways that "terror breaks through the surfaces of literature" (Literature 18). The Gothic's emphasis on fear means much more to readers and critics than mere sensationalism, however. Because fear is the central characteristic of the Gothic style or mode, it allows authors to regularly explore the outer limits of cultural fears and anxieties in ways no other genre can. Authors are often specifically trying to create fear in the reader so the layered and symbolic horrors and anxieties experienced by the story's characters allow us to better understand the author's or culture's anxieties. Because invoking fear in the reader is central to Gothic fiction, the representation of taboo issues and anxieties - though often in displaced form - is more complete and explicit in such texts. This area of analysis is useful in understanding and explaining the past and it also allows us to more fully comprehend our own historical moment. 
Other aspects of the Gothic make it unique and a critical genre of inquiry for scholars. Given Gothic's intimate relationship to transgression, the mysterious, and the unexplainable, elements of the occult (as well as foreign myths, religious beliefs, and secret knowledge) offered a fitting place for Victorians to address anxieties about the dangers and limits of seeking knowledge. Literary critic Clive Bloom discusses the power of the Gothic in its fantastical and dark possibilities, as well as being a "foundation of a new sense of imagination" (4). Bloom explains that the Gothic is more than just a "set of exterior devices through which to have cosy inglenook adventures, but a mechanism for describing not only the workings of the mind, but also the mind in relationship with the supernatural, the universal and the divine" and therefore the Gothic "dealt in the unspoken, the difficult and the painful in ways no other form of art could do" (4). The Gothic's fascination with otherness and transgression also makes it an ideal mode for expressing cultural fears and anxieties.

Fred Botting's Gothic notes that Gothic effects "exceed reason" through their passion, excitement, and sensation by which they transgress social proprieties and moral laws (3). Uncertainty and ambivalence produced by the Gothic obscure any simple or single meaning for sought definitions and boundaries related to the nature of identity, sexuality, power, or society; this indicates transgression. Depending on the cultural context, the Gothic has flexibility in meanings, metaphors, and social critiques, even when similar figures, settings, and plot devices are (re)used. Botting recognizes that the Gothic is a "mobile" yet "specific form" in its recurrent crossing of boundaries as:

the images and figures that are reiterated constitute a place where cultural fears and fantasies are projected. Thus similar figures have different significances, depending on the culture that uses them. Indeed, this is a pattern of Gothic as a 
genre that, in generating and refracting diverse objects of fear and anxiety, transforms its own shape and focus. (20)

For example, this mobility is well recognized in the figure of the vampire. Gordon and Hollinger note that rather than describing a particular physical being, vampire myths represent something "much more powerful, a creature who can take on the allegorical weight of changing times and collective psyches" (4). Vampires have stood as metaphor for imperialists, aristocrats, capitalist consumers, gays, lesbians, and other sexual nonconformists, consumption (tuberculosis), HIV/AIDS, social deviants, and many others.

Traditionally, the Gothic mode of writing was useful to writers who especially sought to caution readers about the dangers of moral transgression. The terror, horror, and pleasurable frisson provoked by transgression in the Gothic are powerful reactions that can be used to suggest the importance of redefining and abiding by cultural boundaries. However, as William Hughes and Andrew Smith argue in Queering the Gothic, even though apprehensive publishers might insist on a conventional, conservative moral ending to a taboo-ridden text, Gothic typically "lack[s] the commitment to absolute definitions of identity and substance that arguably characterise such mainstream literatures" (1). Even when conservative morality ostensibly triumphs, Gothic is deconstructive and exhibits the notion of undecidability exceedingly well. That traditional moralities and identities have been challenged in Gothic texts "signifies that they have been interrogated and, if their boundaries have been tested, then they have equally been contemplated" (1-2). Hughes and Smith suggest that the Gothic delineates the "questionable moment, however brief, hints of pleasures still unrealised or unavailable but now known. Known and experienced, even vicariously, they become now a temptation, now an alternative. They trouble the mind, expand its capability to look beyond the obvious and immediate" (2). Rather 
than merely re-establishing binaries or boundaries that have been crossed in a "good triumphs over evil" ending of a Gothic story, the possibility (even allure) of seeing and experiencing the world differently creates doubt and undecidability — and even liberation-within readers.

The Gothic genre in literature has long been recognized for its ability to represent cultural anxieties in particularly powerful ways, as readers are "safely" detached through supernatural phenomena and/or remote times and settings. Given Gothic's intimate relationship to transgression, the mysterious, and the unexplainable, elements of the occult (as well as foreign myths, religious beliefs, and secret knowledge) offered a fitting place for Victorians to address anxieties about the dangers and limits of seeking knowledge. Brantlinger's notion of "imperial Gothic" is useful here, as discussed above. The characteristics of this sub-genre symbolize the relative ease of regression, contamination, and the (supposed) appalling consequences.

"Barbaric" or "demonic" forces, one aspect of imperial Gothic, are certainly invoked in Gothic tales of secret knowledge; because the narrators and characters are unable to understand or articulate the alternative knowledges of the Other in Western terms, they are typically deemed evil/demonic. The term "imperial Gothic" itself is telling: while "imperial" connotes an organized, rational approach to conquering, knowing, and exploiting the world (and bringing progress and modernity to "barbaric" cultures), "Gothic" always implies an impediment to or overturning of that rationality. Just as late $19^{\text {th }}$-century Britons endlessly sought to construct cultural taxonomies and enforce the "normal" or hegemonic sides of their hierarchized categories, the literary Gothic revealed the inevitable deconstruction of such divisions. Such fiction mirrors real-life epistemological uncertainty/undecidability created by the colonial exchange which included subversive native mimicry as well as failed "reverse mimicry" by Europeans. 


\section{Theoretical Approach: Queer Theory Deconstructs}

While the Gothic genre regularly works to deconstruct from within, queer theory is able to do so retrospectively with additional insights as a theoretical approach. The Gothic and queer theory share a natural affiliation. It can be argued that the Gothic itself is queer: its subject matter overtly addresses transgressive sexuality and gender; the genre is at once subversive and conservative; and it focuses on transgression, liminality, interstices, and hybridity. In Queer Gothic, George Haggerty argues that the Gothic could even be considered as a precursor to queer studies:

Gothic fiction offered a testing ground for many unauthorized genders and sexualities, including sodomy, tribadism, romantic friendship (male and female), incest, pedophilia, sadism, masochism, necrophilia, cannibalism, masculinized females, feminized males, miscegenation, and so on. In this sense it offers a historical model of queer theory and politics: transgressive, sexually coded, and resistant to dominant ideology. (2)

Many of these "unauthorized genders and sexualities" are evident in the novels discussed below. While queer theory discourse certainly deals with nontraditional sexual practices and same-sex desire, it goes far beyond the earlier critical approach of Gay and Lesbian studies. Such an approach focused on celebrating same-sex desire in literature, appreciating gay and lesbian authors both past and present, and diminishing marginalization and discrimination of groups of people who desired others of the same sex. As post-structuralism and deconstruction took hold in literary and cultural theory, however, the notions of simplistic categories such as "man" and "woman" or "gay" and "straight" became problematic. While critics understand that such terms have political leverage to a point (for example, Gayatri Spivak's "strategic essentialism"), these terms also become normative and administrative and thus begin to marginalize on their own. In 
Queer Theories, Donald Hall notes that the term "queer" was reappropriated by groups such as Queer Nation as an "umbrella term" (53) to celebrate the differences not encompassed by simplistic binary terms like "gay" and "lesbian."

Use of the term "queer" has served several functions: as a noun, an adjective, andcritically—a verb. The noun initially referred to individuals who did not meet cultural conventions regarding sexual desire or gender identity/performance; however, it also became more inclusive about other areas of non-normativity. This is where "queer" or "queering" becomes particularly useful in academics and politics. Hall explains that to be queer is to "abrade the classifications, to sit athwart conventional categories, or traverse several" (Queer 13). This definition extends its political utility by considering complexities beyond gays and transgender people to include black Britons born in India or underprivileged, inner-city Latino academics. Queer as a verb thus works to actively challenge, deconstruct, or subvert normative categories (which are, in most cultures, also heteronormative). The work of queer theory then can be defined as "challeng[ing] and undercut[ting] any attempt to render 'identity' singular, fixed, or natural" (15). Similarly, Carla Freccero recognizes the advantage of moving away from "queer" as an identitarian construct to a mode of critique. Using "queer" in terms of identity politics is problematic because in its project for "equality," it tends to efface critical differences; as it normalizes some LGBTs, others are pathologized, demonized, or cast off. Freccero thus urges us toward a "non-identity-based critical cultural and political practice that seeks to resist humanist rights-bearing claims of collective identities understood to be based in a certain affective and sexual practice and a relation to same-sex object choice" (15).

"Queer" connotes strange, unfamiliar, sexually non-normative, and deconstructive in critical approach. Because of the prevalence of transgressive representations of sexuality and gender roles in 
the Gothic literature of this period, queer theory allows for discussion of queer as a "sexual" subject as well as queer as a verb to dismantle. It provides an emphasis of deconstruction to this analysis-a recurring and vital function of the Gothic and postcolonial studies. It also illustrates the notion of undecidability. Carolyn Dinshaw argues that "queerness works by contiguity and displacement, knocking signifiers loose, ungrounding bodies, making them strange [...] Queerness articulates not a determinate thing but a relation to existent structures of power" (qtd. in Freccero 19). This is similar to the way in which postcolonial studies reveal the subversive power of the colonized subject and expose the fatal flaw of European notions of superiority. Queerness relates to hidden/forbidden knowledge, as well. Critic Mair Rigby suggests:

modern sexual discourse has constructed queerness as forbidden knowledge, as something that must be recognized, but which is dangerous because, once recognized, it is imagined to infect and overwhelm the subject. The 'truth' of sexual nonconformity is depicted as a secret that should remain hidden, but despite the supposed prohibitions remains so fascinating that we feel compelled to try and speak about it. (51)

Just as alternate epistemologies and occult knowledge create anxiety in their ability to challenge supposed transcendent truths of European rationalism, queerness also evokes anxieties in its capacity to destabilize binaries and assumptions about identity and normalcy.

The methodology of this project is also queer in a sense. Halberstam describes a "queer methodology" in Female Masculinity, an interdisciplinary approach that combines aspects such as archival research, social science methods, historical survey, and close textual readings (9-10). The approach to my project also combines different ways of knowing in its own hybridized, queer methodology and epistemology. It relies mostly on an historicist approach, one especially 
rooted in understanding the background and ideologies of authors and contemporary discourses on imperialism and colonial practices, gender and sexuality, legal and medical policy at home and abroad, and Gothic authors' participation in and influence on such discourses. The project also engages with theoretical aspects, including components of modern queer theory and postcolonial studies, in order to locate the texts in a longer trajectory of thinking about queries such as how humans acquire and study knowledge or the ways in which queer or alternate ways of thinking and knowing disrupt restrictive and hegemonic forms. The methodology also recognizes the crucial role of close textual analysis and thus the project provides many details from the novels to help appreciate the nuances that coded language and subtle commentaries provide.

The chosen primary texts of this analysis display (or imply) literal queer, non-normative sexuality but their use of sex is also metaphorical. Colonization is frequently described in scholarship as a kind of rape where peoples and lands are penetrated and exploited against their wills. While this is true to a large extent, colonialism was more complex. It was an exchange in which competing cultures and epistemologies influenced and mimicked one another. Just as sex involves a kind of interpenetration and dissolving of boundaries between self and other (whether consensual or not), colonization enacted something similar. Westerners did not simply retain their own cultural systems for generations in the face of competing native cultures and epistemologies. To simply exist, for example, they had to learn to adapt to the climate, geography, available raw materials and food products. Some cooperation and compromise with colonized peoples was imperative for successful production and trade in a colonized setting. This exchange often led to adopting cultural mores of the region such as dress or relations between genders and classes, and could even influence religious beliefs. Differing worldviews in such 
situations led to native mimicry of Europeans (which subverted Western truths as superior and universal) as well as European mimicry of native peoples (which also challenged Western authority - especially when Europeans failed to master and utilize the knowledge of the Other). In this way, then, (deviant) sex exhibited in imperial Gothic fiction becomes a way to articulate imperial anxieties indirectly and can be read as metaphorical for the colonial project and its interpenetration of cultures. Britons had to confront the idea that the West does not simply bring superior culture and knowledge to ignorant and uncivilized natives and remain un-influenced by the encounter. Colonialism was, in fact, a process of exchange and it was one that challenged the superiority and validity of Western "transcendental" truths - and hence the imperial project itself. Exploring and understanding the implications of such epistemological anxieties is enabled through the analysis of imperial Gothic fiction and the conceptual tools of postcolonial and queer theory.

\section{Chapter 1: The Egyptian Curse and Failed Reverse Mimicry: Epistemological Anxiety and Empire in Haggard's She}

Just as mummies exhibit an uncanny defense against decay, the quest for longevity of lifeeven immortality - has fascinated humans for millennia. In Rider Haggard's She (1887), Cambridge fellows Leo and Holly undergo an adventure to seek a civilization in central Africa ruled by a white woman "who is reported to have power over all things living and dead" (Haggard 28). Leo's father wishes him to seek that knowledge: "I believe that if it can only be re-discovered there is a spot where the vital forces of the world visibly exist. Life exists; why therefore should not the means of preserving it indefinitely exist also?" He hopes his son will defy "time and evil," be "lifted above the natural decay of flesh and intellect," and "one day certainly rule by the pure force of accumulated experience" (29). The great white Queen Ayesha is cruel, evil, and endures a life of suffering as she 
has slain her beloved Kallikrates (a Priest of Isis) in a fit of jealousy and thus lives for thousands of years in lonely bitterness, desperately awaiting her beloved's reincarnation. Kallikrates's wife Amenartus, an Egyptian priestess, curses Ayesha for slaying Kallikrates - a curse that reaches its cruel climax only when Ayesha finds her "reincarnated" Kallikrates (Leo) two thousand years later and endeavors to give him immortality. She claims that defying death is not magic: "There is no such thing as magic, though there is such a thing as a knowledge of the secrets of Nature" (152). However, when she attempts to revitalize herself in the mysterious "life-giving" pillar of fire, she shrivels into a monkey-like form and perishes - which can be understood as the final element of the Egyptian curse of Amenartus. Not even the "omniscient" queen can achieve true immortality through forbidden knowledge. The British men barely escape the dangers of this African adventure and return to Cambridge disillusioned about seeking such doxai knowledge, though they are still enraptured by the charismatic and superhumanly beautiful Ayesha.

\section{Chapter 2: Competing Epistemologies and Irrational States: Sexual Terror and \\ Contamination Anxiety in the Colonial Encounter}

This chapter on Richard Marsh's The Beetle (1897) examines fin de siècle anxieties about sexual knowledge, contamination, and the fear of the female colonial "prostitute." I argue that the novel supports the continuation of the colonial Contagious Diseases Acts as it portrays syphilitic contagion and the psychological, as well as physical, breakdown into irrational states from exposure to the colonial woman. The eponymous Beetle (a shapeshifting Priestess of Isis) seduces foolish British tourists in a forbidden native Cairo quarter and forces them to participate in "orgies of nameless horrors," including sadistic sexual violations, human sacrifices, and ritual consumption of victims' remaining ashes (Marsh 243-244). Such assaults are represented not only as a literal rape, but also a psychological one. The Beetle later surfaces in London to take 
revenge on a gentleman who had sought sexual knowledge in Cairo but after his capture and months of horrifying orgy-related atrocities, he escaped her grasp. Notably, The Beetle uses mesmeric powers to control her victims. Mesmerism was popular throughout various circles of Victorian society; however, this text demonstrates the particular strength (and evil purposes) of this queer knowledge in the hands of the colonial Other. Importantly, it also portrays fatal seductive powers of colonial women to entrance British men and control their wills. Julian Wolfreys notes the link between mesmeric and sexual possession: "to be subjected to the will of another is to be invaded in a way that is equivalent to a sort of (mental) rape" (qtd. Margree 67).

The Beetle's attacks have contaminating, enervating effects on victims, leading even to death. S/he/its influence puts Western men and women in various kinds of irrational states, undermining "rational" Western authority as logical and superior. Specifically, the insanity, phobia, and physical ailments caused by the sexual/ized attacks of the Beetle symbolize syphilitic contamination via the colonial woman. Marsh's novel engaged in popular and legal discourse of the day, particularly in regards to the steady problem of venereal disease amongst men traveling throughout the empire. The Contagious Diseases Acts and its mandatory medical treatment and containment of suspected prostitutes had been recently eradicated in Britain in 1886. However, such laws continued throughout the empire into the $20^{\text {th }}$ century as the military retained high rates of venereal disease and native/non-European women were viewed as particularly promiscuous and disease-ridden, requiring special legal action. The novel uses contagion or contamination as a metaphor for epistemological undecidability. The potential for Western "truths" to be corrupted by hybridization reveals that such concepts are not, in fact, transcendental. Boundaries-including forms of knowledge-are permeable and subject to deconstruction: contagion erodes distinctions such as clean and unclean, healthy and unhealthy, 
self and Other. In The Beetle, this blurring and queering demonstrates the danger of such hybridity. The sex in the novel symbolizes not just concerns related to British health and morality, but also a deeper anxiety about the melding of cultures and epistemologies occurring in the colonial context.

\section{Chapter 3: "A New and Strange World": Dangerous Hybridity in Stoker's The Jewel of}

\section{Seven Stars}

The third chapter focuses on a Gothic tale of mummy reanimation: Bram Stoker's The Jewel of Seven Stars (1903) ${ }^{6}$. Interestingly, several Gothic texts of this period focus on Egyptology and corpses that are reanimated are mummies. Hornung notes that even in the Old Testament, Egypt was already a magical land and "waking the dead was no problem for an Egyptian conjurer like Zatchlas," the prototype for the resurrector of Osiris (55). He cites many authors from the $19^{\text {th }}$ and early $20^{\text {th }}$-centuries who believed that at the time of the pyramids, "Egyptians were at a scientific level that was reattained in Europe only in the $19^{\text {th }}$ century" and that this scientific knowledge had been lost by Alexander the Great's destruction of Heliopolis, "the center of Egyptian science" (162). Stoker himself credited ancient Egypt with magical powers and the use of radioactive materials (Hornung 168). Because mummies could be so perfectly preserved, raising them from the dead seemed more innocuous (if more indelicate, especially for female mummies) than reanimating a decayed body or skeleton. Penetrating the depths of sacred tombs and undressing beautiful mummies by British men, however, were represented in Gothic fiction as not merely disrespectful but as a kind

\footnotetext{
${ }^{6}$ While the proposed primary texts are not all canonical, they were very popular and thus carried influence on lateVictorians. They have been chosen mostly for their shared characteristics of the tension between Western/scientific and forbidden/queer knowledge, sexual violence or terror, and imperial or foreign settings and characters. Additionally, some may prove enlightening to other (extensively) analyzed texts such as Dracula which include similar themes in more veiled forms (eg, Dracula as a foreign mesmerist from the empire committing sexualized atrocities).
} 
of rape. As the British Egyptologists of several tales discover, reanimation of a magical, powerfuland potentially evil—presence is far from harmless.

In Jewel of the Seven Stars, Egyptologist Trelawney undergoes a "Great Experiment" to resurrect the ancient mummy of Queen Tera, an ambitious, intelligent beauty known for her magical powers. David Glover notes that throughout the novel, Trelawney "steadfastly maintains that the purpose of his 'Great Experiment' is the recovery of ancient knowledge for modern science" (89). Ancient, occult and modern scientific knowledges are hybridized in the novel. Stoker is praised for his ability to use "scientific discovery as a springboard for metaphysical conjecture, bringing questions of immortality or reincarnation into the world of radium and X-rays" (Glover 81). As Trelawney works toward the "Great Experiment," his daughter Margaret becomes possessed—in a sense, colonized - by the spirit of the ancient queen Tera. This represents a dangerous hybridity that undermines Trelawney's work. When the experiment is finally carried out, however, the results are tragic: all the characters (excluding the narrator) die mysteriously in horror when the subterranean chamber fills with black smoke. Reanimation, then, is presented as an ancient and foreign knowledge that cannot be mastered by a Western, scientific approach—even by a "specialist" of that culture (here, an Egyptologist). The attempt to know and control the Other fails miserably, even under circumstances that seem ethically productive. The novel was revised years later in 1912 with a happier ending (no one is killed but the experiment seems to fail). However, Margaret continues to embody elements of Tera and readers may conclude that she has simply fully possessed Trelawney's daughter in an ominous hybridity that threatens to turn tragic at any moment. The Jewel of Seven Stars thus portrays hybridity as a force of menacing mimicry upon Victorian tomb-raiding Egyptologists. The ambiguity espoused in both the dissimilar 1903 and 1912 editions of the novel attest to the inability to truly know anything for certain and cautions against the flawed arrogance of 
such assuredness, particularly when it relies on the exploitation of archeological artefacts from colonized lands.

\section{Chapter 4: "I couldn't define it to you, I only know I felt queer": The Great God Pan, Queer Knowledge, and the Horrors of a World Beyond Epistemology}

Arthur Machen's The Great God Pan (1894) begins with an experiment in Wales, in a town built on ancient Pagan Roman ruins, in which a British doctor attempts a brain surgery on a young woman to enable her to see the god of nature, Pan, and thus the spiritual and occulted forces of life. The experiment is a disaster; while it seems she has seen "Pan," the young woman's mind is instantly destroyed, she becomes mysteriously pregnant by a sort of "infernal conception" (later revealed to be by the god Pan), and births a monster in the guise of a beautiful though sinister demigod, Helen. Years later, Helen travels the world and mysteriously leads many respectable young men to insanity and suicide. The novella's occult scientists and explorers come to realize that for humans, "seeing Pan" is horrific and damning, not beautiful or enlightening, concluding that "men long ago veiled their knowledge of the most awful, most secret forces which lie at the heart of all things; forces before which the souls of men must wither and die and blacken" (Machen 225). Encountering these "secret forces" of queer, forbidden knowledge (symbolized by Pan) leads only to insanity and death. While the experiment has attempted to hybridize or queer knowledges, as the previous novels have also illustrated, Machen presents readers with an emotional, corporeal knowledge beyond language and rationality — one that queers epistemology into a phenomenology in which individuals merely exist without awareness. The Great God Pan thus illustrates an extreme case of queer/ing knowledge whereby epistemology itself is deconstructed into a chaotic and destructive phenomenology. 
This analysis, then, addresses the imperial and scientific impetus for understanding and subordinating the foreign Other and his knowledges in order to hybridize (or "domesticate") them into a controllable and useable form. It attempts to locate the cultural and epistemological anxieties created by this impulse and tease out the nuances behind the Gothic form's cautionary tales about this Western drive for mastery. Additionally, it focuses on the recurring trope of queerness and sexualized terror (beyond its sensational and exploitative power) and the impact on/implications for Victorians. The project considers ways in which gender and sexual anxieties relate to medicine, science, law, and imperial policies. Even though sexuality is frequently the surface metaphor utilized in late Victorian Gothic texts, this analysis reveals a deeper source of apprehension regarding epistemology and what is knowable and controllable — and what is better left occulted beyond the veil. 


\section{Chapter 2}

The Egyptian Curse and Failed Reverse Mimicry: Epistemological Anxiety and Empire in Haggard's She

From Freud and Jung to Spivak, Showalter, Said and beyond, many intellectuals have recognized the influence and significance of H. Rider Haggard's 1887 best-selling imperial Gothic novel, She: A History of Adventure. Critics have discussed Haggard mostly in relation to fin de siècle cultural anxieties, imperial decline and atavism, and gender and sexual politics. She is described by Sandra Gilbert as "one of the century's turning points, a pivot on which the ideas and anxieties of the Victorians began to swivel into what has come to be called "the modern"" (43). In postcolonial studies, the 1880s stories by Haggard have "become coordinates for the exploration of Victorian and Edwardian narratives of empire, and those related and intersecting discourses of knowledge, power and difference which helped to condition the apparatus of colonialism and control" (Rodgers 35). In a late-Victorian text so clearly commenting on imperialism (including the "Egyptian Question" of the 1880s), however, it is astonishing that so few critics distinguish between the Egyptian and Arab components of She. For example, in various critical sources, Ayesha is (incorrectly) assigned ancient Egyptian origin or race. ${ }^{7}$ Such a conflation of Near East cultures denies us the opportunity of examining this text in light of the immense mystery and power surrounding Egypt in the late-Victorian imagination, as well as socio-political discourse about historical civilizations, race, empire, knowledge, and power.

The Victorian compulsion to categorize and the rise of imperial sciences (such as anthropology, archaeology, ethnology) in the wake of Darwin led to heated debates regarding civilization, racial hierarchies, and national superiority. While most Britons at this time believed

\footnotetext{
${ }^{7}$ See Brantlinger, Victorian (138), Hinz (421), Monsmon (H. Rider Haggard 193), Parramore (103), Pearson (228), and Rodgers (38) for some examples.
} 
the Anglo-Saxon "race" to be the most advanced, Victorian Prime Minister Benjamin Disraeli, for example, argued that Arabians (including Jews and other Semites) were the greatest religious and imperial race and were in fact Divine, arguing that "the intellect of Arabia comes from the Most High" (qtd. Brantlinger, Victorian 75-76). Haggard's She challenges the idea that either Arab or Anglo-Saxon is supreme- Ayesha is degradingly destroyed in the climax of the novel and British heroes Holly and Leo barely escape Africa with their lives, forever haunted by the horror experienced in Kôr, a (fictional) civilizational precursor to Egypt.

Ayesha, an ancient though perfectly preserved and beautiful near-immortal Arab, holds forbidden knowledge she has appropriated from the secrets of Kôr and wisdom from centuries of scholarship and scientific experimentation. Her authority is reversed, however, by the power of an Egyptian Priestess of Isis. This repudiation is reflected by Ayesha's 2,000-year grief, isolation, and inability to leave Kallikrates's body or the fallen imperial Kôr and finally, by her appalling, grotesque devolution upon her second entrance into the "life-giving" Pillar of Firejust as her beloved has returned to share immortality with her. Ayesha, for all her Orientalization, still serves as a (white) example of imperial hubris and the dangers of dabbling in forbidden knowledge, particularly in relation to the powers of Egypt and its ancestor, Kôr. Ayesha describes herself as an "Arab of the Arabs" (Haggard 146) from the powerful and ancient civilization of Yemen (Haggard 231-2). Believing she has mastered Kôr's secret knowledge and ignoring the curses brought upon her by the Egyptian Amenartas, Ayesha arrogantly attempts to "rejuvenate" herself in and initiate Kallikrates's descendent (or reincarnation), Leo, into the Pillar of Fire beneath desolate Kôr. The repercussions are immediate and devastating: Ayesha shrinks into a hideous monkey-like creature and dies shrieking, Leo's youthful golden hair immediately turns snow white, Holly scarcely recognizes his own face which forever bears the 
"wild look" of a "startled person" (308), and their manservant Job actually "died of terror" (296).

The civilization tacitly left with the most mysterious and lasting supremacy in She is thus ancient Egypt (and, to an extent, the powers of fallen Kôr).

The most popular manifestation of enigmatic Egyptian authority in British culture was the Egyptian curse and indeed, this is the most critically overlooked aspect of She. The Egyptian (usually mummy) curse became quite fashionable in literature and popular culture during the late $19^{\text {th }}$ and early $20^{\text {th }}$-centuries, often as an expression of anxieties relating to contemporary archaeological quests and discoveries, tomb and artifact robbing, the Rosicrucian Revival ${ }^{8}$ and occult interest, and general imperial intervention in Africa and the Orient by Europeans. Haggard's She presents an Egyptian curse by Amenartas, the wife of Kallikrates and Priestess of Isis, on Ayesha, the "immortal" Arab queen who murdered Kallikrates when he refused to leave Amenartas to become her lover. The novel's textual evidence for the curse is rather substantial. However, Haggard's narrator Holly fails to see Ayesha's horrific and shocking devolution in the Pillar of Fire as stemming from the Egyptian curse or power of Amenartas and his admittedly limited interpretation has seemingly influenced subsequent critical readings. His final sentence, though, does suggest her importance (and lasting power) to the narrative. Considering the future of this "great drama" (Ayesha has vowed to return), Holly asks, "And when that final development ultimately occurs, as I have no doubt it must and will occur [...] what will be the part played therein by that beautiful Egyptian Amenartas, the Princess of the royal race of the Pharaohs...?" (317).

\footnotetext{
${ }^{8}$ Rosicrucianism was developed in seventeenth-century Germany as a secret mystical society of Protestants. Their philosophy centered on findings by Christian Rosencreutz who had claimed to master the Hermetic secrets and the magical symbol of Elizabethan-era John Dee which supposedly "revealed the unity that ordered the world," explains Luckhurst (Mummy's Curse, 221).
} 
The power of the Egyptian curse can be read as the central moment of anxiety in the novel, though most previous scholarship has focused on the sexual components in She. For example, critics have discussed the book in terms of psychoanalysis (the Pillar of Fire as a phallus punishing feminine power ${ }^{9}$ ), gender politics ${ }^{10}$ (Ayesha as the New Woman, a femme fatale, an infectious prostitute), Queer Theory ${ }^{11}$ (the homoerotic love triangle of Ayesha, Leo, and Holly; the deconstructive nature of Ayesha), colonialism ${ }^{12}$ (Haggard's anxieties about miscegenation, femininity/female sexuality as primitive and dangerous), and archeology $y^{13}$ (necrophilia, mummy as fetish, tomb-robbing as a form of rape). While the sexual components are certainly significant, they are transcoded as a metaphor for a larger anxiety about competing forms of knowledge and the universality of Western truths. A strategy often utilized in discourse is to confront the epistemological and political crises (of empire, for example) and transpose them onto sexuality. Focusing on the complexities raised by such discussions can enlighten readers to various related anxieties and nuances of the novel; however, the deeper source of the metaphor must also be considered—an area largely overlooked by Haggard scholars. Thus, while the sexuality components engender useful points of discussion, the deeper source of the metaphor (epistemology) needs closer examination.

Like many other imperial Gothic novels, She represents the larger epistemological anxiety about the transcendence of Western truths when confronted with other forms of knowledge. This greater anxiety contains several facets, such as the fact that positivistic science does not explain all, the Other's knowledge may be more powerful than Western knowledge, and

\footnotetext{
${ }^{9}$ See Gilbert and Gubar, Parramore.

${ }^{10}$ See Auerbach, Murphy, Rodgers, Gilbert and Gubar, Stott, Bristow.

${ }^{11}$ See Arata, Heller, Young, Chrisman.

12 See Bristow, Heller, Wilburn, Chrisman, Driss, Rodgers.

${ }^{13}$ See Mazlish, Brantlinger, "Mummy Love," Pearson, Rodgers.
} 
Europeans and imperialists cannot fully understand or master the knowledge of the Other. Ayesha's unexpected defeat at the end of the novel illustrates the undecidability of Western epistemology when challenged with the power of occult/doxai knowledge. Though Ayesha is an ancient Arab, to British observers Holly and Leo, she stands as a displaced metaphor of imperial presumption and folly. Her "truths" are not transcendental. Ayesha's hubristic search for forbidden knowledge, her largely unproductive and savage empire, and her downfall from failed "reverse mimicry" of appropriated secret knowledge all serve as an admonition to Victorian Britain. Haggard's novel, emerging shortly after the start of Britain's military intervention in Egypt and the Sudan, suggests anxiety and restraint concerning the Egyptian Question as the powerful (and often corrupt) Ottomans ${ }^{14}$ and the British banded together in their occupationand exploitation —of Egypt, challenging Arabi's new Nationalist movement "Egypt for the Egyptians."

\section{Epistemic Anxieties: Positivistic Science Does Not Explain All}

As mentioned in the introduction, Victorian notions of epistemology and knowledge were varied and innovative. While science and technology were advancing in unprecedented degrees, the late- $19^{\text {th }}$ and early- $20^{\text {th }}$ centuries were a time of "noticeably marked" public interest in the occult "as triumphant positivism sparked an international reaction against its restrictive world view" (160), observes Janet Oppenheim in her discussion of British Spiritualism and psychical research. Auguste Comte (1798-1857) developed the concept of positivism in epistemology which relies on empirical data and scientific methods; it "confines itself to the data of experience

\footnotetext{
${ }^{14}$ The Ottomans began as ruling Turks in 1299 AD, viewed separately from Arabs, whom they often exploited; however, as time went on, a great deal of cooptation occurred and Arabs became crucial in the continuation of the empire. The political ideology of Islam was invoked by $1389 \mathrm{AD}$ and two elite groups (the a'yan, urban notables, and the ulama, Muslim religious scholars) played a particularly vital role in imperial rule. See Bruce Masters's The Arabs of the Ottoman Empire, 1516-1918 for a full discussion.
} 
and excludes a priori or metaphysical speculations" (Feigl). Importantly, emerging tales, rumors, anthropological studies and observations from Britain's vast colonial empire significantly fueled growing interest in the occult. Dissatisfaction with scientific materialism also urged many to explore new sources of faith and wisdom. The popularity of books such as Blavatsky's Isis Unveiled (1877) and Edwin Arnold's The Light of Asia (1879) point to the "desire for alternatives to both religious orthodoxy and scientific skepticism" (Brantlinger, Rule 228). For many, modern science was inadequate in helping people deal with loss, death, and questions about creation and the afterlife. Discussing the late-Victorian "Aporia of Science and Religion," Tania Zulli notes that man had ideas about "what is beyond the mere materialist substance of nature, and pondering over these he gave birth to existential problems that science itself could not solve" (87). While empirical science was incredibly useful and provided the means to reach greater possibilities of truth and understanding, it did have certain limitations.

Many Britons seemed to reason that a combination of knowledge forms (whether drawn from ancient or contemporary, foreign or domestic, sacred or secular sources) might lead to greater wisdom. Luckhurst notes that movements such as Hermeticism and Theosophy created a "synthesis that outflanked both orthodox religion and science by embedding them in longer trajectories that diminished the claims of modern scepticism" (Mummy's Curse 233). Using science in combination with religious, mystical, or occult aspects could engender a new hybridized (queered) form of knowledge that might reveal esoteric mysteries. Luckhurst acknowledges that Theosophy purported to fuse ancient magic with modern scientific discoveries and offered a history of ancient wisdom "lost in diaspora"—one that could be discovered and studied to catalyze a spiritual transformation (Mummy's Curse 218). 
The Society for Psychical Research, founded by Cambridge professors Henry Sidgewick and Frederic Myers in 1882, expressly applied scientific methods to examine the occult (for example, by taking photographs or measuring temperatures). Rather than using scientific laws to discredit paranormal occurrences, the SPR sought to "document that which resisted scientific explanations and to bring mystical modes of knowing into accord with scientific practice," explains Gerald Monsmon ("Who is Ayesha" 19). ${ }^{15}$ This might simply lead to a new understanding and categorization of what counted as "natural" as opposed to "supernatural." Researchers of psychic and occult phenomena "exploited the vanishing points in contemporary energy physics or dynamic psychology," states Luckhurst, to propose that supposedly "supernatural" experiences were actually a valid area of science that would soon be discovered (Mummy's Curse 233). In general, the epistemic challenges of late-Victorians were not unlike those of today: it was felt that the spiritual and supernatural world needed more empirical evidence and explanation while the scientific world needed better answers regarding creation, afterlife, paranormal experiences, and moral and spiritual subjectivity.

In "Cosmic Plots: Occult Knowledge and Narratives of Belief," Delgado recognizes a shift regarding the occult in certain literary genres toward the end of the $19^{\text {th }}$-century. For example, earlier tales of "psychic detection" 16 exhibited the occult as a kind of "orientalized threat" that is remedied by scientific rationalism or "the reinforcement of patriarchal organization" (197). However, popular writers such as Algernon Blackwood and William Hope Hodgson soon viewed the occult as a "body of knowledge that informs the psychic detective's

\footnotetext{
${ }^{15}$ Myers said that the duty of the SPR was the "expansion of Science herself until she can satisfy those questions which the human heart will rightly ask, but to which Religion alone has thus far attempted an answer" (qtd. Mustafa 198).

${ }^{16}$ She describes it as a hybrid genre, neither ghost story nor detective fiction but a combination of "the irrational elements of the former with the acutely rational elements of the latter" (Delgado 199).
} 
investigations" and indeed was critical to solving the mysteries (198). This shift meant that instead of focusing on the "pathology" of occult interest, fiction could now celebrate lateVictorians' "intellectual curiosity," argues Delgado (198). Unsurprisingly, the Gothic genrebest known for its ability to articulate cultural anxieties-was typically less optimistic for its characters seeking forbidden knowledge, as the present study indicates. However, literature did often reflect changing attitudes toward the occult and alternative knowledges generally as a valid area of inquiry for Westerners. Such texts frequently utilized scientific methods in their construction of a new, queered epistemology.

Sir Henry Rider Haggard (1856-1925) was representative of the Victorian zeitgeist surrounding alternate forms of knowledge and blended epistemologies. Neither his orthodox Christianity nor empirical science provided him with adequate answers. The "genesis" of Haggard's occult interests began with his mother (Ella Doveton Haggard), the daughter of a colonial civil servant who lived in India from girlhood to age 21. Her writings exhibit a blend of mysticism and Christianity (Monsmon, "Who is Ayesha" 18). At 17, Haggard joined Lady Paulet's London spirit circle and took part in various séances where, seemingly, mediums were astrally projected and spirits visited fully materialized. The group discussed ritual magic, Kabbalistic lore, Hermetic texts, astrology, telepathy, and more. Lady Caithness, one of the circle's mediums, believed in the Hermetic tradition of lost wisdom from ancient Egypt. Like many others of the era, explains Luckhurst, she syncretized a variety of religious and spiritual aspects (such as merging the Virgin Mary with Egyptian Isis) while still maintaining her Catholic faith. Haggard also reconciled his theosophist ideas and rhetoric, including reincarnation, with 
his Anglican Christianity (Luckhurst, Mummy's Curse 92; Burdett 223). ${ }^{17}$ While he only attended séances for about one year, his decision to quit participating was not because he thought the content of séances was false, but rather because it took a toll on one's nerves and the modes of communication were confined by fraud and suggestion (Luckhurst, Mummy's Curse 92). Haggard's 1912 autobiography (published posthumously) is "strikingly full of references to occult phenomena" (Burdett 222). He discusses séances, his interest in the Society for Psychical Research, ${ }^{18}$ his telepathic dream communication, and the reverie-like visions of his previous lives as a Norseman, a Zulu, and an ancient Egyptian. Clearly, Haggard was unable to accept either a secular, positivistic worldview or traditional Anglicanism. He longed for the explanations, wisdom, and power of esoteric Truths and thus looked away from a Western scientific epistemology to foreign and ancient ones. The heroes of his novel She do something similar.

Holly and Leo are highly educated Cambridge fellows, generally happy in their university bachelor lives. When Leo turns 25 and opens his father's old locked chest, he reads a letter from his long-deceased father regarding an ancient sherd and a quest bestowed on his family line to locate a cruel white queen in Africa and kill her, if possible, to avenge the death of his ancestor, Kallikrates. The quest, indicated by Amenartas's sherd, also included learning the "secret of life" by bathing in the fire for longevity so that her descendent may "sit in the place of the Pharaohs" (Haggard 31). While Leo's father had himself undertaken the quest (without success), he warns his son: "He who would tamper with the vast and secret forces that animate

\footnotetext{
${ }^{17}$ In a letter, Haggard wrote of reincarnation: "If only one could be sure. It seems reasonable, a quarter of the inhabitants of the world believe in it to this day, it explains things, there is nothing against it (and one or two things for it) in the Bible, and yet if one could be sure!" (qtd. Burdett 224).

${ }^{18}$ Haggard's close friend Andrew Lang was an enthusiastic member of the SPR who published books about anthropology, folklore, and occult topics.
} 
the world may well fall a victim to them" and that living indefinitely may not prove to be a happy existence for Leo. He adds, however, that "in the event of your success, you would one day certainly rule [the world] by the pure force of accumulated experience" (29). Leo's response to this incredible history reveals that he and his adopted father Holly had been feeling a subtle dissatisfaction with their quiet life: "We have been looking for a mystery, and we certainly seem to have found one" (30). Holly rejects the letter as resulting from his friend's (and Amenartas's) madness, although his examination of the ancient artifacts and various histories of those who attempted the quest over the centuries convinces him of their authenticity. Regarding the supernatural aspects, however, Holly initially holds an empiricist epistemology: "I know that there are curious things and forces in nature which we rarely meet with, and, when we do meet them, cannot understand. But until I see it with my own eyes, which I am not likely to, I never will believe that there is any means of avoiding death" (45-46). Without verification through his own senses, he rejects such knowledge. His doubt is not enough to keep him from joining Leo on the journey, however, as Leo is more open to the possibilities of secret knowledge outside positivistic terms and is determined to embark on the quest.

Even if the tale were to prove to be a fantastical one, both Holly and Leo justify the trip for its opportunities for adventure. Leo is excited for "first-class shooting" and Holly admits, "It must be a very wild stretch of country, and full of big game. I have always wanted to shoot a buffalo before I die" (46). They even convince their hesitant servant Job to come: "It's time you began to see the world" (46). Brantlinger's discussion of Imperial Gothic notes that while the actual frontiers of the world were waning in the late $19^{\text {th }}$-century, occultist literature, rising in popularity, was rife with "metaphors of exploration, emigration, conquest, and colonization"; it was a new metaphysical realm to conquer (Rule 249). An interesting aspect of She is that 
Haggard combines the "new frontier" search for secret or occult knowledge with an actual imperialist adventure into the depths of unknown Africa. By the time Holly reaches the edge of Ayesha's empire, he has embraced the quest for more than its physical excitement: "We came to find new things," he boldly explains when he first encounters Amahagger tribal leader Billali. "We are tired of the old things; we have come up out of the sea to know that which is unknown. We are of a brave race of men who fear not death... that is, if we can get a little fresh information before we die" (78). They feel that their current Western epistemology is insufficient and therefore seek the powerful, occluded knowledge of the Other. Their investigative outlookwhether across the physical or spirit world—is indicative of the prevailing Victorian attitude.

\section{Epistemic Anxieties: The Other's Knowledge is More Powerful}

As indicated above, dissatisfaction with both traditional Christianity and Western rationalism led many Victorians to seek alternative paths to wisdom, often within ancient and/or foreign epistemologies. Important areas such as colonial expansion, the growing tourism industry, and the burgeoning fields of archeology and anthropology played a role in this epistemic shift. Millions of $19^{\text {th }}$-century Britons worked, lived, visited, served, studied, explored, and researched abroad. They encountered mysterious religions, rites, philosophies, and inexplicable or paranormal occurrences. Many believed that there was legitimacy in at least some aspects of these alternate forms of knowledge. Some late-Victorian theorists applied racialist Darwinian thinking to occult and supernatural abilities. For example, Monsmon explains that supposedly, modern European races had evolved beyond their ancestors' exceptional capacity for telepathy, clairvoyance, and other special powers ("Who is Ayesha" 19). ${ }^{19}$ This helps explain

\footnotetext{
${ }^{19}$ This theory was not unchallenged, however; for example, F.W.H. Myers, credited with coining the term telepathy in 1882, questioned major contemporary theorists such as Lombroso and Nordau as to whether aspects considered degenerate could be, instead, "progenerate." Myers argued that "telepathy and other forms of hyperacuity were markers of evolutionary advance, rather than symptoms of reversion" (Luckhurst, Invention 184).
} 
why "lower" races were often seen as having better aptitude for occult gifts in much the same way that women were considered better mediums. Women were supposedly more passive and susceptible to spirits and emotions (as opposed to the logic and rationality of their "superior" male counterparts). Haggard himself believed Africans' "psychic abilities, lost to the moreevolved colonizers, to be culturally desirable" (Monsmon, "Who is Ayesha" 19). Luckhurst's discussion of knowledge and the supernatural at the edges of the British empire also notes the complex epistemological views held by Westerners living in such areas. Empirical and positivistic modes of knowledge were blurred with occult and alternative religious authority. Where Western forms of communication did not reach, occult systems reigned ("Knowledge" 203). Among indigenous peoples away from the imperial center, "narratives concerning occult relation, uncanny methods of communication and instances of telepathic rapport abounded" (Luckhurst, "Knowledge" 200). ${ }^{20}$ Sarah Willburn's "The Savage Magnet: Racialization of the Occult Body in Late Victorian Fiction" delineates the connection between non-whites and occult powers reflected in literature: there was a "strong motif of characters whose interactions with the unseen rely on a physical ability provided and circumscribed by a racialized body" and nonwhite race, "even above gender," was the "reason for a character's occult powers" (438). There was something alluring, though possibly dangerous, about the secret knowledge and power nonwhites (especially at the margins or outside the empire) seemed to possess.

While some feared and avoided the strange abilities possessed by the Other, many were inspired to learn the esoteric knowledge for themselves for both wisdom and power. If there was authoritative secret knowledge that could trump Western knowledge, why risk being outdone by

\footnotetext{
${ }^{20}$ This was not exclusive to native peoples, however, as locale played a significant role. In addition to "native spirits, supernatural powers of native magicians and witch-doctors," there were also "mental sympathies" that emerged "across racial divides" and indeed, Luckhurst discusses several colonizers who also experienced paranormal occurrences in the far reaches of empire ("Knowledge" 200).
} 
it when one can appropriate it for oneself? The serious interest in and reverence for non-Western forms of knowledge reveal a somewhat surprising reality of the colonial encounter. While the central tenets of colonialism included enlightening indigenous peoples with Western knowledge, values, and civilization (in addition to spreading commerce and Christianity), actual contact between Europeans and non-Europeans was a much more interdependent. As with colonized peoples learning Western ways, some Victorians attempted to master the secrets and practices of native peoples (with varying degrees of success). Such efforts are a form of "reverse mimicry," to adapt Bhabha's term. Bhabha explains that colonized peoples were (always) viewed as unsuccessful in their "mimicry" of Europeans—regardless of their actual achievement—as it was necessary to justify colonizers' sustained presence (and continue the benefits of exploitation). This perception paradoxically worked to subvert the supposed universality of "superior" Western knowledge, however, as such knowledge was apparently not-so-universal. Compounded with this was the disturbing notion, buried deep, that the native actually held a more powerful form of knowledge that could be neither countered nor mastered by the Westerner. Late-Victorian literature, especially the imperial Gothic genre, exposes this epistemological anxiety as many fictional Westerners seeking forbidden or esoteric knowledge are astoundingly unsuccessful in their endeavors.

Reflected in both history and popular/fictional representations in late-Victorian Britain, the mystique of Egypt reigned as the most influential source of interest in occult powers and ancient wisdom. The alleged power of Egyptian wisdom dominated the scene of alternate knowledge. Lynn Parramore's Reading the Sphinx: Ancient Egypt in Nineteenth-Century Literary Culture notes that both "Spiritualism and male-centered occult societies pointed directly to ancient Egypt as the source of traditions that could enrich and enliven their activities" (98). 
Blavatsky's important contribution Isis Unveiled (1877), for example, points to Egypt's central place in the Victorian mystical/magical revival. ${ }^{21}$ Luckhurst notes that the revival of the period was "heavily invested in recovering the lost wisdom and supposedly supernatural powers of the ancient Egyptian priests," and theosophists and Golden Dawn members "regarded Ancient Egypt as the seat of a lost lore of fabulous magical powers" which could be recovered through dedicated study (True 213). Freemasonry also "claimed to guard knowledge passed down from Ancient Egypt" (qtd. Luckhurst, True 219). Erik Hornung's The Secret Lore of Egypt: Its Impact on the West delineates "Egyptosophy," the notion, already in antiquity, of (a largely imaginary) Egypt as the "fount of all wisdom and the stronghold of hermetic lore" (3). In literature, references to Egypt and its centrality to plots became more and more common. This includes what Luckhurst has termed "Egyptian Gothic," a subgenre that emerged in the 1880s and permeated Victorian culture through the 1930s. More than just a literature, he defines it as a "set of beliefs or knowledges in a loosely occult framework" that existed in a variety of areas from museums and theatres to journalism, travel writing, Orientalist scholarship, and the mystical revival ("Mummy's Curse" 123). Egyptian Gothic was partially inspired by the discovery of a cache of Royal mummies (including the supposed Pharaoh of Biblical Exodus) in 1881 which spurred the "golden age of tomb hunting" ("Mummy's Curse" 133) and subsequent anxieties about disturbing graves. The British military invasion of Egypt the following year also contributed to the interest (and the anxieties).

The growing popularity of archeological discoveries in Egypt as well as Hermeticism (exhibited especially well in the Order of the Golden Dawn) greatly influenced Haggard's beliefs

\footnotetext{
${ }^{21}$ Isis, considered the world's best known goddess, is remembered for resurrecting her brother-husband Osiris, creating an artificial phallus for him and bringing him back to life long enough for her to conceive a child, Horus (Cox and Davies 127). She is often considered an ideal mother and wife and is connected with protection, nature, magic, and wisdom.
} 
and writing. His interest in Egypt—one he called "strange" and a "queer fascination"—is wellknown. "From a boy," shares Haggard in his autobiography, "ancient Egypt had fascinated me, and I had read everything concerning it on which I could lay hands" (qtd. Addy 1). Shirley Addy's Rider Haggard in Egypt points out that his contributions as an amateur Egyptologist earned him an entry in Who Was Who in Egyptology, the conclusive bibliographic guide of the Egypt Exploration Society (1). Haggard traveled extensively in Egypt (in 1887, 1904, 1912, and 1924) and maintained an expansive collection of antiquities, including mummies. Haggard wrote ten adventures specifically devoted to Egypt (Addy 2); indeed, in 1889, his friend Rudyard Kipling called him "the King of Egypt" (qtd. Luckhurst, Mummy's Curse 190).

Haggard's most resonant novel, ${ }^{22}$ She, while not set there, is riddled with links to ancient Egypt. While many details invoke Egypt (the numerous and perfectly preserved mummies, for example), the connection to the "Gift of the Nile" is best illustrated through the central tension of the plot in which an ancient Egyptian priestess of Isis pits forces against an Arabian queen who has appropriated secret knowledge from Egypt's lost ancestral civilization (the fictional Kôr). The supernatural powers exhibited in the novel are thus Egyptian or proto-Egyptian. Some contemporaries made much of Haggard's supposed connection to powerful occult or Hermetic knowledge. Parramore explains that his fascination with "Egyptian archaeology, Spiritualism, and mysticism converged in She, which he wrote in a miraculous six weeks. Some contemporaries attributed the speed of his production to Haggard's membership in the Hermetic Order of the Golden Dawn, which gave him access to secret sources of ancient knowledge" (105). The novel utilizes various aspects of the Victorian Spiritualist/mystical revival such as

\footnotetext{
${ }^{22}$ She was initially published serially in 1886 and then in 1887 as a novel; it has never been out of print (Stauffer 23). It sold 25,000 in the first few weeks and became a "global phenomenon" (Luckhurst, Mummy's Curse 189).
} 
mesmerism, telepathy, reincarnation, reanimation, and immortality/longevity. It also takes advantage of the emerging Egyptian Gothic genre-including a prevailing Egyptian curse.

Although Haggard was a proponent of and wrote within the faded genre of "romance,"23 he titles his best-selling novel She: A History of Adventure. From the outset, then, Haggard alludes to a blended epistemological approach of fantasy/romance and history/adventure (or occult/supernatural and science/empiricist) that was quite common in the late-Victorian period. His narrator, L. Horace Holly, Cambridge scholar of middle age, begins as a skeptic whose positivist approach shifts as he is gradually exposed to inexplicable and powerful knowledge exhibited by ancient and foreign people. His epistemic and existential challenges arguably mirror what many Victorians experienced in the face of epistemological anxieties, and, of course, Holly emerges from the adventure much less sure of his original convictions about knowledge and nature. As "ordinary reasoning men" who had witnessed inexplicable things, Holly confesses, he had a "deep sense of the impotence of human knowledge, and the insolence of its assumption that denies that which it has no experience of to be possible" (244). Haggard utilizes various facets of his culture's interest in the occult as well as much older concepts (such as immortality and reincarnation) to explore questions of epistemology.

The British heroes' first introduction to supernatural knowledge occurs with Amenartas's sherd and the accompanying documents Leo inherits on his $25^{\text {th }}$ birthday. What is most remarkable about Leo's family's ancient history is not that a wicked, beautiful white queen murders his ancestor Kallikrates in a fit of jealousy but rather that she is a "magician having a knowledge of all things, and life and loveliness that does not die" (Haggard 30). The concept of

\footnotetext{
${ }^{23}$ Burdett notes that Haggard saw "romance writing as the height of literary art" as it supposedly "taps, or mirrors, some primordial quality" (219). In his 1887 article "About Fiction," Haggard asserts that the "love of romance" is universal throughout history and reflects "an innate quality of mankind" (qtd. Burdett 219).
} 
immortality is certainly not a new one and within the Gothic genre, had been discussed for some time. ${ }^{24}$ Apart from eternal afterlife discussions, immortality was also sought by those infatuated with the Fountain of Youth or the Holy Grail, for example. Near the end of the novel, the characters enter the "womb of the Earth, wherein she doth conceive the Life that ye see brought forth in man and beast" to the Pillar of Fire, the "very Fountain and Heart of Life as it beats in the bosom of the great world" (Haggard 286-7). However, the shocking destruction of Ayesha makes clear that the secret to immortality or longevity is not entirely understood.

Ayesha may not truly have a knowledge of all things, but she does understand and display many secrets of appropriated "magic" throughout her encounters with the British adventurers. While she always explains that "there is no such thing as magic, though there is such a thing as understanding and applying the forces which are in Nature" (Haggard 194; see also 151-152, 207), readers, of course, do not get details about how her secret knowledge works. Like the SPR, however, she does claim the possibility of natural explanations to supernatural occurrences and abilities. One of her strongest powers reiterated throughout the novel would likely be considered mesmerism. Her use of mesmerism is slightly different from Marsh's The Beetle, in which the villain employs it to paralyze victims for sexual terror and assault, or simply to get others to do what s/he/it wants. Ayesha's mesmeric forces can induce fear and even kill, but she also makes people fall in love with her and desire her beyond anything else; the feeling remains when not under her gaze (indeed, even after her destruction). Often, conflicting feelings arise for the British heroes as Ayesha conjures up in them love, fear, attraction, repulsion, admiration, disgust. ${ }^{25}$

\footnotetext{
${ }^{24}$ For example, immortality is explored through the figure of the vampire which emerged most directly in English literature with John Polidori's 1819 The Vampyre, based on the mythology surrounding Lord Byron, and would explode into popularity with Stoker's Dracula in 1897).

${ }^{25}$ This disorienting effect is taken to an extreme in Machen's character Helen from The Great God Pan.
} 
When Holly is about to meet Ayesha for the first time, he feels her watching him from behind a curtain: "I felt the gaze of the unknown being sinking through and through me, and filling me with a nameless terror, till the perspiration stood in beads upon my brow" (Haggard 141). Holly describes her unveiling: "Drawn by some magnetic force which I could not resist, I let my eyes rest upon her shining orbs, and felt a current pass from them to me that bewildered and half-blinded me" (156). Using terms such as "magnetic force" and a passing "current" were commonplace for mesmeric references of the era. Indeed, moving well beyond Mesmer's ideas about animal magnetism, many late-Victorians linked the scientific developments in areas of unseen forces such as electricity and telegraphy with new possibilities and legitimacy for "mesmerism." 26

Holly feels that Ayesha's "celestial" beauty, "with all its awful loveliness and purity, was evil" (155) and "the very diablerie of the woman, whilst it horrified and repelled, attracted in even a greater degree" (159, emphases in original). Holly, a middle-aged, self-described misogynist (and possibly gay man) ${ }^{27}$, admits that he has immediately "fallen absolutely and hopelessly in love with this white sorceress," a "Circe" (159). He is unable to deny her requests ("even if I had wished, which I did not") as he is caught up in "the web of her fatal fascinations" (177). He views her "wonderful" eyes as "more deadly than any Basilisk's" and yet proclaims that "Life-radiant, ecstatic, wonderful_-seemed to flow from her and around her" (189). Holly soon professes his love and that he would give up his immortal soul to marry her (190). When he

\footnotetext{
${ }^{26}$ Luckhurst notes that electrical and mesmeric forces were both discussed in "'occult' frameworks" in the lateVictorian period ("Trance-Gothic" 161).

${ }^{27}$ Joseph Bristow notes that in Haggard's fiction, the "homoerotic elements are legion, and they are designed to rise up as a superior amatory force against the love of woman" (141). Hager Ben Driss agrees, noting how "homosexuality is carefully hidden in Haggard's narratives... subtly couched in an ethos of male bonding of friendship" (177). Shannon Young explores the specific queerness of She, noting, for example, the homoerotic connotations of the "Beauty and the Beast" nickname ascribed to Leo and Holly (250) and Holly's kissing Leo (257). Young also references Regina Barreca's (She, Signet Classics, 1994) discussion of Holly's sexual rivalry with Ayesha (253).
} 
attempts an embrace, she reminds him that she loves only one man (Kallikrates) and uses a kind of mesmeric force to snap him out of what he calls his "mad passion": "Reaching out her hand, she held it over my head, and it seemed to me that something flowed from it that chilled me back to common sense, and a knowledge of propriety and the domestic virtues" (191).

This mesmeric-type force also has fatal implications. Ayesha finally sees Leo's face when she cures him of fever and recognizes him as her long-lost Kallikrates "reborn." When Ustane, Leo's beautiful and steadfast Amahagger "wife," defies the jealous Ayesha's decree of banishment, Ayesha is able to use her unseen powers to kill her. Ayesha looks "fixedly at her victim" and moments later, "she was stone dead—blasted to death by some mysterious electric agency or overwhelming will-force whereof the dread She had command" (227). In Leo's rage, he then tries to attack the still-veiled Ayesha, but she sends him staggering with a "violent blow in the chest," feeling "as if all the manhood had been taken out of him" (228). Her unveiling to Leo evinces a similar response as it did to Holly: her "dread beauty" took "possession of his senses, drugging them" (229). When she looks at Leo, her "eyes drew him more strongly than iron bonds, and the magic of her beauty and concentrated will and passion entered into him and overpowered him" (230). She kisses him over the corpse of his beloved Ustane.

Even though Leo claims to "hate" Ayesha, he also knows he is forever in her power and "must follow her as a needle follows a magnet" (241). The Other's knowledge is clearly much more powerful than the British heroes' and it challenges positivist and empiricist modes of knowledge. What Luckhurst calls "trance states" (which include mesmerism and hypnosis, generally) in his discussion of late-Victorian "Trance-Gothic" are not merely useful for invoking horror, but also provide an arena to explore new forms of subjectivity. Victorian Gothic can "debunk conservative scientific elites and ageing positivist ideologies, and can point the way 
towards a modern, dynamic subjectivity which breaks the determinist chains of Victorian materialism" (Luckhurst, "Trance-Gothic" 150). Haggard's use of mesmeric-like powers reflects the larger questioning and queering of Western epistemologies in She.

Ayesha also exhibits certain powers of clairvoyance or telepathy, a supernatural phenomenon studied in earnest by the SPR, whose members believed it could be eventually understood in scientific terms (like other invisible forces such as magnets or electrical currents). ${ }^{28}$ Generally, telepathy is understood as communication between minds occurring outside of typical sensory channels. Ayesha's version of telepathy involves a mystical vessel of water which serves as a kind of magic mirror. Ayesha explains that in the water, "I see what passes if I care to summon up the pictures, which is not often. Therein I can show thee what thou wilt of the past, if it be anything to do with this country and with what I have known, or anything that thou, the gazer, hast known" (152). As Holly looks into the water, he is shocked to view a scene of himself and his traveling companions in the African swamp on their way to Kôr. When gazers think of a face or some other memory, it is reflected in Ayesha's water vessel-not in absolute clarity, but as the person envisions it. When Job looks into the water, for instance, his vast family appears (he is one of 17 children), some with clear faces, some blurry or splotchy, some with exaggerated features (215). This version of second sight is ancient, Ayesha explains, and she is still attempting to master it (she notes that she cannot see the future). She admits that she did not discover this old secret, claiming it was known centuries before in Egypt and Arabia $^{29}$ (152). Telepathy, as Haggard presents it here, is thus an ancient skill rather than one of

\footnotetext{
${ }^{28}$ Especially at the fin de siecle, telepathy for the SPR flourished in "ether-physics" since radiant matter, electromagnetic waves, and X-rays could all be interpreted as "ethereal communications" that were "undetectable to the empirical eye of the naturalist" (Luckhurst, Invention 88).

${ }^{29}$ Ayesha rarely mentions Arab knowledge, which would have recognized and respected amongst Victorians since much of it had been incorporated into Western traditions of knowledge. However, because Ayesha has been removed from Arab learning for thousands of years, Haggard attributes her knowledge to what she has learned from Noot (a "proto-Egyptian" from Kôr) and her own experimentation and contemplation.
} 
"more evolved" people (as Myers claimed), but seemingly only for those enlightened to the secret method.

Ayesha possesses other kinds of supernatural abilities, including a form of reanimation. In a rather voyeuristic scene, Holly spies on Ayesha in Kallikrates's tomb where his corpse lies flawlessly preserved. A fire is burning in the center of the room but Holly notes that it has a whitish flame and does not produce smoke. Without any use of fuel or accelerant, Ayesha "raises" the flames up to the ceiling merely by elevating her arms; the flame follows her arms up and down as she delivers incantations. She curses Amenartas in a lengthy sort of ritual (which Holly calls "unholy rites," 164) and frustrated, she finally addresses the corpse: "Shall I raise thee," she asks, "so that thou standest there before me, as of old? I can do it" (165-66). Holly watches in horror as she holds her hands over Kallikrates's body and it begins to quiver and breathe under the winding sheet. She soon withdraws her hands in sadness, however, as her ability to reanimate does not bring consciousness or sentience to the corpse: "Of what use is it to recall the semblance of life when I cannot recall the spirit?" (166). While the practice of reanimation was rather uncommon in Victorian occult circles, reanimated (or attempts to reanimate) mummies were very popular in Egyptian Gothic literature. ${ }^{30}$ In general, most mummy stories were romance tales (at least before 1882), and Bradley Deane explains that they typically featured a beautiful young female mummy who comes back to life (whether textually or literally), capturing the fancy and fantasy of modern British men (384). Indeed, such romances outnumbered curse tales (Luckhurst, "Mummy's Curse" 131). In She, Ayesha is a sort of ancient living mummy, beautiful and veiled in her gauzy wrappings. ${ }^{31}$ In a rather necrophilic fashion,

\footnotetext{
${ }^{30}$ Kelly Hurley describes the late-Victorian fascination with mummies as both commodity and sexual fetish. In addition to literary fiction, mummies were widespread in artistic, archeological, and historical lectures and exhibits, as exotic collectibles, and public unwrappings ("Victorian Mummy" 182).

${ }^{31}$ Holly's first glimpse of her reminded him "most forcibly of a corpse in its grave-clothes" (Haggard 142).
} 
she sleeps every night beside an actual Egyptian mummy, ${ }^{32}$ her beloved "spouse" (236), Kallikrates.

When Ayesha asks Leo to visit Kallikrates's tomb with her, another theme of the Other's powerful knowledge emerges: reincarnation. Given Leo's resemblance to Kallikrates, Ayesha believes him to be not merely a look-a-like descendent, but Kallikrates reincarnated. In the chapter titled "The Dead and Living Meet," Ayesha speaks at some length about reincarnation, arguing that "Time hath no power against Identity" and while the resetting of memories during each "sleep" keeps us from unendurable grief, down each chain of existence, "the Spirit" will "work out the purpose of our being" and shape our various lives into "a staff whereon we may safely lean as we wend to our appointed fate" (237). Holly is terrified at the "uncanny" sight of what appeared to be Leo's body, "robed in white and perfectly preserved"; he exclaims that he "never saw twins so exactly similar as that dead and living pair" (238). Holly, the narrator, wonders whether Leo is truly a reincarnation or just a descendent with hereditary resemblance; he ultimately concludes that while readers may judge for themselves, he believes Ayesha "made no such mistake" (316). Burdett's "Romance, Reincarnation, and Rider Haggard" discusses the enduring theme of reincarnation, which grew with "increasing intensity" throughout Haggard's oeuvre (217). The Theosophical movement, of which Haggard was a part, embraced the concept and Blavatsky's successor Annie Besant attempted to characterize Theosophy as an "evolutionary science" with reincarnation at its core, Burdett explains. Referencing Spencer's theories, Besant argues that moral or mental heredity is passed on through reincarnation and human progress would stagnate without the rebirth of genius in societies. Karma, a sort of moral account we accrue during our lifetimes, was seen as a powerful antidote to a world where self-

\footnotetext{
${ }^{32}$ While Kallikrates is born Greek, he has resided in Egypt as a Priest of Isis.
} 
interest reigned. Besant also suggested that reincarnation aligned with scientific concepts such as the conservation of energy (Burdett 225). For those interested in archeology (certainly including Haggard), reincarnation also offered a "literal version of the continuity" it promised (Burdett 225). Haggard presents the ancient and Eastern theme of reincarnation through Kallikrates/Leo in She but continues the trope in other works, including Ayesha sequels written decades later in which he reincarnates Ayesha herself.

In these sequels, Haggard suggests and ultimately rewrites Ayesha as an Egyptian or Isis figure. In Ayesha: The Return of She (1905), it is suggested that She was actually "the goddess in old Egypt to whom Kallikrates was priest, or at the least her representative" who vengefully murders him for his betrayal (Haggard 24). ${ }^{33}$ In Wisdom's Daughter (1923), Ayesha narrates her origins as a priestess of Isis. These sequels, however, exhibit "odd inconsistencies," notes Burdett, who suggests that especially regarding Wisdom's Daughter (published two years before his death), "Haggard probably did not care" (230). This attempt to rewrite Ayesha as Egyptian has complicated scholarship on the original She which stood on its own as a novel for nearly 20 years. Subsequently, contemporary critics simply overlook the fact that Ayesha is explicit about her Arabian origin. ${ }^{34}$ For example, in discussions about the original novel She, Ayesha is referred to as the "mother of all Egyptian monsters" (Parramore 103), an "avatar of Isis" (Hinz 421), "perhaps Egyptian, perhaps white" (Brantlinger, Victorian 138), "erstwhile priestess of Isis, moon goddess of the Egyptians" (Monsmon, H. Rider Haggard 193), an "Egyptian princess living across the millennia" (Seed 191), and of "Egyptian origins" (Rodgers 38, Pearson 228). This oversight limits discourse relating not only to historical and cultural specifics pertaining to

\footnotetext{
${ }^{33}$ Interestingly, this aligns her in some ways with the vindictive villain of Marsh's The Beetle.

${ }^{34}$ Even Holly and the "editor" of She note Ayesha's connections to ancient Arabian culture, such as her poetic declamation delivered to Leo (Haggard 231).
} 
Arabs but also by ignoring the tension Haggard explicitly sets up between Egyptian Amenartas and Arabian Ayesha, her nemesis, in the original novel. In this power struggle, Ayesha ultimately defers to Amenartas's superior abilities (admitting her inferiority) and the horrifying experiences She endures can be read as part of Amenartas's Egyptian curse.

Given Egypt's status to late-Victorians as the center of esoteric wisdom and magical ability, the power of the ancient or foreign Other was epitomized by the notion of the Egyptian curse. While ancient Egypt itself had no true concept of the curse, ${ }^{35}$ such superstitions appeared in the seventh century with the Arab occupation of Egypt (Cox and Davies 70). ${ }^{36}$ In Anglophone literature, Egyptian curse stories first emerged during the 1860s (Luckhurst, "Mummy's Curse" 129). During this time (which included the construction of the Suez Canal), Egyptian themes in literature turned darker (Bulfin 412). Between 1881-1882, with the discovery of a cache of royal mummies, Egypt's political unrest, and Britain's subsequent invasion, Egypt became the "premier location for the Imperial Gothic" in popular journals and magazines (Luckhurst, Mummy's Curse 166). Interestingly, late-Victorians did not always view the curse as an ancient (though enduring) phenomenon. In the midst of the mystical revival and medical embrace of hypnotism, "lost Egyptian 'science"” was given some legitimacy and especially among feuding occultists, the curse was "an active possibility, an agency alive and operating in the world" (Luckhurst, Mummy's Curse 213-14). David Frankfurter's discussion of curses and Egyptian magic defines a curse as a "ritual performance that transfers subversive power to some object" or

\footnotetext{
${ }^{35}$ Other than one or two admonitions against grave-robbing, the idea of the curse is absent from ancient Egyptian culture (Luckhurst, "Mummy's Curse" 129).

${ }^{36}$ This is partially exacerbated by the fact that hieroglyphics were impossible to decode until the finding of the Rosetta Stone in 1799, Cox and Davies suggest.
} 
the "subversive power that plagues one following such a performance" (158). ${ }^{37}$ Ayesha experiences the effects of both.

After Ayesha murders Amenartas's husband Kallikrates, Amenartas leaves Kôr and gives birth to her son Tisisthenes ("the mighty avenger"). A version of "avenger" in the family name appears in each of the many following generations. Amenartas's story and vow for vengeance are recorded on her sherd which Haggard based on the Rosetta Stone (Brantlinger, "Mummy Love" 40). ${ }^{38}$ Stephen Arata argues that the sherd is a "talisman" against Ayesha's power (98) and indeed, outside of her immediate domain, it is effective as a lasting source of knowledge, history, and perhaps physical protection to Kallikrates's patrilineal line. However, the sherd itself does not protect Holly or Leo from Ayesha's powerful gaze or influence, even for a moment. Amenartas's power is applied in a different way. She casts a curse that damns Ayesha during her 2,000-year lifespan and most dramatically, through the Pillar of Fire. Frankfurter asserts that "ritual speech-act[s]" (curses and blessings) "convey a beneficial or destructive power rather than effect an immediate transformation" (184). Indeed, Ayesha's "transformation" is deferred until the perfect moment for revenge- - just as her beloved Kallikrates is reborn and returns to her. Ayesha explains that after killing Kallikrates, Amenartas, "the swart Egyptian—she cursed me by her gods. By Osiris did she curse me and by Isis, by Nephthys and by Hekt, by Sekhet, the lion-headed, and by Set, calling down evil on me, evil and everlasting desolation" (282). While this curse is made explicit to Holly and Haggard's readers, Holly does not remark about it (nor do Haggard scholars).

\footnotetext{
${ }^{37}$ Frankfurter notes that "spells" read aloud by Egyptian priests were typically "protective utterances" (162) rather than the vengeful, malevolent cursing reflected in popular culture.

${ }^{38}$ Haggard had a colleague create the sherd for him and he proudly displayed it amongst his own Egyptian antiquities.
} 
Desolation and evil do follow Ayesha. From the outset, Ayesha is unable to leave Kôr even though she despises the people she rules and lives in an inaccessible, fallen, desolate city in the middle of Africa. Kôr seems "haunted" to her, "a place of evil omen" (267-68), but she cannot flee. She tells Holly that she waits for Kallikrates to be reborn and "here I tarry till he finds me" (149). The centuries of waiting are years of misery. With a "tortured look" of "agony," Ayesha weeps in Kallikrates's tomb, lamenting her bitter memories and inability to die (165). She later explains to Holly: "I have lived for full two thousand years—-for some six and sixty generations, as ye reckon time-in a Hell, as thou called it —-tormented by the memory of a crime, tortured day and night with an unfulfilled desire - without companionship, without comfort, without death" (199). Even her dreams are haunted—not only by Kallikrates, but by Amenartas, suggesting an influence beyond mere guilt. After a poor night's sleep, she explains that she dreamt "of one I hate and one I love" (171). As she gets closer to the Pillar of Fire in which she intends to initiate Leo, Ayesha experiences "strange and hideous dreams" and feels that "some evil overshadowed me" (267). Ayesha admits that the power of the Egyptian Other is stronger than hers. She could not kill Amenartas "for she was too strong for me" (239). During her "unholy rites," Ayesha incants: "Curse her, because her magic hath prevailed against me" but soon asks, "What is the use of cursing? — she prevailed, and she is gone" (164). Surprisingly, however, she does not overtly consider the possibility of Amenartas's curse as specifically contributing to her continual misery.

The climax of the curse's power occurs in the shocking Pillar of Fire scene. As the British heroes approach the Fire, it seems to be all that Ayesha has told them-a source of youth, beauty, knowledge, and thousands of years of life. The ether from the flame made the men "feel strong as giants and swift as eagles" with a "divine intoxication of our brains" (288). Holly's 
description of the Fire's influence is worth quoting at length, especially in light of Ayesha's contrasting experience:

I felt as though all the varied genius of which the human intellect is capable had descended upon me. I could have spoken in blank verse of Shakespearean beauty, all sorts of great ideas flashed through my mind $[\ldots] \mathrm{I}$ seemed to live more keenly, to reach to a higher joy, and sip the goblet of a subtler thought than ever it had been my lot to do before. (288) When Leo has doubts about entering the roaring flame, Ayesha decides to go first. However, what she experiences is the darkest aspect of Amenartas's curse. Ayesha is not purified and renewed; instead, she ages 2,000 years in a matter of minutes. In horror, Holly witnesses "her face growing old before my eyes"; Ayesha's lovely tresses fall to the floor, her body shrivels up to the size of a small baboon, her hands turn to claws, her skin changes to a dirty brown and yellow "like an old piece of withered parchment," and she looks like a "badly-preserved Egyptian mummy" (293). Shrieking and dying, on her "shapeless face was the stamp of unutterable age" (294). At the exact spot where she had murdered Kallikrates and where Amenartas had cursed her centuries before, She herself expired, promising Leo she would one day return.

Holly and Leo do not enter the flames; the grisly effect on Ayesha and "of the exact causes that produced that result we were, of course, ignorant" (297). Holly ascribes the appalling and unexpected devolution to Ayesha's hubris as "she opposed herself against the eternal Law, and, strong though she was, by it was swept back to nothingness-swept back with shame and hideous mockery!" (295). Holly believes "the finger of Providence" intervened because Ayesha, who would now leave Kôr, could have "changed the destiny of Mankind" and the "order of the 
World" (295). Critics have also interpreted her reversion as a result of pride and ambition, as representing degeneration anxiety, or in terms of gender politics and the punishment of an ambitious and forceful (New) woman. Entirely absent from this discourse, however, is the possibility of the Other's powerful knowledge - the Egyptian curse of Amenartas. It is important to remember that the Pillar of Fire and Egyptian "magic" or power are not necessarily different or competing forces. Haggard establishes the fictional Kôr as the ancestor of Egypt. ${ }^{39}$ What dooms Ayesha is not merely that the Egyptian is more powerful than she, but that Ayesha attempted to appropriate knowledge that she could not truly understand or master.

\section{Epistemic Anxieties: The Other's Knowledge Cannot Be Mastered}

Much of Ayesha's early training and wisdom came from Noot, the wise hermit who, in the latter days of Kôr, lived in the cave of the Pillar of Fire. Having heard of this philosopher, she sought him out. She explains to Holly and Leo that she essentially seduced and took advantage of the old man to appropriate his secret knowledge: "I beguile[d] him with my beauty and my wit, and flatter[ed] him with my tongue, so that he led me down and showed me the Fire, and told me the secrets of the Fire," though he would not allow her to stand in it as "man was born to die" (280). Ayesha studied under Noot and simply bided her time until his death so that she could reject his advice and step into the flame. Reflecting Haggard's interest in Theosophy, Ayesha is characterized as an adept, one pursuing practical skill in the study of the occult. Crucially, however, she does not heed her mentor's advice and clearly misunderstands the powers and limits to the Pillar of Fire. Just before her destruction, she scoffs at Noot because

\footnotetext{
${ }^{39}$ For example, this is seen through Kôr's obsession with tombs and the preservation of corpses, the veiled statue of Truth which is effectively an Isis figure, and by Ayesha's assertion that the survivors of Kôr emigrated to establish Egypt.
} 
even though he had "all life at his command," for his "conscience sake would have none of it" (281).

Ayesha's arrogance is likely her most damning attribute and, in some ways, reflects the hubris of $19^{\text {th }}$-century Western imperialists. They tended to reject knowledge outside their accepted epistemologies and when they did try to learn and appropriate the Other's knowledge, there was a significant chance that they would be mimicking dangerously or ineffectively. Contrary to the notion of natives mimicking Western rulers to be subversive (akin to Henry Louis Gates's concept of "Signifyin") or colonizers' condescendence to natives who are not quite/not white, this form of failed "reverse mimicry" reflects the faulty assumption of Western superiority in all areas of knowledge and mastery. Blavatsky warned in Isis Unveiled that Western men are arrogant and "unlike their Eastern counterparts," summarizes Parramore; "they lack the intuition and will that were required to harness occult forces" (103). While certain Victorian areas of study such as Theosophy had capacity for critique of colonial power structures, they also relied heavily on certain racist assumptions. Theosophy, Luckhurst explains, "offered strange reversals, placing primitive magic before modern theology or science, and subordinating Western seekers to Eastern masters, inverting the relation of power between colonial centre and margin"; however, racial stereotyping persisted and some Westerners feared the use of "black magic" by "oriental magicians who could unleash the dark energies of their fatal will" (Luckhurst, Mummy's Curse 218-19). He points out that many Victorian occultists "tottered on the brink of losing their alleged mastery of will to a greater force that could threaten annihilation with punitive currents of murderously directed willpower" (Mummy's Curse 236). ${ }^{40}$

\footnotetext{
${ }^{40}$ Some believed that hypnotic rapport, for example, could be reversed and such deconstruction worried magical revivalists. Similarly, the persecution of the "evil eye" might be reversed back onto the gazer, as with the case of Medusa (Luckhurst, Mummy's Curse 236).
} 
There was a genuine cognitive dissonance amongst many Victorians, then, as they struggled to reconcile their ingrained sense of cultural and racial superiority to the powerful, mysterious forces of ancient and foreign peoples whose supernatural and esoteric abilities simultaneously attracted them. As occult discourse and Gothic literature suggest, it was possible (and perhaps likely) to misunderstand and/or misapply the Other's knowledge. If Ayesha, a trained adept with 2,000 years of experience, does not grasp the complexities of her occult powers, what does this failure suggest to Haggard's readers with interests in imperialism, archeology, the occult? Because both Amenartas and her Egyptian curse outflanked Ayesha's abilities (and certainly the British heroes'), Haggard's novel presents deep epistemological anxieties and a cautioned stance regarding the subversive - though sometimes dormant or subtle - power of the Other.

During the 1880s when She was written and published, Britain's military intervention in Egypt inspired not only a surge of Egyptian-related themes in popular culture, academic study, and archeological digs, but also a darker sense of foreboding exhibited in emerging Egyptian Gothic fiction and curse stories. Luckhurst recognizes that popular representations of Egypt as an "uncanny land of the dead, a wasteland laced with hidden treasure, works exactly to obscure the other blindingly obvious element of this conjecture: the revolt of living Egyptians" ("Mummy's Curse" 133). Haggard's fictional choices of the Egyptian-Arab-British triangle in She relate to the history of Egypt and the cultural context of the late $19^{\text {th }}$-century Egyptian Question in particular. While "Arabs" have been integrated into Egyptian culture since at least $641 \mathrm{AD},{ }^{41}$ Ayesha represents an "outsider" Arab (closer to the Ottomans of Haggard's time). She explains her roots to Holly: "Arabian am I by my birth, even 'al Arab al Ariba' (an Arab of the Arabs), and of the race of our father Yárab, the son of Káhtan, for in that fair and ancient city Ozal was I

\footnotetext{
${ }^{41} 641 \mathrm{AD}$ is when the Byzantine Empire lost Egypt to the newly-established (Muslim) Arab Empire.
} 
born, in the province of Yaman the Happy" (146). Ayesha thus distinguishes herself from the "naturalized Arabs" (146) - who were then believed by some to be the descendants of Ishmaelas a "pure" Arab. She was born around the time of Nectanebo II of the thirtieth dynasty, the last native ruler of ancient Egypt from 360-342 BC before the Persians took control (and soon after, the Greeks in $332 \mathrm{BC}$ ). It was also during this time that Amenartas and Kallikrates fled Egypt after renouncing their vows of celibacy to Isis in order to wed. In the novel, Ayesha has thus lived in Kôr for about 2,000 years.

The "great race" that Ayesha suggests was the precursor to ancient Egypt was largely obliterated via "pestilence" 6,000 years before Holly and Leo arrive in Ayesha's domain (Haggard 149). While a few survivors of the great empire remained, most emigrated. "Doth it not occur to thee," Ayesha asks Holly, "that those men who sailed North may have been the fathers of the first Egyptians?" (180). She rules the savage Amahagger tribe on the outskirts of Kôr, a race made up of lost Kôr descendants who have mixed with either the "barbarians from the South" or Ayesha's people, "the Arabs" (181). Whether the Amahagger are supposed to represent $19^{\text {th }}$-century Egyptians is debatable. ${ }^{42}$ Indeed, Haggard's novel did not address the contemporary state of Egypt, largely to provide a comfortable distance with which to more subtly discuss the controversial Egyptian Question of the 1880s. However, it is clear that after 2,000 years of manipulation, study, and experiments, Ayesha presumptuously (and inaccurately) believes herself to be an expert on her acquired empire and the secret knowledge of Egypt's precursors. Additionally, she does not realize or anticipate the power of Amenartas's Egyptian curse upon her.

\footnotetext{
${ }^{42}$ See, for example, Brantlinger's "Mummy Love: She and Archaeology" (46).
} 
Haggard chooses to specifically contrast Ayesha's Arabian lineage—and power-with her Egyptian rival Amenartas's. Ayesha is perspicuous about her ancestry and national origin, as evidenced above. To emphasize her distinction from her rival, she often refers to Amenartas by her nationality rather than her name. Ayesha calls her "the swart Egyptian" (182) and "that Egyptian asp" (261); she says "I sent her-the Egyptian—away through the swamp" (182), "accursed be the memory of the Egyptian" (163), etc. Amenartas's background is also made clear by her story recorded on the ancient potsherd. She begins, "I, Amenartas, of the Royal House of the Pharaohs of Egypt, wife of Kallikrates (the Beautiful in Strength), a Priest of Isis whom the gods cherish and the demons obey $[\ldots]$ fled with thy father from Egypt in the days of Nectanebes" (30). She narrates their encounter with Ayesha and notes the power Egypt has in the face of Ayesha's, even after She had bathed in the Pillar of Life. Amenartas importantly notes that Ayesha "could not slay" her "because of the magic of my own people that I have, and that prevailed thus far against her" (31). Ayesha herself admits this weakness to Holly (239). Given Ayesha's power and potentially immortal status, however, Amenartas relies on the speech act of the Egyptian curse for justice, rather than attempting direct physical violence.

Cursing (like betting, promising, commanding, marrying, naming, begging, declaring war, and so on) is what philosopher J.L. Austin would designate as a performative aspect of language in his speech-act theory. ${ }^{43}$ Rather than using words to merely describe things ("constative"), language can also simultaneously do things ("performative") (Petrey 4). Cursing typically calls on the power of gods or occult forces to carry out malevolent effects upon the cursed; words, then, (in collaboration with supernatural forces) can actually bind fate. Utilizing a curse—including Haggard's fictional use — can tell us much about the power relationship of the

\footnotetext{
${ }^{43}$ Ülker Vanci-Osam explains that "speech act theory attempts to capture all the possible functions of language by classifying the kinds of action that can be performed by speech" (73).
} 
context. For example, in linguist Ülker Vanci-Osam's analysis of curse utterances in Turkish history and culture, she explains that curses are generally "part of women's discourse" because the "main precondition for the production of such utterances is the lack of power and inability to use physical force" (75). This also makes sense regarding the origin of Egyptian curses; the words inscribed on tombs intending to ward off any disturbance were necessary in the absence of continuous guards and impenetrable locks. Since Amenartas may not be able to bodily attack Ayesha, Amenartas uses a curse to carry out justice for Ayesha's murder of Kallikrates. The effects of this incantation which stretch over 2,000 years ultimately prove to be much more devastating than a quick death.

Haggard's use of the curse in She works metaphorically regarding the Egyptian Question of the 1880 s to illustrate British anxieties about unknowable, un-masterable, inaccessible foreign powers. Since native Egypt is unable to succeed militarily in its retaliations against either imperial Ottomans or Britons, it must rely on an indirect method that gains its power from Egyptian gods. The increasingly popular motif of the Egyptian curse in British literature and popular culture illustrate the looming anxiety engendered not only by Egyptomania's tombraiding and desecrations, but also by imperialist and martial actions in the region. If Egypt does hold special, esoteric knowledge and authority, what consequences might the colonizers and excavators suffer? When would they feel the repercussions and how could they know what was attributable to the vengeance of Egyptian gods? What Austin would call the perlocutionary ${ }^{44}$ effects of the speech act—here, the consequences of the curse—are not necessarily immediate. The inability to understand or recognize what the curse may entail, how to combat it, or even when to expect its effects thus exacerbates the anxiety felt about the Other's mysterious power.

\footnotetext{
${ }^{44}$ Perlocutionary consequences for Austin are the after-effects of a speech act, or "the result or effect that is produced by an utterance in a given context" (Vanci-Osam 73).
} 
Even as Egypt inspired awe and anxiety for many Britons, the country was crucial to the British empire for both economic factors and security/defense strategy. Protecting trade routes, especially to India, was at the heart of the Egyptian Question of Haggard's time. Egypt's astronomical debt during the latter $19^{\text {th }}$-century prompted the ruling Ottoman Khedive to obtain a significant loan from Britain to finish the Suez Canal (1869), which gave a direct shipping route from Europe to South Asia. ${ }^{45}$ While Egypt was increasingly amenable to Western travelers (and businessmen), the accumulating control by foreigners vexed most Egyptians who were already subjected to the outside rule of the Ottomans and suffered extreme poverty. ${ }^{46}$ Nationalist sentiment and frustrations continued to grow and in 1881, Colonel Ahmed Arabi revolted against the Khedive. As an Arabic-speaking fellah and popular army commander, Arabi became a national hero and was called the "George Washington" of Egypt ${ }^{47}$ Like Haggard's ruling Arab Ayesha and her imperial British cohorts experience, the power of Egypt might be underestimated. The British naval bombardment of Alexandria in 1882 only strengthened nationalist sentiment and Arabi's popularity. It would take a full-scale military invasion to quell Arabi and (ostensibly) restore Ottoman Khedival rule, though Britain remained in Egypt for 40 years as first an unofficial and later official protectorate. The turn toward darker depictions of Egyptian forces (seen in the emergence of Egyptian Gothic as a genre) reflects Britons' suppressed anxiety that retaliation from the land of the Nile may occur at any time.

\footnotetext{
${ }^{45}$ By 1880 , the development of steam engine ships made the Suez Canal indispensable to the British Empire. Travel time to her "Crown Jewel" was cut in half and steamers through the canal were responsible for $88 \%$ of the India trade (Harrison 5).

${ }^{46}$ Of particular contention were the "capitulations," which allowed foreigners to enjoy not only freedom from taxation, but immunity from Egyptian law. While Europeans made up just $2 \%$ of the Egyptian workforce, they monopolized upper echelon positions and earned $15 \%$ of revenues, tax free (Harrison 47).

${ }^{47} \mathrm{He}$ was at the center of the nationalist movement whose slogan was, aptly, "Egypt for the Egyptians." This slogan is credited to journalist and Arabi supporter Ya'qub Sanu' (Colla 168).
} 
Britain was able to suppress the Egyptian nationalist movement through military invasion in 1882 and by exiling Arabi to Ceylon, not unlike Ayesha's ability to banish Amenartas from Kôr after their conflict. However, these "victories" were not without lasting negative repercussions. Ayesha's fate included centuries of isolation, the inability to leave desolate Kôr, and her appalling transformation in the Pillar of Fire. Holly and Leo grieve the loss of Ayesha and experience hardships and imprisonment while barely managing to reach their homeland two years after leaving it. The real-life repercussions from Britain's military involvement in Egypt also produced both local and global sufferings. The Gladstone administration misrepresented Arabi's nationalist movement as dangerous to justify "saving" Egyptian liberties; however, Harrison argues that "in reality, Egypt's native-born constitutional movement perished with Arabi" and did not recover for another seven decades (6). The occupation created more difficulties in the Sudan — which was now closely linked with Britain as part of the Egyptian empire - and helped lead to the emergence of the savage "Mahdi" (the supposed redeemer of Islam) against whom gruesome battles were fought and numerous lives lost in the coming years. It inspired the "scramble for Africa," an area largely untouched before 1882 (Harrison 7-8). Regarding Britain's relationship with Europe, Harrison asserts that the "hypocritical nature of the aggression thrusting the Liberal imperialists into Egypt completely shattered the alliance with France, provided a tool for German colonial adventurism in Africa, and finalized Britain's overall isolation from the Powers up to the First World War" (156). Britain's short-term goals thus did not adequately consider long-term complications arising from their actions.

While Haggard obviously could not foresee all the major implications from this imperial involvement, it seems he was right to have concerns about Britain's aggression in Egypt. His use of the curse in She reflects his doubt about the West's dominance and "superior" knowledge. 
Ayesha's epistemological certainty is exposed as flawed because she does not recognize the perlocutionary effects of Amenartas's speech act. Ayesha does not make the connection between the Egyptian's curse and her inability to leave her situation of constant misery and loneliness. This folly eventually leads her back to the location of the curse and to her own destruction. Holly and Leo recognize that Ayesha's knowledge (and thus power) is incomplete and limited; therefore, they choose to forego the temptation of the Pillar of Fire. The novel then illustrates both imperial hubris and relative wisdom through the choices of Ayesha and the Cambridge fellows.

Haggard's best-seller She reflects a general epistemological crisis experienced by many late Victorians. Scientific discoveries and technological advancements interrogated and influenced ideas about knowledge. For example, "invisible" forces were being legitimized through areas such as electricity, and medicine began viewing hypnosis as a valid form of treatment. Concurrently, disciplines such as geology, paleontology, and biology challenged orthodox religious beliefs about humans' superiority as a species, theories of evolution, and the age of the earth. With widespread emigration and travel to colonial regions, mysterious and seemingly powerful forces of non-Westerners also complicated these questions of epistemology. Being confronted with alternate forms of knowledge created a sense of undecidability in the imperialist abroad; Western knowledge (and values) may be insisted upon as superior, but the alleged inability of colonized or native peoples to properly imitate Western ways subverted the notion of Western knowledge's universality, thus calling into question the very enterprise of imperialism itself. Imperial Gothic novels capture and explore these anxieties through the comfortable distance of fantasy. Haggard's She utilized contemporary conversations about the esoteric power of the foreign and/or ancient Other through references to occult, Hermetic, and 
Theosophist interests. These areas included mesmerism, telepathy, reanimation, reincarnation, immortality/longevity, and Egypt's connection to the supposed secrets of the world. His tale is cautionary, however, and illustrates that the hubristic imperialists appropriating lands, peoples, their alternate knowledges and practices, may find that they have arrogantly erred in their assumption of mastery. While Haggard's life reflects a continued interest in the occult and knowledge outside typical Western empiricism, She advocates for wariness and respect for potentially dangerous forces as well as adherence to wisdom held and advice given to students by their native mentors. Also, by utilizing the unexpectedly powerful and lasting authority of an Egyptian and her curse, Haggard can subtly comment on the late-Victorian Egyptian Question. His novel evinces a cautionary attitude exemplified in one of General Wolseley's officers after taking control of Egypt. The officer warned about the potential negative outcomes to Britain since Egypt "has ever played a strange part in the destiny of empires" (qtd. Bulfin 414). As indicated in Haggard's She, British imperialists and despotic rulers from Arabia and Asia Minor might yet be overpowered by the occulted and unpredictable authority of Egypt. 


\section{Chapter 3}

Competing Epistemologies and Irrational States: Sexual Terror and Contamination Anxiety in the Colonial Encounter

Victorians seemed to have an incessant drive for knowledge: the world, its inhabitants, customs, and mysteries were to be explored, understood, categorized, utilized. In an age when the British quite literally ruled much of the world, seeking adventure outside the norm of middle-class life in England (in the empire, through alternate spiritualities, via sexual escapades, in pursuit of forbidden knowledge, and so on) was part of the British instinct to discover, experience, and exploit. Western knowledge was perceived as rational, scientific, explainable, natural, and normative while foreign and ancient knowledges (curses, hauntings, reincarnation, and so on) were often deemed irrational, superstitious, magical, inexplicable, supernatural, non-normative, and thus in a sense, queer. The colonial enterprise juxtaposed competing epistemologies, but as Bhabha indicates, Western rationality was not simply elevated as superior to the queer knowledges of the Other. This set of doxai knowledges — as well as the complications arising from colonized peoples' mimicryreveals a challenge to Western "transcendental truths." European failures of what might be called "reverse mimicry" further elucidate this epistemological crisis, whereby Europeans cannot understand or master the Other's knowledge. Colonization is frequently (and rightly) described as metaphorical rape; however, rather than simply controlling another culture against its will, the actual colonial context included a cultural osmosis between colonizer and colonized. Sex itself can be considered a powerful metaphor for the colonial project as a dissolving of boundaries between self and Other - an interpenetration of cultures. With this mutual influence, however, persist anxieties, which late-Victorian Gothic fiction exhibits: the angst associated with colonialism as metaphorical sex between self and Other is often illustrated as terrifying and contaminating literal sex. Such is the 
case in Richard Marsh's The Beetle (1897), which represents epistemological anxiety through a focus on sexual contamination and disease. The forbidden knowledge sought here by the European is sexual knowledge of the colonized woman. During the $19^{\text {th }}$-century, Western truths were challenged not only by encounters of varying epistemologies during colonization but also, for example, through sexually transmitted diseases between Europeans and non-Europeans. If such truths (symbolized by Bhabha's "English book") were truly transcendental, boundaries would stay intact and divisions such as clean/unclean and healthy/unhealthy would remain distinct. However, epistemological undecidability in the colonial encounter exposes boundaries as porous and contagion as a dangerous hybridity; components can spread, blur, queer, and even destroy one another.

The motif of sexualized terror in The Beetle is compelling; besides its sensational utility, the focus on dangerous sexuality reflects British anxieties about rampant venereal disease in general and the recently repealed Contagious Diseases Acts (CDAs) in 1886 in particular. ${ }^{48}$ Relaxed sexual regulations abroad provided especial anxiety because colonial climates, notes Phillipa Levine, "were seen as likely breeding grounds for infection and contagion, and they were regarded, too, as inflaming the passions and negating caution and reason" ("Public" 164). Marsh's novel suggests that such serious health risks indicate a call for a stricter moral code abroad and increased state intervention into sexual affairs as a matter of national public health. In The Beetle, an Egyptian femme fatale uses mesmerism to entrance, paralyze, exploit, terrorize, rape, control, and even kill her victims. On one level, the sexual encounters and metaphors, as well as depictions of disease and insanity in the novel, delineate symbolic tales of sexual contamination, particularly syphilis. Mesmerism and madness are not the only representations of irrational states and forbidden knowledge that test Enlightenment reason, however. In a wider consideration, the novel's

${ }^{48} \mathrm{CDAs}$ typically meant the compulsory detainment and examination of suspected prostitutes (in certain areas of the Mother country as well as in British colonial areas), and (forced) treatment for venereal disease in "lock" hospitals. 
proliferation of irrational states and doxai knowledges of both colonizer and colonized serve to critique the notion of British superiority and challenge Western rationality and epistemology. This is also reinforced through the structure and plot of the novel, which allow for considerable ambiguity.

\section{Colonial Syphiliphobia: Sexual Deviance and Disease}

The year 1897 marked a significant moment for British publication. "Sexual sage" Havelock Ellis produced Sexual Inversion, signifying the widespread and hotly debated discourse on the "nature" of gender and sexuality. Fear of syphilis and other venereal diseases, particularly coming from colonial contexts, were exacerbated by a new upsurge in British press coverage concerning the (colonial) Contagious Diseases Acts (CDAs). Fueled by a sharp increase in venereal disease among British soldiers abroad in 1896, the controversy among imperial legislature has been dubbed "the storms of 1897" by Philippa Levine ("Rereading" 606, 602). Bram Stoker released Dracula, and another influential and widely read Gothic novel also emerged that year: The Beetle by Richard Marsh. Marsh's text, as much an example of fin de siècle fiction as Dracula, was even more popular than its vampiric rival. ${ }^{49}$ In the "imperial Gothic" mode outlined by Patrick Brantlinger's Rule of Darkness, The Beetle represents not only invasion anxiety (reverse colonization), but also a particular dread of sexual disease and degeneracy being passed from "lower race" ("less evolved") women to "superior race" Britons, ultimately leading to degeneration, insanity, and death for British men and their families. By the time the domestic CDAs were repealed in 1886, many Victorians had indeed shifted the blame from the female prostitute as disease carrier to the middle-class man, and especially condemned the spread of syphilis from married men to their wives and children. ${ }^{50}$ The continuation of such

\footnotetext{
${ }^{49}$ Victoria Margree, "'Both in Men's Clothing"' 63.

${ }^{50}$ See Showalter, Sexual Anarchy, 197-198; also Smith 114-115.
} 
laws in imperial contexts, however, suggests another important displacement of blame from the British male client to the seductive and "sexually dangerous" colonial woman.

Allowing a somewhat comfortable distance for Victorian readers through the supernatural Gothic literary mode, Marsh engages in social scientific and legal discourse of his day concerning empire, sexuality, venereal disease, and degeneration. His novel displays the stereotype of the colonial ("savage") woman as sexually excessive, deviant, and polluting (much like a prostitute). Marsh positions his antagonist Other as primitive and threatening by her race and nationality (Arab/Egyptian), religion (from the ancient Egyptian cult of Isis), but also in a strikingly unusual way for Victorian fiction: as bisexual (in both the hermaphroditic sense as well as being sexually attracted to men and women). Havelock Ellis and some other contemporaries believed that bisexuality was "latent" in highly evolved humans but often present in less evolved, primitive, or atavistic persons. ${ }^{51}$ The foreign Beetle's sexually executed and degenerative, paralyzing effects on the novel's British characters can be understood as syphilitic contagion and disease. Interestingly, the use of bi-sexual contamination among both men and innocent women not only allows Marsh to titillate his audience with homoeroticism and other sexual taboos, but also to represent venereal contagion of the "innocent" in Gothic horror form. Here, males are not the only victims of the diseased colonial woman - the Beetle reveals the possibility of syphilitic contagion to British women via their husbands, as well. At a time of what I would call "colonial syphiliphobia," to extend Showalter's discussion of domestic fin de siècle syphiliphobia, The Beetle promotes the necessity of regulating venereal disease abroad to protect the vitality and superiority of the Mother country and conservatively warns against the potential consequences of dabbling with the sexually "primitive" and dangerous Orient.

\footnotetext{
${ }^{51}$ See Angelides, 44-46.
} 
The Gothic genre in literature has long been recognized for its ability to represent cultural anxieties in particularly powerful ways, as readers are "safely" detached by supernatural phenomena and/or remote times and settings. The Beetle uses tropes of fin de siècle and imperial Gothic to engage in uneasy popular discourses of the 1890 s — especially degeneration, sexual deviance and contamination, disease, and empire-from a secure distance. Glennis Byron recognizes that nearly all fin de siècle Gothic texts "drive to define and categorize the features of a culture in crisis, to determine the exact nature of the agents of dissolution and decline" in an attempt to identify and contain what is "unfixed, transgressive, other and threatening" ("Gothic" 133). Reestablishing the status quo or "norm" is then used to (supposedly) redraw clear distinctions and boundaries that the Other has destabilized. Marsh's novel does just this: it examines late-Victorian concepts of degeneration ("dissolution and decline") in relation to sexuality and empire. Rebecca Stott notes that fin de siècle Britain perceived a "decline in power and virility ${ }^{52 "}$ and "inevitable sexual discourses were increasingly mobilized to speak about this decline in power" (29). Encompassing these concepts, The Beetle's utilization of the Gothic allows a sensational interplay between the foreign and the sexual in relation to Britain's greatest fears of degeneration, decay, and cultural superiority.

The Beetle tells the story of Paul Lessingham, who as a young man foolishly entered a dangerous native quarter in Cairo one night for "amusement" and a "spice of adventure" during a tour abroad (Marsh 238). This seeking of "adventure" implies a sexual encounter that would have been recognizable to Marsh's contemporary readers (and Lessingham does indeed enter a brothel-like "café" populated only by women where he drinks intoxicants and is seduced). Ronald Hyam explains, "many young Victorians going overseas expected to indulge in casual

\footnotetext{
${ }^{52}$ Virility here is the "ability to progress and evolve successfully — to propagate the race" (Stott 29).
} 
sex as a routine ingredient of life" (88). The empire offered a considerable arena for sexual opportunity as more space and privacy were available, inhibitions were relaxed, "European standards might be held irrelevant," and "abstinence was represented as unhealthy in a hot climate" (Hyam 88). Men were expected to indulge their natural instincts and Hyam states that abroad, the "white man's status put him in a strong position to get his way" (88). A beautiful Egyptian "Woman of Songs" entrances Lessingham and he finds himself mesmerized into complete paralysis. However, he is quickly repulsed by his seductress, the "Priestess of Isis," as he witnesses atrocities committed by the surrounding cult upon white men and women alike. These include sadistic sexual violations, human sacrifices, and ritual consumption of victims' remaining ashes (Marsh 243-244). After several months, Lessingham eventually breaks the mesmeric trance, strangles the Priestess (who, at the point of death, suddenly metamorphoses into a Beetle-creature), and escapes.

Twenty years later in London, the still-haunted Paul manages to become an influential politician and proposes marriage to a respectable and independent woman named Marjorie Lindon. Seeking revenge on Lessingham, who had rejected the evil priestess and apparently killed her, the Priestess of Isis (or a compatriot) invades London as an "Arab"-looking man with the ability to transform from scarab-creature to human "hermaphrodite" form (with the body of a young woman, disguised in men's clothes, but with the ugly face and voice of a man). To the reader, it is unclear whether the Beetle is a transmigration of the Priestess strangled by Lessingham or another member of the cult of Isis, avenging her sister's death. While the Beetle's vengeance is focused on Lessingham, the Briton's punishment will be the abduction, violation, and ritualistic murder of his fiancée. Despite the attempts to protect Marjorie by her friends and fiancé, she is eventually kidnapped by the Beetle, sexually violated, and disguised as a London 
tramp named Robert Holt, who had also been mesmerized and vampirically drained to his death by the Beetle. Marjorie's protectors desperately seek to rescue her, employing telegrams, hansom cabs, and special trains. However, a random train accident that she barely survives is what saves Marjorie as the wreck apparently kills the Beetle. After three years in an insane asylum, Marjorie and Paul are finally married though both are still (justly) paranoid about beetles and the potential return of the avenging Priestess of Isis.

Marsh's creation of the Other is, of course, informed largely by the dominating ideologies of late-Victorianism. The Beetle's primitiveness - physical, moral, and sexual-is her overriding threat through contamination (and subsequent degeneration) of British subjects. Hideously ugly, she (or he-Holt and other characters believe her to be a man) is described as having an abnormally small cranium, saffron yellow skin, a large beak-like nose, absent chin, and blubber lips (Marsh 53); such features, as Julian Wolfreys notes, are "suggestive of the kinds of 'racial' and criminal categorization that can be found in both Lombroso and Havelock Ellis," as well as Nordau, which would likely be recognizable to Marsh's readers (17). Indeed, Holt tells us (and other characters consistently concur) that he "had no doubt [the Priestess] was a foreigner" (52). Late-Victorian ideology, of course, held the British and other Northern European white "races" at the highest end of the human evolutionary scale while non-white "savages," such as Fuegians, Tasmanians, and Aborigines, were deemed lowest on the developmental line (Ledger ánd Luckhurst 315). The physical features of this "foreign" Beetle imply a savage primitivism in various threatening ways.

For Victorians, the notion of "less evolved" bodies belonging to non-white races easily extended to a "less evolved" sexuality. Levine notes that the sexuality of "primitive" peoples (frequently encountered within Britain's vast empire) was considered part of a "premodern 
phenomenon that modernity and rationality had learned to contain," and that natives' problem was their "failure to move beyond the primitivism of unchained nature" where pleasure was placed above the purpose of reproduction (Prostitutes 180). Subsequently, colonial contexts were viewed as "sexually distinct from Britain: sexually loose, sometimes predatory, and frequently excessive" (Levine, "Sexuality" 134). Marsh's use of a voracious, genderambiguous/hermaphroditic "Oriental" antagonist implies (colonial) sexual primitivity; the Priestess clearly possesses a sadistic sexual interest in both men and women, seen through the activities of the Cult ${ }^{53}$ as well as her encounters with both sexes in London. ${ }^{54}$ Havelock Ellis explains that "by bisexuality it is possible to understand not only the double direction of the sexual instinct, but also the presence of both sexes in the same individual" (236). Angelides's The History of Bisexuality discusses Ellis's theories, which included the belief that blacks, women, and children evidenced an "arrested form of development" and were thus closer to "primordial and primitive bisexuality" than the more "evolved" men. Ellis, like his contemporaries, placed heterosexual white males at the top of the hierarchy and "in this evolutionary schema, the path to (hu)manhood necessitates the stripping of race, and (bi)sex" (Angelides 44-45).

The Beetle displays primitivity through (non-white) race, hermaphroditism, and bisexuality. Interestingly, while discussing sexual inversion among women, Ellis notes that in Egypt "[inversion] is almost fashionable, and every woman in the harem has a "friend"" (249). Many Victorians feared that harems and other all-female communities—-such as the cult of Isis depicted in The Beetle - were threatening loci for various forms of "contamination." Hall explains that during the Victorian period, "uncontrolled and antagonistic, virulent and sexually

\footnotetext{
${ }^{53}$ We know that both young white men and women were lured, as was Lessingham, into the temple of Isis.

${ }^{54}$ Also, Holt believes he is violated by a man, while Marjorie knows later on that her attacker is bodily female.
} 
threatening, women independent of men and working together were commonly represented as communities pervaded by mental and physical disease" (Fixing Patriarchy 179). The Beetle's Gothic temple of Isis envisions a threatening Oriental harem or brothel of primitive and diseased women through its sexual deviance, foreign rituals, and group sex in a space dominated by women.

In Prostitution, Race, and Politics, Levine reveals how colonial women, in their sexual "excess," were all typically considered (by the British) as potential or actual prostitutes, "with the colonies depicted as a giant brothel" $(182,180)$. Native prostitutes were imagined as sexually primitive, as "woman in her natural state, untamed and unchained from modesty and propriety," while white prostitutes were atavistic "throwbacks" (Levine, Prostitutes 183). The threat of sexually degenerating was exacerbated by the widespread problem of venereal diseaseespecially syphilis among soldiers and sailors-in Britain as well as her colonies. For example, by WWI, the Army Medical Services warned that the prostitutes of Egypt (the Beetle's homeland) were "all more or less infected with disease" (qtd. Levine, Prostitution 155, emphasis in original). And Cairo-where Lessingham sought a "spice of [sexual] adventure" and encountered the demonic women of Isis - was dubbed "the home of all that is filthy and beastly" by the official press correspondent for the AIF in Egypt (qtd. Levine, Prostitution 155).

The most feared of venereal disease during this time was certainly syphilis, the disease that "changed the course of history, shaped the path of medicine, and had more influence on psychiatry than any other illness" (22), argues research psychologist Robert Kaplan. By 1914, there were 3 million cases in Great Britain alone. There was a "constant interaction between syphilis, prostitution and sexual crime," and the disease is even considered the motivator for the 1888 Whitechapel Jack the Ripper murders: a mad doctor infected with syphilis was believed to 
be taking revenge on those he deemed responsible- prostitutes $^{55}$ (Kaplan 22-23). Syphilis was pronounced by the American Medical Association as "the great question of the day" in 1876 (Levine, Prostitution 41) and Elaine Showalter argues "syphilis was surely the symbolic disease of the fin de siècle ("Syphilis" 166). Syphilis, caused by a bacterium, is generally transmitted sexually. The Center for Disease Control notes that symptoms include sores, skin lesions, rash, muscle ache, fatigue, and fever; syphilis eventually attacks the nervous system, leading to paralysis, numbness, blindness, and dementia. Symptoms may come and go, and remain dormant for years at a time. In the final stages, it damages internal organs, nerves, the heart, liver, eyes, bones, and can result in death ("Syphilis").

Medical literature of the period recognized most of these symptoms and by the 1890 s, "research in medical science and pathology proved what had long been suspected: general paralysis of the insane [GPI], a form of madness that affected up to 70 per cent of male asylum patients, was actually the terminal form of syphilis" (Showalter, "Syphilis" 167). The figure of the male syphilitic was popular in medical literature, "quack advertisements," and sensational and Gothic fiction of the period. While the syphilitic male was the "arch-villain of feminist protest fiction," the sexually promiscuous disease carrier who infected unsuspecting faithful wives and innocent unborn children, men's writing blamed women as femme fatales or frigid wives who drove them to the brothels (Showalter, "Syphilis" 167-168). Since the blame of syphilis had transferred from the British prostitute to the bourgeois male client, the notion of colonial or non-white women as the most dangerous source of VD became more widespread.

Anxiety about venereal disease circulating throughout the empire is largely what kept debates about state intervention and regulation alive. Levine notes that venereal disease came to

\footnotetext{
55 See Charles van Onselen's The Fox and the Flies: The World of Joseph Silver, Racketeer and Psychopath (2007) for more on the Jack the Ripper and syphilis theory.
} 
be viewed as "racially mono-directional"; it was not only a sexual disease but a racial one (Prostitution 66). Lord Kitchener warned the troops abroad that diseases "passed on from one race of men to another always increase in severity" and Levine argues, "the implication that [sexual] contacts with locals was a risky business, physically and morally" is a theme seen repeatedly during this period, "shared alike by $[\mathrm{CDA}]$ regulationists and abolitionists" (Prostitution 135). "Venereal disease was the foreign disease" (Prostitution 66), a "racial poison" (Prostitution 195), Levine explains, and it served as a "metaphor for the imperfections and failings of those deemed its source. Native behavior thus became the faultline both of the need for colonial medical control and for the spread of painful and disfiguring diseases" (Prostitution 66). Other Western powers of the time also shared this fear of contaminating foreign women: Showalter notes that by the turn of the century, "most of French literature dealing with syphilis was sexist, xenophobic, and racist. In a pattern that became true for other countries as well, they made the foreign-born prostitute the alleged source of venereal contagion and the scapegoat for male sexual anxieties" (Sexual 189).

Through The Beetle, Marsh reveals fin de siècle anxieties of sexual and syphilitic contamination by primitive, savage women/prostitutes from the British Empire. The Egyptian Priestess's worst outrages are sexualized assaults of deviance, violence, and contamination committed against several different characters. Kelly Hurley recognizes that "the precise nature of the Beetle's atrocities...clearly points to some Gothicized version of rape, inflicted upon male and female bodies alike" ("Inner Chambers" 193). At the beginning of the novel, the vagrant Londoner Holt—paralyzed and horrified by the Beetle's mesmerizing effects—-feels the polymorphous creature slowly crawl up to his chest: "I became more and more conscious of an uncomfortable wobbling motion, as if each time it breathed its body heaved [...] it touched my 
lips $[\ldots]$ it enveloped my face with its huge, slimy, evil-smelling body, and embraced me with its myriad legs" (51-52). Later, lying naked, the Beetle attacks in human (hermaphroditic) form; Holt says, "his fingers prodded me then and there $[\ldots]$; they were thrust into my mouth $[\ldots]$ the blubber lips were pressed to mine - the soul of something evil entered into me in the guise of a kiss" (57). Holt is eventually (literally) drained of life, found emaciated with two small puncture wounds on his neck (303), much like a vampire's mark. ${ }^{56}$

The Beetle also assaults Marjorie, though the reader is spared most of the details by Marjorie's slip into unconsciousness (and her unwillingness to narrate her later assaults). Recalling her first violation, she says that, while strangely paralyzed and naked in her bed, the Beetle "began to find its way inside,--to creep between the sheets [...] I felt it coming nearer and nearer, inch by inch; I knew that it was upon me... and then oblivion did come to my aid" (207). After being kidnapped, mesmerized, disguised as a man, and repeatedly violated by the Beetle, the results after Marjorie's escape are devastating: "even after her physical powers were completely restored - in itself a tedious task — she was for something like three years under medical supervision as a lunatic" (Marsh 319). However, she reportedly recovers "satisfactorily" in time as a docile and devoted wife to Lessingham.

The colonial sexual atrocities began, however, with Paul Lessingham, 20 years prior to the setting of the novel. At the age of 18, Paul goes alone to an Egyptian neighborhood one night and hears the "enchanting" beauty of "Eastern harmonies" sung by the "Woman of Songs" (239). He enters the café of women to hear more music, drinks their "liquor" (probably a drugged drink), and after a period of "oblivion" awakens nude on a bed in a temple for the cult of Isis.

\footnotetext{
${ }^{56}$ Interestingly, in "Vampires and the Empire," Warwick notes that the "disease that has already been observed as equivalent to vampirism is syphilis" (209). Erotic/sexual assaults such as the Beetle's and Dracula's vampires are thus seen as fatally contaminating, much like certain venereal diseases.
} 
The Priestess "wooed [his] mouth with kisses," though something "unnatural" about her fills Paul with horror and loathing (241). He recalls her paralyzing effects: "I was wholly incapable of offering even the faintest resistance to her caresses [...] she did with me as she would, and in dumb agony I endured" (243). As Holt did, Paul feels his "manhood" is in jeopardy and that he is "emasculated" (245). After Paul's escape, he suffers greatly in physical and psychological health (246) and scarcely survives his ordeal with the colonial Other. The sexual nature of Paul's experience in the cult's temple well represents menacing sexual primitiveness and the degenerative effects of venereal infection at the hands of colonial women.

Such assaults are represented not only as a kind of literal rape, but also a psychological one. Attacks like these can signify vengeance for the "rape" of European colonization; here, it is reversed and inflicted back onto the Western colonizers and tourists. It also points to a connection with secret knowledge and irrational states. Wolfreys notes the link between mesmeric and sexual possession: "to be subjected to the will of another is to be invaded in a way that is equivalent to a sort of (mental) rape" (qtd. Margree 67). He also notes the analogy between the paralyzing effects of mesmerism (a popular Victorian "science" and form of entertainment) and syphilis, recognizing that the common late-Victorian term for syphilis was "general paralysis of the insane" (Wolfreys 13). ${ }^{57}$ Interestingly, the Beetle (in "human" hermaphroditic form) is described as likely having "been afflicted by some terrible disease, and it was that which had made him so supernaturally ugly" (53, emphasis mine). Syphilis certainly included visible and often grotesque physical degeneration. ${ }^{58}$ The Beetle-always recognized by Londoners as "foreign," "Arab," or "Oriental"-is also seen here as degenerate by means of a

\footnotetext{
${ }^{57}$ Syphilis was also known as GPI, syphilitic insanity, cerebral syphilis, syphilis of the brain, or dementia paralytica (Showalter, "Syphilis" 167).

${ }^{58}$ For example, see Showalter, Sexual Anarchy 194.
} 
"terrible disease," again signaling the horrifying threat of contaminating colonial sexuality. Lessingham also shows signs of syphilis when he recalls his time in Cairo as "one of mirage, of delusion, of disease" (79) and ascribes his recent hysteria to a "local lesion" (115). Diseases like syphilis attack the nervous system and brain and break down the distinction between physical and psychological illness.

Not only does syphilis cause physical and mental deterioration in its victims, but the mere anxiety of contracting the disease sometimes led to psychological pathology-a kind of "syphilitic phobia" discussed in Alfred Cooper's medical text Syphilis (1895), among others. Cooper claimed that such individuals experienced paranoia, hysteria, and symptoms of insanity at the possibility of infection, and sometimes believed they had contracted it even when they were still healthy (Smith 112-113). Showalter notes that anxieties about syphilis were so intense that "Victorian nerve specialists complained of rampant syphiliphobia among their male patients" and it was compared to female hysteria (Sexual 196). These symptoms, such as hysteria and mental instability, are seen particularly through the character of Paul—the "haunted" man responsible for bringing such havoc to London. He is described, for example, by his level-headed private investigator Champnell as having near "feminine hysterics" (294). Paul, Holt, and Marjorie all have feelings of insanity from their appalling interactions with the Priestess/Beetle (e.g., 242, 246, 294, 319), discussed in more detail below. The Beetle herself also lapses into moments of hysterical hatred and vengeance. The sexual nature of the Beetle's contaminating assaults, her paralyzing effects, and the ability to induce physical and mental degeneration on her victims allow Marsh an apt Gothic metaphor for "syphiliphobia."

Wolfreys's Introduction to The Beetle briefly notes the novel's potential representation of (domestic) syphiliphobia, despite the statistically declining rates of the disease in Britain during 
the 1890s (14). What Wolfreys neglects, however, is that the contagious carrier of disease in Marsh's novel is a bisexual "Oriental" woman from the Empire and that the 1890 s encountered a well-publicized "constitutional crisis" regarding venereal disease in Britain and its primary colony, India (Levine, "Rereading" 585). After two decades of feminist efforts (especially those of Josephine Butler), the domestic CDAs were officially repealed in 1886 and the party deemed most "responsible" for disease-carrying shifted from the lower-class female prostitute to the middle-class male (Smith 95). However, the fact that official venereal regulation continued off and on in various ways throughout the colonies well into the $20^{\text {th }}$-century ${ }^{59}$ suggests a second displacement from white prostitutes onto colonial women.

Some colonies were relaxed about regulation. ${ }^{60}$ However, other colonies believed regulation was central to healthy, military efficiency. Venereal diseases acquired in the tropics were considered "more virulent, long-lasting and damaging — at least to Europeans — than domestic versions" (Levine, "Public" 167). Levine states that throughout the 1890s, "the question of how to minimize military venereal disease" and "whether to regulate prostitution as a means to do so, remained a debate of intense sensitivity in political circles" in both Britain and its colonies ("Rereading" 586). "The venereal disease issue did indeed erupt yet again in 1897," notes Levine, "this time with far fuller British press coverage-prompted by allegations of a substantial and damaging rise in troop venereal disease rates consequent upon the total abandonment of the examination of women" ("Rereading" 601-602). The 1895 Act was thus

\footnotetext{
${ }^{59}$ See Levine, Prostitution.

${ }^{60}$ Levine notes, for example, that by 1888 "the Indian CD Act had fallen into disuse" and the cantonment rules had been suspended ("Rereading" 592).

${ }^{61}$ Abolition and reinstatement of regulation would come and go; for instance, the Cantonment Act of 1895 forbid compulsion, licensing, or legal sanction of prostitution among colonies. However, the next year, when statistical sanitary reports of the army revealed allegedly high rates of venereal disease hospital admission, a new public interest formed regarding the controversial colonial CDAs ("Rereading" 592-3, 597).
} 
repealed and examination of women allowed under certain circumstances, finally followed by additional unannounced venereal inspections of soldiers in $1898^{62}$ ("Rereading" 603).

The politics and texts of the late-Victorian period display the cognitive dissonance of who was most at "fault" concerning venereal disease. In Victorian Demons: Medicine, Masculinity, and the Gothic at the Fin-de-Siècle, Andrew Smith considers the ways in which constructions of masculinity in various literary and social-scientific contexts "are united by a shared concern that the middle-class male had become susceptible to moral decline and physical disease" (177). While examining late-Victorian discourse surrounding syphilis, Smith argues that for medical authors such as Alfred Cooper and Jonathan Hutchinson, the "pathologization of the male client posed a problem for medicine even while such a redirection became a cultural imperative" (98). Their texts, therefore, "indirectly developed this link between men and disease, and in many ways attempted to suppress this link while, paradoxically, they were constructing it" (95). Marsh's own text also represents this paradox for bourgeois British males through its ambivalence toward the central character Lessingham (as both "victim" and "villain" through its antagonist who sexually contaminates both men and women.

In "Dracula and The Beetle: Imperial and Sexual Guilt and Fear in Late Victorian Fantasy," Rhys Garnett argues that it is the "New Womanish tendencies [which] lead to Marjorie's downfall" (39). While Marsh's text can arguably represent the fear (and "necessary" taming) of the New Woman, ${ }^{64}$ critics ignore the fact that The Beetle's sole purpose during her invasion of London is to take revenge on Lessingham not merely by killing or tormenting him, but by discovering the identity of his fiancée and abducting, violating, and killing her. ${ }^{65}$ Whether

\footnotetext{
${ }^{62}$ See Levine, Prostitution and "Rereading" for an in-depth analysis of colonial VD regulation.

${ }^{63}$ For a discussion of the novel's ambivalence toward Paul, see Margree, especially pages 68-71 and 78-79.

${ }^{64}$ See, for example, Margree's "'Both in Men's Clothing."

${ }^{65}$ Even the manipulation of Holt by the Beetle is solely to aid in this scheme on Marjorie.
} 
Marjorie is independent ${ }^{66}$ or docile, the text implies that the mesmeric powers of the Beetle will inevitably prevail over her. Paul's transgressions abroad as a young man are revisited only when he is on the verge of marriage and a long lasting "contamination" received from the Empire infects his fiancée-almost fatally.

While the Beetle commits the most atrocious contaminating acts upon Marjorie in the novel, Paul can be viewed as a source of potential contamination, as well. During the Beetle's initial attack on Marjorie, she feels an "invisible horror,--which at any moment, might become visible $[\ldots]$ that this thing which was with me was with Paul. That we were linked together by the bond of a common, and a dreadful terror" and the "same awful peril which was threatening me was threatening him" (204). Marjorie's friend Sydney Atherton calls Paul "leprous" and has long believed there was "something about [him] which I found it difficult to diagnose;--in an unwholesome sense [...] non-natural" (177). He sees Lessingham as a poisonous "Upas tree or horror" and the "thought that [Marjorie's] sweet purity was likely to be engulfed in a devil's slough in which he was wallowing was not to be endured" (176). Lessingham himself recognizes his danger to Marjorie: "If the blight which has fallen on my life is likely to continue, I would not wish,--God forbid that I should wish to join her fate with mine" (182).

Public discourse recognized the tragic reality of syphilitic contamination of the "innocents" by the time of The Beetle; it was used to demonstrate the sexual double standard and illogic of CDAs (which customarily required inspection and treatment of females but not males). For example, Cooper noted in 1895 that the chief horror of syphilis is that it "communicates itself from the guilty husband to the innocent wife, and even transmits its taint to her offspring" (qtd. in Smith 114). Showalter explains: "It was well-known that the worst physical as well as

\footnotetext{
${ }^{66}$ Importantly, her independence does not indicate a sexual independence; Hurley notes that Marjorie loves "intensely" but "not sexually," her "desire sublimated" into her man's work ("Inner Chambers" 194).
} 
mental effects of syphilis were hereditary. Congenital syphilis $[\ldots]$ is even more devastating than the acquired form of the disease, because it has already begun to attack the nervous system" (Sexual 197). Between 60 and 90 percent of infected infants died within their first year and syphilitic children were likened to sickly and suffering monkeys or old men, a real-life portrait of the degeneration represented by the disease (Showalter, Sexual 197). Marsh's use of the Gothic allows for a colonial hermaphroditic and bisexual antagonist to not only entertain readers with sexual taboos, but importantly, to show the horror of "innocent" syphilitic contagion: it recognizes no boundaries between those who are and are not at fault.

This representation of colonial syphiliphobia (and syphilitic contagion) signifies the overall perceived decline of the late-Victorian British race. Levine notes that shorter periods of military service "rested on an assumption that soldiers would return to heterosexual life in Britain. Their post-soldierly duties in propagating the race meant that their freedom from constitutional disease became a deeply gendered metaphor for the health of the race and of the nation" ("Public Health" 167). Because Lessingham is an influential member of Parliament, "what is at stake" in The Beetle "is no less than British sovereignty itself" (Margree 68). Marsh's text thus indicates a "colonial syphiliphobia" that demonizes colonial women as contaminating prostitutes and warns imperial men (soldiers, sailors, tourists) of the sexually perilous Empire.

Richard Marsh's Gothic novel enables him to engage in controversial and taboo subjects of the fin de siècle while entertaining readers with thrilling, supernatural sensationalism from a secure-but not too far removed-distance. The Beetle reveals anxieties found in racial, imperial, and sexological discourses concerning primitive or indigenous peoples of the Empirecontaminating Others who would lead Britons to degeneration. Marsh's antagonist is figured as primitive in every way — racially, religiously, nationally, physically, morally, and sexually_and 
her contaminating effects on British men and women are coded as a Gothic form of syphilitic contagion. During a time of increased anxiety about colonial sexuality and venereal disease among British imperialists and politicians, the Priestess's bisexuality represents the horror of venereal disease being passed from an irresponsible middle-class male-whose sexual indiscretions abroad come back to haunt him on the verge of his wedding day - to his unsuspecting and innocent fiancée. Aptly displaying colonial syphiliphobia, The Beetle is a cautionary tale calling for a higher moral and sexual code and suggests the need for a reinstatement of stricter venereal disease regulation in the colonies to help prevent contamination among British imperialists and domestics alike. Sexual responsibility, reaffirms Marsh, was crucial for ensuring the virility and superiority of England's dominating race.

\section{Enlightenment Reason is Not All: Irrational States, Secret Knowledge, and the}

\section{Supernatural}

Syphiliphobia is but one of many different irrational states Marsh depicts throughout The Beetle. The novel consistently illustrates exchanges of competing epistemologies and objections to Enlightenment reason. The novel's structure also denies readers the explanations of an omniscient narrator, which reinforces the uncertainty engendered by such exchanges (readers do not even know if the Beetle is or can be destroyed, for example). Western rationalism and scientific advancement do not overpower the knowledge of the colonial Other in this tale. While the novel portrays a specific anxiety about the colonial woman as sexually contaminating, it also evinces a larger concern of epistemological anxiety. What is self? Other? Identity? Truth? How can we know anything for sure? The complex colonial exchanges around the Empire revealed the reality of hybridity, mimicry, "reverse mimicry," unexplainable knowledges and powers of the Other, and generally a cross-cultural osmosis that dissolved supposed divisions or binaries 
between European colonizer and native colonized. Marsh's novel captures the unsettling nature of this reality and illustrates numerous challenges to British rationality and Enlightenment reason. This is seen through the myriad irrational states of the characters (madness, paralysis, hypnosis, aphasia, and so on), secret/doxai knowledge (powers of hypnosis or mesmerism), and the supernatural (such as shapeshifting, transmigration, and religious power). The genre and structure of the novel—including lapses and gaps in narration—support the uncertainty of knowing anything absolutely.

The very beginning of Marsh's novel depicts a man in an irrational state. Robert Holt is an educated, long out-of-work clerk whose misfortunes point to British societal failure on a systemic level. A supernatural avenger does not haunt this man; he is physically exhausted from starvation and exposure. Though he is honest and capable, he cannot find work and is even turned away from his last resort for help —a casual ward. ${ }^{67}$ Holt staggers through the streets of London in a "backboneless state" like "a drunken man." In extreme hunger and pain, he is affected by "overpowering giddiness," loses his wits and then recovers as if from a "swoon" (46). Holt stumbles upon the temporary abode of the Beetle and Holt's physically deteriorated state, unfortunately, makes him even more vulnerable to the psychological manipulation and cruelty of the Beetle.

Upon entering the seemingly empty house to escape the harsh outdoor elements, Holt feels the presence of something "strange" and "evil" in the house with him. He recounts that he was seized by "panic fear" and is "spellbound" and "constrained" as if his "mental organization had been stricken by a sudden paralysis" (49). Holt desperately wants to escape but is powerless

\footnotetext{
${ }^{67}$ A short-term version of a workhouse (usually offering vagrants a single night's shelter), severely harsh conditions of casual wards were specifically designed to discourage the poor from applying for help. Altick notes, the "alternative to earning an honest living on one's own therefore had to be made so unattractive that the poor would be forced to find work outside rather than submit to the semi-starvation and indignities of the workhouse" (123).
} 
to act of his own free will. He explains, "I could not control a limb; my limbs were as if they were not mine" (50). A mysterious set of eyes watches him and the "creature" proceeds to terrorize and violate him: "I felt something on my boot, and, with a sense of shrinking, horror, nausea, rendering me momentarily more helpless, I realized that the creature was beginning to ascend my legs, to climb my body [...] it mounted me, apparently, with as much ease as if I had been horizontal instead of perpendicular" (51). The sexual nature of the attack becomes clearer; Holt recalls that the creature's legs "embraced me softly, stickily" and moving higher and higher, "gained my loins" and inflicted an "uncomfortable wobbling motion" (51). The creature touches his lips, "envelops [his] face," and embraces him with its legs (52). Holt shrieks like a "lost spirit" but is still incapable of fleeing, feeling like an "automaton" and "invertebrate" (52).

The creature transforms into a hideously ugly man and Holt notes the powerful nature of his gaze: "Never before had I realized what was meant by the power of the eye. They held me enchained, helpless, spellbound" (54). The Beetle's eyes have "powers of penetration" and control Holt's willpower (55). He feels the unmanning effects of the Beetle's mesmeric force over him as Holt's "manhood was merged in his"; the Beetle forces him to strip naked and then admires his white skin (54-5). While Holt is lying naked on the bed, the Beetle's fingers poke him in various places and are shoved into his mouth. He feels the "soul of something evil" enter him when the Beetle kisses his lips (57). The homoeroticism, rape, lack of willpower, and amalgamation of souls and selves represent the interpenetration of Briton and Other in an exchange with a colonial. Holt's manhood is merged with another's, something "evil" enters his body during a terrorizing erotic exchange, he is psychologically controlled by an outside force, and he even feels he has been possessed by a demon (71). The Beetle calls him its "slave" and "familiar spirit" (62). Indeed, Holt describes his condition as that of a "dual personality" (69), 
meaning that he had some degree of mental freedom but was not in control of his corporeal body. The Beetle seems to have a "mesmeric force" over Holt (62) with a "strong magnetic current" (84) and can paralyze him or compel him to do whatever he wants, even from a distance. Holt goes through cataleptic, entranced states on one end of the spectrum and paroxysms, "shaking palsy" (221), and seizures on the other. He experiences delirium and hysteria. Several times throughout the novel, Holt even embodies a queer state between life and death. For example, when Marjorie finds him insensible on the street, her nurse notes that he does not breathe or have a pulse but is still alive (202) and just before Holt's (apparently "final") death, he resembles a vampire's victim with an "abrasion" (303) on each side of his neck and tells Atherton the "Beetle killed me" (305). The extensive merging of Holt's identity with the powerful Beetle's also complicates the notion of Holt's death as absolute.

This integration of British and colonial selves represents the breakdown between self and Other in the colonial context. The sexualized nature of the assault is metaphorical for colonial exchange but clearly indicates specific sexual anxieties, as well. The scene involves rape, homoeroticism, and sex with a ("diseased") racial Other and the devastating effects can be understood as a contamination or contagion. Eve Sedgwick's Between Men notes a recurring theme of anxiety in Victorian culture: "a partly Gothic-derived paranoid racist thematics of male penetration and undermining by subject peoples became a prominent feature of national ideology in western Europe. Its culmination is an image of male rape" (qtd. in Harris and Vernooy 356). The assault of Holt by a vengeful colonial "man" 68 signifies a reversal in the typical story of European "rape" of vast regions of the world via imperialism. But the vengeance the Beetle seeks is not focused on an impoverished Briton who has likely never left London; she seeks

\footnotetext{
${ }^{68}$ Though Holt has doubts about the Beetle's gender, in the chapter "The Man in the Bed," he decides, "I knew it to be a man" because "it was impossible such a creature could be feminine" (53).
} 
revenge on the colonialist/tourist-turned-statesman who "murdered" a Priestess of Isis while traveling abroad twenty years before: Paul Lessingham.

At eighteen years old, Lessingham's foolish curiosity led him to that strange café in Cairo's dangerous Native quarter. He hears beautiful singing from inside and, "inspired by I know not what impulse," Lessingham recalls, he is drawn to the window of the café to peer at the young chanteuse (238). The singing has a kind of mythic force on him as the Cairene "sirens" play on. He listened, "entranced" (239), and his lethargic condition is exacerbated by the drugged liquor given to him. Lessingham eventually recognizes the late hour and tries to leave; however, the femme fatale stops him and exhibits a powerful "magnetic influence" over him, making him "powerless in her grasp" (240). He ascribes her unnatural control over him to the devil, asserting that her eyes "were a devil's" and their effect "diabolical." Lessingham loses all rational ability and control; the effect of her eyes "robbed me of my consciousness, of my power of volition, of my capacity to think, - they made me as wax in her hands." He experiences memory loss and loss of consciousness, stating that a "curtain seem[ed] to descend" followed by a period of "oblivion" (240).

The Woman of Songs, as he calls her, denies Lessingham willpower, movement, consciousness, and memory. She then puts him in an even more vulnerable and terrifying state. He awakens undressed on a makeshift bed in an unfamiliar room. He explains that the Woman of Songs, described as "unnatural" and "inhuman," seeks his affection with kisses (which now disgust him), and gives him a "sense of horror and of loathing with which the contact of her lips oppressed me" (241). When Lessingham tries to resist, she gently lays her hand on his chest with the "equivalent to a ton of iron," despite the fact that her kisses filled him with "an indescribable repulsion" (242) he desperately wants to escape. He alludes to the ensuing rape and his frozen, 
irrational state: "I was wholly incapable of offering even the faintest resistance to her caresses. I lay there like a log. She did with me as she would, and in dumb agony I endured" (243).

Lessingham cannot fully speak of the horrifying events, even to his private investigator. He does explain that during those "two unspeakable months" in the den, he witnessed "orgies of nameless horrors" (243) and atrocities of white women being raped, subjected to "every variety of outrage of which even the minds of demons can conceive," burned to death on an altar, and their ashes consumed as part of "religious services" (244). The mesmeric "cord was loosed" one day when Lessingham is alone with the Woman of Songs- - he knows not why. He comes out of his "hypnotic trance" and "mesmeric stupor" in a rage and is able to strangle the Woman of Songs (244). At the moment of death, she transforms into a monstrous beetle and Lessingham makes his hasty escape, although he is forever an altered man.

The irrational and cataleptic state of lost physical willpower Lessingham experiences then shifts to one of psychological impairment. Though he mostly recovers physically from his ordeal (aided by an American missionary living in Cairo), he admits, "for years I was but a wreck of my former self." He has amnesia, "was in a state of semi-imbecility," and "suffered from a species of aphasia" (246). He endures "visions" or hallucinations day and night, putting him in a state of "abject terror" so extreme that he places himself "under the treatment of an expert in mental pathology." His doctor is perplexed, however, as to the cause of Lessingham's problems. His experience suggests a possible physical contamination (such as syphilis) from his two months of intimate contact with the Cairenes, although his symptoms also point to a chronic phobia. In Minna Vuohelainen's article on language and xenophobia in The Beetle, she notes that late-Victorian "medical accounts define phobia as 'morbid fear' or 'a symptom of nervous disease' that occurs 'due to insanity or a diseased brain"" and that people with "pre-existing 
mental or physical weaknesses" were predisposed to such states of fear (314). While Vuohelainen ultimately argues that the phobia in question is xenophobia (as opposed to colonial syphiliphobia), she shrewdly recognizes that the "weakness" of such states is, in fact, not simply the fault of a terrifying Other: "if phobic reactions are to be read as signs of irrationality or disease, their true origin lies not with the alien presence but within the British psyche" (315). The recurring hysterical and phobic states of characters throughout the novel challenge British rationality and superiority. "While the British characters describe the foreigner as monstrous," notes Vuohelainen, "the narrative subtly undermines their authority by emphasizing the irrationality of the phobic impulse" (316).

Lessingham continually struggles with irrational and hysterical states throughout the novel, particularly with the return of the Beetle into London. He has worked for 20 years to attain the public reputation of a "man of iron nerve," though some have doubts about his calm and rational demeanor. Atherton, in particular, claims that Paul's is "one of those individualities which, confronted by certain eventualities, collapse" (108). This potential inclination is, of course, the case when the Beetle seeks revenge. When the Priestess sends Robert Holt to Lessingham's house to obtain his personal letters from Marjorie, Holt has only to repeat two words ("The Beetle!") to send Paul into a downward hysterical spiral. He speaks in "frenzied, choking accents" with a "burst of childish fury" and shows "a species of excitement which it was unpleasant to witness," crouching against a bookshelf "as if he was afraid to stand up" (77). "So far from exhibiting the impassivity for which he was renowned," Holt explains, "all the muscles in his face and all the limbs in is body seemed to be in motion at once; he was like a man afflicted with the shivering ague,--his very fingers were twitching aimlessly" (77). 
Similarly, Lessingham later glimpses sight of a drawing of a scarab in Atherton's laboratory that "transfigured him." He drops his belongings and retreats to cower against the wall, "crouching on his haunches," "gibbering, his hands held out as if to ward something off from him" (114-115). His reaction is so severe that Atherton initially thinks he is in a fit of epilepsy. The sketch causes Lessingham to back away "shrieking, trembling as with palsy," screaming, "Take it away!" in great agitation (116). He is described by Atherton as a "nerveless, terror-stricken wretch, groveling, like some craven cur, upon the floor, frightened to the verge of imbecility, by a shadow" (126). Such extreme reactions to the mere thought of the Beetle are certainly read as phobic and irrational, giving credibility to the description of Lessingham as a "haunted man" (148). Later, Atherton asks about the haunting and whether the "delusion" Paul is suffering from takes the shape of a beetle. At this mention, Lessingham collapses and is "transformed"; he "sank in a heap on the floor; he held up his hands above his head; and he gibbered,-like some frenzied animal" (180). Atherton comments that he has seen such behavior "matched in the padded rooms of lunatic asylums, but nowhere else" (180). Lessingham himself wonders whether his haunting is due to a lesion, madness, witchcraft/Obeah, or hallucinations, and refers to a book on "Obscure Diseases of the Brain" (181). His reputation as having a stolid, calm demeanor (even under pressure, such as while arguing in Parliament) contrasts sharply with his private sufferings and susceptibility to hysterics.

Lessingham's confidential agent Champnell notes this contradiction when they are pursuing the Beetle (who has absconded with Marjorie): "this Leader of Men, whose predominate characteristic in the House of Commons was immobility, was rapidly approximating to the condition of a hysterical woman" (292). This works to deconstruct the image of the cool, logical, rational British statesman. His encounter with the "Oriental" Other 
has permanently affected him, despite his earnest attempts at rational impassivity. "Given such weaknesses within British society," Vuohelainen argues, "the underlying fear in the novel is that contact with the alien may strip the English characters, already somehow lacking in quintessentially British characteristics and physical and mental stamina, of their national and cultural identity" (326). The doubt and undecidability of British superiority is emphasized during encounters with colonial Others where the Other does not necessarily need to "strip" Britons of their "superior" Britishness but rather expose the flaws already present in a flawed epistemological system of arrogance and exploitation.

Marjorie's encounter with the Beetle's presence through Robert Holt (and later, more horrifically with the Beetle herself) also leaves her "haunted" (162) and drifting away from her typically level-headed and rational demeanor. The daughter of a conservative politician, she is well-educated, -spoken, and exhibits some forms of independence (notably, this progressivism includes her refusal to cut herself off from "radical" statesman Paul Lessingham, whom she loves, at her father's request). However, when she takes the injured and exhausted Holt into her home to care for him, she encounters the supernatural and irrational powers of the Beetle. She explains that Holt appeared to suffer from a "cataleptic seizure" (164), a "trance" (203), or a "state of clairvoyance" (165). He has a "curious" and "weird" quality to his voice and is apparently under the control of another: "whoever had him under influence was forcing him to speak against his will, for the words came from his lips as if they had been wrung from him in agony" (165). Holt's lost power to control his own words reveals his state of illogical and supernatural duality while under the mesmeric influence of the Beetle-something Marjorie will soon also experience. 
Marjorie then encounters other queer powers from doxai or religious knowledges. After her interview with Holt, Marjorie was "possessed by a profound conviction that some appalling, intangible, but very real danger, was at that moment threatening Paul" (165); this could perhaps be the Beetle's influence sent through Holt to terrify her. She does indeed feel the power of the Beetle at that time, explaining "I had an altogether indescribable feeling, a feeling which amounted to knowledge, that I was in the presence of the supernatural" (165), of "something awful yet unseen" (202), and "I was conscious, completely, conscious, that some frightful peril was assailing Paul," "something altogether awful" (166). She experiences a clairvoyant "sort of second sight" or "vision" where she sees Paul in another room, cowering and shrieking, which "goaded [her] to a frenzy" of madness (204).

Atherton is shocked at Marjorie's revelations ("My dear Marjorie!-—you who pride yourself on having your imagination so strictly under control! —on suffering it to take errant flight!" 165) but she continues to relay her fantastic tale. Although she had wanted to rush to Paul's assistance, she found herself physically unable to go to him and felt terror in the room. She knelt down to pray but lost her ability to form words: "I tried to ask God to remove this burden from my brain, but my longings wouldn't shape themselves into words, and my tongue was palsied" (166). She felt "worse than ill" and "had even lost the control of [her] tongue," being "quite incapable of describing what [she] felt to nurse" (203). As with Holt, the Beetle's mesmeric influence controls her use of language. Vuohelainen argues that the major British characters are "defined by their associations with language, writing, oratory, and the command of facts" and Britishness is associated with "measured linguistic expression," "knowledge, culture, and order" (321). Vuohelainen continues: 
This failure of language is equated in the text with a challenge to Western knowledge, the loss of national and cultural identity, and, ultimately, the destruction of Western civilization itself: the English characters' linguistic regression implies a degeneration of the entire nation, resulting from internal weaknesses, defined through its command of the vernacular. (325)

The lost ability to command one's speech thus reveals an irrational, illogical state that subverts the professed superiority of British rationalism.

Marjorie's inability to pray is not merely due to her loss of speech, but also implies a battle between religious powers. The authority from the cult of Isis competes with Christianity's power rather evenly in the novel. When the Beetle is attacking Marjorie, she feels an evil presence with her but finds she cannot pray to her Christian God (and He does not spare her the Beetle's torment). After the horrifying, rape-like experience of the Beetle's assault in her bed, she seeks confidante Sydney Atherton to pray for her, as she still cannot herself pray. Though he is a scientist and not a particularly religious person (he admits he has not prayed in a long time), his Lord's Prayer releases her from the Beetle's grasp. "As the divine sentences came from my lips," he narrates, "I make no doubt, her tremors ceased. She became calmer. Until as I reached the last great petition, 'Deliver us from evil,' she loosed her arms from about my neck, and dropped upon her knees [...] And she joined me in the closing words" (167).

The fact that a Christian prayer (said over the body of someone afflicted by the influence of the Beetle) can temporarily free that person implies a battle between gods or otherworldly beings. This supernatural struggle is also supported by the fact that the power of Isis can inhibit the "haunted" person from saying such a prayer to save herself. While $19^{\text {th }}$-century scientific developments had created a more secular Victorian world with increasing skepticism toward 
Christianity, encountering other world religions and their own authorities abroad also contributed to this sense of doubt. The competition between gods in the novel mirrors what some colonists and tourists experienced across the Empire. And, as with the case of Richard Burton, some people converted away from the traditional Western religion of Christianity to other faiths. Additionally, the religions themselves influence one another as cross-cultural encounters so often do; Wolfreys's editorial notes in The Beetle explain that "the worship of the Virgin Mary in early Christianity develops and is influenced by worship of Isis" (106), for example. This struggle between religious deities and practices is part of Bhabha's notion of undecidability, where the encounter with the knowledges of the Other actually destabilize the colonizer's own supposed superior knowledges. Western religion holds some power in this novel, but not enough to prevent or stop the damage of the Egyptian Beetle of Isis. This is evidenced by the religious cult's numerous ritualistic atrocities committed against Christians in the Temple of Isis. ${ }^{69}$

The battle between Christianity and the cult of Isis is one component of a larger scale battle between epistemologies. As seen with other fin de siècle Gothic tales such as Dracula, the modern science and technology of England confront ancient and foreign power in The Beetle. Sydney Atherton's confrontations with the Priestess of Isis reveal the clearest contrast of knowledges - and their interconnections. On their first meeting in his laboratory (which, notably, Marjorie calls a "wizard's cave" 154), Atherton recognizes the "mesmeric quality" of the Priestess's eyes, "oftener found, thank goodness, in the east than in the west" although the "sensitive something which is found in the hypnotic subject happens, in me, to be wholly absent" (105-6). He asks his visitor (whom he assumes is a man), "Pray, sir, are you a magician?" to which the Beetle responds, "You, Mr. Atherton,--are you also a magician?" (104). They both

\footnotetext{
${ }^{69}$ Indeed, the young women who were sacrificially burned alive were "preferably white Christians" (Marsh 297).
} 
have powers that are magical to the other, as Atherton later exploits, although they also share certain traits. For example, Marjorie comments on Atherton's "most extraordinary eyes" and that he "possesses the hypnotic power to an unusual degree" (194). Notably, however, Atherton does not even attempt hypnosis on the Beetle and does not mention such an ability in his narrative.

When Atherton is demonstrating his "Magic Vapour" (poison gas, on a cat he supposes is Lessingham's) to his friend Percy Woodville, a vial accidentally breaks on the floor and Woodville is near death. The Beetle arrives at Atherton's just in time and reveals some magic of his own: "Putting his lips to Percy's, he seemed to be pumping life from his own body into the unconscious man's," reviving him to an extent. "Passing his hand to and fro in front of the unconscious countenance," Atherton narrates, "as if by magic all semblance of discomfort vanished from Percy's features, and, to all appearances, he was placidly asleep" (139). The Beetle seeks Atherton's help to "try experiments together" on Lessingham as he is his greatest rival in the quest for Marjorie's affections. Though Atherton claims immunity from hypnotic influence, he admits that "it was only by an effort of will that I was able to resist a baleful something which seemed to be passing from his eyes to mine" and the Beetle's mesmeric power "might approach almost to the supernatural" (141). As the conversation continues, Atherton becomes enraged and tries to attack the Beetle; however, "quite involuntarily, I pulled up dead,- - as if my progress had been stayed by bars of iron and walls of steel" (144). He was "incapable of advancing another inch" and "could only stare and gape" as the "scoundrel had almost succeeded in hypnotizing" him (144).

Atherton then displays his "magical" skills with electricity, a frequent motif of the Gothic genre since Frankenstein (1818). Rather than melding science to supernatural reanimation, however, Atherton's use of electricity is closer to the rather common comedic trope of a 
Westerner capitalizing on the superstitions of a native unfamiliar with modern science.

Luckhurst's work on late-Victorian "trance-Gothic" fiction notes the connection between these two "magics" and argues that what is "surreptitiously acknowledged is the proximity of mesmeric and electrical forces, both of which were discussed in 'occult' frameworks well into the late nineteenth century" ("Trance-Gothic" 161, emphasis in original). Atherton's "electrical machine" emits an eighteen-inch spark at which the Beetle "shook with terror. He salaamed down to the ground. 'My lord! - my lord!upper hand for a time and tells the Beetle: "You may suppose yourself to be something of a magician, but it happens, unfortunately for you, that I can do a bit in that line myself,- - perhaps I'm a trifle better at the game than you are" (145). Atherton performs another modern marvel by dropping phosphorous-bromide onto the floor from which flames and a "blinding vapour" arise. In the Beetle's terror she disappears, then quickly reappears, entreating Atherton to "use [her] as his slave" (145). Her disappearance startles Atherton: "Was it something new in scientific marvels? Could [she] give me as much instruction in the qualities of unknown forces as I could him?" (146). Atherton's epistemological openness prompts him to ponder the potential exchanging of secret knowledges with this mysterious figure from an ancient Egyptian cult.

The Beetle eventually shapeshifts into her scarab form, giving Atherton even more pause, though he maintains his "presence of mind" like an "investigator" (150). He attempts to trap the large insect under a tin but she quickly metamorphoses back into human form, with a surprise for Atherton: "My visitor was not a man, but a woman, and, judging from the brief glimpse which I had of her body, by no means old or ill-shaped either" (152). At this shocking transformation (between species as well as sexes), even the cool and rational Atherton was "witless," "breathless," and "could only gape" (152). 
While Atherton at first seemed confident that he is "a trifle better at the game" than his Near East Priestess counterpart-as colonizers are confident in their own cultural and epistemological superiority - the doxai knowledges of the Beetle challenge that self-assurance. Had he "retained the normal attitude of a scientific observer," Atherton believes he might have pinned the giant beetle on a monstrous piece of cork. However, he admits that this was "a game at which civilisation was once more proved to be a failure" (154). Although he is a modern man of science and has developed cutting-edge inventions (such as advancing the "flying machine" and telegraphs to ships at sea), Atherton also understands that Western rationalism cannot explain all. He elaborates:

My attitude towards what is called the supernatural is an open one. That all things are possible I unhesitatingly believe,-I have, even in my short time, seen so many so-called impossibilities proved possible. That we know everything, I doubt... [that] our forebears of thousands of years ago, of the extinct civilisations, knew more on some subjects than we do, I think is, at least, probable. (176)

He believes there are secret or doxai knowledges long forgotten or undiscovered in modern (especially Western) civilizations. More than any other character in the novel, Atherton recognizes the potential validity of competing epistemologies and even gives credit to the skills of the East. While chasing the Beetle through London, he tells the confidential agent that in "matters of prestidigitation, Champnell, we Westerns are among the rudiments,-we've everything to learn,--Orientals leave us at the post. If their civilisation's what we're pleased to call extinct, their conjuring — when you get to know it! —is all alive oh!" (263).

The East - particularly Egypt_-does seem to contain most of the magical or supernatural powers exhibited in the novel. Overall, the forces of the Beetle remain supreme throughout, and 
Western rationality and science cannot disarm them. The Beetle displays a supernatural knowledge of Lessingham's house and private letters; she has the ability to shapeshift at will and can disappear and reappear; she has apparently been transmigrated or reincarnated after Lessingham strangles her in Cairo; she revives Percy Woodville and calms him after the poison gas accident. The Beetle's strongest power, however, seems to be her ability to mesmerize others. Mesmerism involves the ability to control (even remotely) the words and actions of another person. It is an apt choice of supernatural power for a cross-cultural encounter of colonial origins; it can be viewed as analogous to both sex and the hybridity and undecidability produced through colonial exchange. Wolfreys states that mesmerism allows a foreign predator the ability to control and harm a person not only physically, but "also through the psychic erasure of the boundaries which one imposes on oneself as the necessary limits of selfdefinition" (13); "the borders of any identity or location are always permeable and always available for haunting in the most uncanny ways imaginable" (15). The notions of "identity," "self," and "other" are thus deconstructed through mesmerism, as are "colonizer" and "colonized." For British or Westerners to come under the influence of the colonial or foreign Other "produces an imaginative reversal of colonial relations between master and servant, as there is produced in such a narrative the association of the "vulnerability of the mesmeric subject with colonial subservience,"” notes Wolfreys, paraphrasing Alison Winter (qtd. Wolfreys 15). This "vulnerability" reflects the doubt that the cultural and epistemological superiority assumed by modern Western rationalism supersedes all others.

The ending of the novel also displays this uncertainty regarding modern science and technology. While the band of men seeking to rescue Marjorie is able to follow her and her abductor via modern transportation and technology — particularly by train and through telegraph 
messages - only a random train collision halts the Beetle and appears to destroy her. Some "heavy loaded trucks broke loose" from a train in front of them and "came running down the hill on top of us," explains the train official (317). In the compartment where Marjorie is found-still alive - were "huge blotches, - stains of some sort" which were damp and gave a "most unpleasant smell" (318). Experts disagreed on what the mysterious fluid was: some believed it to be "parboiled" human blood; some thought it blood of a cat species; others called it mere paint, and another declared it "a deposit of some sort of viscid matter, probably the excretion of some variety of lizard" (318-319). The Beetle seems to be defeated and gone, but the possibility of her Gothic return remains-and Western knowledge cannot prevent it.

The uncertainties regarding Western epistemology and rationalism are reinforced not only through the ambiguity of the ending, but also in the structure and genre of the novel itself. The novel initially presents as a mystery but does not gradually explain all events to a conclusive ending like a traditional mystery. It is a Gothic novel, though not in the mode of a classic author such as Ann Radcliffe whose flirtations with the supernatural are eventually explained away. Marsh's novel aligns more closely with other late-Victorian Gothic texts that finally ask the reader to accept some degree of fantasy or irrationalism. Texts such as Strange Case of Dr. Jekyll and Mr. Hyde (1886) and Dracula (1897) require a certain acceptance of what lies outside the limits of Western science but are presented in a scientific and even legal manner. This approach often involves "testimonies" of various characters (which are first-person limited accounts), inclusion of letters, legal documents, journals, telegraphs, etc. and, notably, excludes a thirdperson omniscient narrator. The Beetle follows this procedure, although the ending is more ambiguous than Jekyll and Hyde, Dracula, or a range of other late-Victorian texts. Unlike Dr. Moreau or Ayesha or Dorian Gray or Dr. Jekyll, for example, the Priestess of Isis is given very 
little time to relate her point of view (or explain other plot ambiguities - is this Priestess the same one Lessingham strangled twenty years before? Is she a reincarnation or fellow cult member? Does she die in the train wreck? Is the mysterious explosion in the desert related to the cult of Isis? Could brilliant scientist Atherton himself have played a role in it? Could this cult of longevity and immense power be eradicated so easily?). In an emerging Modernist vein, Marsh seems purposefully to remind the reader that —as in real life - there are often no actual, logical answers for the mysteries and irrational forces at work in this world. We may assume our modern, Western epistemologies are supreme, but the novel reveals that they are consistently challenged (and sometimes defeated) in an expansive world of many competing cultures, deities, and knowledges.

Victorians initially believed they could exploit and experience the world largely without harm and that their modern, Western epistemologies would guide them safely through a backward, ignorant, and superstitious world. They thought their superior knowledges would successfully combat the queer or irrational beliefs of natives abroad. The colonial exchange, however, destabilizes this certainty and reveals undecidability. Reality showed Victorians that colonial peoples did not simply accept and understand the "English book" (symbolizing English national authority and Enlightenment reason) and then properly and effectively enact its epistemological values and mores. "Enlightening" native peoples proved more difficult than anticipated: their interpretations and often powerful subversions of Western transcendental truths undermined the supposed universality of European epistemology. Additionally, colonial regions were found to hold their own mysterious truths, powers, and doxai knowledges, and were not easily understood, debunked, or defeated by Western reason (or the Western God of Christianity, for that matter). "Natural" divisions became complicated: concepts such as self/Other, 
clean/unclean, dominant/submissive, science/magic or superstition, healthy/unhealthy, rational/irrational, exploiter/exploited, and superior/inferior are among many that were clouded by the colonial enterprise. And, as the Gothic genre consistently works to reveal, boundaries are not stable or permanent but rather porous and changing. In The Beetle, this indeterminacy is displayed in one way by terrifying literal sex - a sort of interpenetrating dissolving of boundaries between self and Other. Sexually transmitted disease and contamination illustrate another level of boundary deconstruction as elements of one person spread beyond her body to a separate body, sometimes in a permanent way (as in the case of syphilis, which was incurable at the time). The difficult truth of this reality caused high anxiety among Britons, as seen through the continued discussion of CDAs amongst the empire long after its abandonment in Britain itself. Venereal diseases contracted abroad continued their effects at home once soldiers, sailors, tourists, and colonists returned to the mother country. In this way-though here, negatively-it symbolizes how aspects of colonial cultures influenced British culture abroad and at home. The challenge to Western truths and concepts resides not merely in sexual contamination or related fears (colonial syphiliphobia), but is, in fact, much wider in scope. In Marsh's novel, the multiple forms of irrationality that undermine the archetypal calm, cool, logical Englishman reflect this anxiety and the possibility of truly knowing anything is denied through the text's lapses and ambiguities in plot, narrations, and conclusion. 


\section{Chapter 4}

"A New and Strange World": Dangerous Hybridity in Stoker's The Jewel of Seven Stars What is assuredly Bram Stoker's most pessimistic novel, The Jewel of Seven Stars (1903) merges late-Victorian apprehensions about knowledge and empire with thematic and structural uncertainty. Produced shortly after Queen Victoria's death, this text serves as a transitional piece between the late $19^{\text {th }}$-century's anxiety-ridden tales that tended to re-establish a semblance of order and boundaries, and those of the early $20^{\text {th }}$-century that were often more ambiguous and cynical. Carol Senf calls the novel Stoker's "most Gothic" (Bram Stoker 110) in its bleakness and Kate Hebblethwaite's editorial introduction describes the story as "almost sphinx-like in its enigmatic nature" (xi). A central component of the novel's ambiguity stems from its two disparate endings (both of which are vague). When a Victorian Egyptologist attempts a "Great Experiment" to reanimate an ancient Egyptian mummy queen, he and all but one of his entourage are killed under mysterious and horrifying circumstances and as the novel ends abruptly, the success of the reanimation is unclear. This original 1903 ending generally received critical acclaim ${ }^{70}$ despite its uncharacteristic bleakness and lack of denouement; Meilee Bridges attributes its success to the tale's unusual place in the genre of mummy fiction as most "Egyptian revenge fantasies re-establish safety, order, and reason by shooing their ill-behaved mummies back into their coffins and crypts" (140). Nine years later in 1912, shortly after Stoker's death, a new edition emerged with a rather dramatically different ending in which the experiment apparently fails, nobody is killed, and the story results in a comedic ending of marriage. Even though critics agree that Stoker's endorsement of this new ending remains unclear ${ }^{71}$, British publishers followed the revised text for 80 years (Hebblethwaite xi). The doubled structure and

\footnotetext{
${ }^{70}$ See Senf, Bram Stoker 100-101, Hebblethwaite xi, Meilee Bridges 140.

${ }^{71}$ See Bridges 141.
} 
ambiguity of the novel complicates our ability to make meaning of the plot but the uncertainty, hybridity, and the deconstructive nature of the text/s suggest something in itself.

Stoker's novel reveals anxieties not only about the power and knowledge of the foreign/ancient Other, but also regarding the colonizer's attempts to appropriate or hybridize such knowledges into Western culture. This theme is manifested through the work's focus on archeology — specifically Egyptology—and its interconnectedness to the exploitations of imperialism. Abel Trelawney, the wealthy amateur Egyptologist around whom the plot centers, attempts to combine his knowledge and research about ancient Egypt with modern science and technology to resurrect Queen Tera (a fictional mummy inspired by Hatshepsut, discovered by Howard Carter in 1902). Trelawney has himself robbed tombs in colonized Egypt, stolen artefacts, and employed others to procure archeological objects for him through unethical or criminal methods. His house in Britain is like a museum (and mausoleum), filled with curios and mummies from abroad. The results of the Experiment expose Stoker's pessimism: in the original edition, the endeavor appears to work but with devastating consequences (death for the experimenters and a foreboding sense of destructive, vengeful energy released upon Britain via Tera's reanimation and disappearance). The destructive climax has also been partially engendered via the mimicry of Tera through Trelawney's daughter Margaret as she encouraged her cohorts to carry on in the Experiment. The revised edition offers a possible reading of seeking the Other's secret knowledge as innocuous (if the Experiment fails entirely) but it can also be interpreted as portraying a "reverse colonization" of Margaret's soul; this possession or hybridization of Margaret by Tera appears harmless, though it may prove insidious in the future, given what is known about the history and personality of Tera. 
Arising out of and interrelated with colonialism, archeology is an area of both interest and excitement in Stoker's novel, but also connects to the larger imperial venture through its ethical questionability. The novel gives detailed descriptions of Europeans traveling through Egypt in search of Tera's sarcophagus and other artefacts, repeated tomb-robbing and its deadly repercussions (to Arabs more frequently than Europeans, interestingly), guilt over such intrusions into the repose of the dead, and the tale exhibits mummy unwrapping as a rather shameful, sexualized violation. Trelawney's initial sojourn to Tera's tomb occurs shortly after Ahmed Arabi's nationalist uprising and Britain's subsequent military action and occupation. This plot detail further emphasizes the relationship between the dangerous and exploitative practices of colonizers and those of many early/amateur archeologists.

As noted in the Introduction chapter, the emerging field of archeology was not a purely scientific area of study but rather exhibited a kind of queered or hybridized epistemology. Paradoxically, science-based "legitimate" discourse within the discipline tended to encourage and spread doxai knowledge, particularly surrounding artefacts and the rumors related to them (Luckhurst, "Mummy's Curse" 123). Some archeologists were interested in the potential "supernatural" potency of ancient and Eastern religions, as well as esoteric knowledge that could be acquired through research and powerful objects. This is seen particularly in relation to ancient Egypt which was regarded as the center of lost wisdom and mysterious authority. Drawing from figures such as British entertainer and magician Charles Bertram, Catherine Wynne recognizes that in "the world of Victorian magic, Egypt has a particular resonance" (67). Trelawney's version of Egyptology reveals such a hybridization of modern scientific methods as well as belief in "magic" rituals and the power of Egyptian gods. His attempts to adapt or appropriate aspects of ancient Egyptian religion, philosophy, and "Old Magic" for his own purposes and rituals 
appear to be arrogant and deadly, however. Pursuing esoteric wisdom from ancient Egypt often extended beyond archeology into theurgy and occult practice. In this way, Stoker seems to caution readers not only about respect and moderation within archeological inquiry ${ }^{72}$, but also about societies such as the Hermetic Order of the Golden Dawn. Stoker's wife and many friends were known members (Hebblethwaite xxxiii) and Stoker himself was allegedly part of the society, although this claim is disputed (Hughes, Beyond Dracula 52). Alex Owen explains that although the society's "founding documents were probably spurious, and its major rituals undoubtedly the work of Victorian scholars and magicians, its teachings were based on an imaginative reworking of Hermetic writings further informed by nineteenth-century scholarship in Egyptology and anthropology" (qtd. in Hebblethwaite xxxiii).

The Golden Dawn society thus claimed authenticity but was in fact hybridized in a manner akin to Homi Bhabha's understanding of mimicry and hybridity in "Signs Taken for Wonders." When the Christian Bible is brought by colonizers to India, it is hybridized. The stories are "changed to suit an Indian audience, thus questioning the authenticity and purity of the 'original' text," explains postcolonial critic Justin Edwards (141). While Bhabha's focus here is on the adaptation of Western knowledge to colonized cultures as opposed to the appropriation of indigenous knowledge for Western purposes, both conceptions of hybridity work to challenge the dominance of the colonial authority. Hybridity disrupts the supposed "single voice of cultural authority and foregrounds a double-voicing process that includes the trace of the other" (Edwards 141). Perhaps recognizing the subversive power of such hybridization and the undecidability it creates, Stoker's pessimism and tragic ending reveal his apprehension about such threats to Western dominance.

\footnotetext{
${ }^{72}$ See Bridges's "Tales from the Crypt: Bram Stoker and the Curse of the Egyptian Mummy" for a detailed examination of Stoker's commentary on archeology through The Jewel of Seven Stars.
} 
While The Jewel of Seven Stars portrays a hybridity of British and Egyptian cultures and epistemologies, another kind of hybridity takes place between the characters of Margaret and Tera. A sort of doubling is evident: for example, Margaret is born just when Trelawney enters Tara's tomb, the two look exactly alike, and as the experiment comes closer to fruition, Margaret becomes a kind of medium or spokesperson for Tera. There are moments when it seems Tera has actually taken full control of Margaret in a "reverse colonization" of her mind and body. Even when the experimenters accept that the "spirit" of Tera resides in Margaret, they are generally happy and unconcerned. While Margaret convinces them of the harmlessness of the experiment and Tera's innocent intentions upon reanimation (she seeks "love," supposedly), this assertion proves to be both false and reckless in the original edition of the novel. This hybridity, then, is portrayed as a menacing mimicry to the colonizers and clearly subverts their authority and control. In the second ending, a complete amalgamation of the two characters is supported by the evidence. With "Margaret" happily and submissively married to narrator Malcolm Ross a few months after the supposedly failed experiment, readers are left wondering whether the more brutal nature of the powerful Queen Tera will emerge in the near future.

In The Jewel of Seven Stars, form reinforces content. Stoker's theme of hybridity and doubling is bolstered through the structure and multiple endings of the novel. There is a hybridization of genres as the novel exhibits elements of Gothic, romance, travel narrative, and detective novel. The multiple endings reveal the themes of undecidability, queering, hybridity, and ambiguity that Stoker is addressing in regards to knowledge. His uncertainty suggests that we cannot master the knowledge of the ancient Other, our scientific knowledge does not trump "Old Magic," we cannot absolutely "know" anything for sure (including our assertion of cultural and epistemological superiority necessary for the justification of imperialism), and our Western 
authority is ultimately undermined. The various forms of hybridity - in relation to culture, knowledge, people, form, and genre-utilized by Stoker in this imperial Gothic tale illustrate that hybridization is subversive to Western dominance and is thus given a negative connotation, particularly in Stoker's original edition of the novel.

\section{Hybrid Epistemologies: Archeology, Old and New Knowledge, and The Great Experiment}

As discussed previously, the late $19^{\text {th }}$-century saw widespread challenges to conventional forms of Western epistemology. In the realm of religion, many steered away from traditional Christianity toward ancient and Eastern theologies, sometimes incorporating aspects of alternative philosophies into their "Christian" theology (Haggard believed in reincarnation while remaining Anglican, for example). Others such as the Society for Psychical Research attempted to scientize occult and supernatural phenomena, using scientific methods and modern technologies in an attempt to rationally explain the "supernormal." Theosophists and societies such as the Golden Dawn adapted aspects of non-Western philosophies and rituals to gain esoteric knowledge and spiritual development (and learn how to use magic and curses for their own purposes). New hybrid epistemologies emerged as a result of such appropriation. David Glover explains that when Victorian "occultists took up ideas and practices drawn from Rosicrucianism, Buddhism, or the Egyptian mystery religions, they tended to systematize them into highly disciplined programs of rituals and initiations which departed from their original sources in subtle ways" (84). This cooptation was a sort of Orientalism by which Westerners constructed their own version of non-Western cultures and knowledges for their own purposes. Even as this was arguably unethical, such hybridization did work to destabilize colonial authority and engender deeper discomfort about the morality and practicality of the imperial project. In emerging fields such as archeology, particularly Egyptology, the lines between science, 
pseudoscience, and occult remained blurred, although their emphases and priorities differed from theosophist groups. Glover points out that for organizations such as the Golden Dawn, "Egyptian magic was always a far more consistent and a far less fatalistic form of knowledge than it was in the disputes among contemporary Egyptologists" (84). Stoker's Egyptologist Trelawney, however, exhibits an interesting nexus of scientist/archeologist/occultist in his commitment to science, knowledge about and collection of ancient Egyptian beliefs and artefacts, and a "less fatalistic" view of magic: he believes that he can control it. This confidence is likely bolstered by his belief that he has accurately interpreted the wishes and design of a forcible and learned ancient Egyptian queen's plan to reanimate herself.

Stoker's characterization of Trelawney is also influenced by what is known as "popular Egyptology." Often found in travel narratives, non-academic journals, and popular fiction, this more sensationalist brand of Egyptology focuses on "the spectacle of death rather than the drudgery of life, its focal points being the tomb and mummy rather than the potsherd," explains Hughes (Beyond Dracula 38). A wealthy collector, Trelawney is an amateur Egyptologist, generally meaning he has not received formal education in the area. Most archeologists of the $19^{\text {th }}$-century were indeed amateurs, although a gradual shift occurred in which collectors became more scientific and emphasized knowledge rather than mere acquisition (Senf, Science 77-78). Though not to the extent of Haggard, Stoker himself can be considered an amateur Egyptologist. Born Anglo-Irish in Dublin in 1847, Stoker often associated with Sir William Wilde (Oscar Wilde's father), an amateur Egyptologist who had participated in expeditions to Egypt and even procured a mummy to bring back to Dublin. Stoker acquired a substantial library of texts about Egypt including works by Flinders Petrie and Wallis Budge (Hebblethwaite xix). Trelawney's knowledge about Egypt reveals that Stoker did considerable research for his novel (Roth 66). 
Despite his accuracy and use of contemporary, authoritative sources on Egypt, however, Trelawney displays negative traits often associated with amateur Egyptologists (especially wealthy collectors).

Ethical concerns regarding the disrespectful treatment of the dead as well as the unscrupulous methods of artefact acquisition arose especially in the latter $19^{\text {th }}$-century. While public protest on the issue was uncommon, Bridges acknowledges that literature (especially mummy curse stories) frequently criticized the seedier aspects of tomb-robbing and the desecration of mummies (152). Such stories were a "metaphoric critique of archaeological practices" and cautioned that knowledge seekers should "demonstrate reverence for the past and its material remains" (Bridges 138). Mummified corpses were very frequently stolen from their tombs, put on display, dismembered, consumed through food, drink, and medicines, used to make products such as paint and paper, and subjected to public, often sensationalized unwrappings. The forceful (and unwanted) penetration of tombs and subsequent unwrappings (a kind of striptease that exposes a naked body) have been fairly considered forms of metaphorical rape. One critic's 1844 letter notes the "sacrilegious" and sexualized aspect of mummy unwrappings as he laments "the 'Friday evening' debauchery of a virtual striptease, complete with 'wild yells' that defy proper decorum" (Bridges 153). It is clear that some Victorians were aware of the intrusive and disturbing nature of mummy commodification.

The Jewel of Seven Stars critiques these negative aspects of popular Egyptology in addition to the theft of mummies and artefacts for personal profit. The 1650 travel narrative that inspired Trelawney's obsession with Queen Tera was written by (fictional) Dutchman Nicholas van Huyn (the narrator, Ross, also reads this story and thus the reader gets the firsthand account). When the "great traveller" stumbles upon the "Valley of the Sorcerer," his Egyptian fellaheen 
traveling companions refuse to stop even briefly to explore. Van Huyn instead finds an Arab sheik and Bedouins who are willing to accompany him, not being "superstitious" like the (native) Egyptians (Stoker 112). Van Huyn steals a ruby jewel and his companions ransack Queen Tera's tomb, looking for items of value or interest. They "groped with their hands in the jars lest treasure should have been there concealed" and ultimately one rips Tera's sevenfingered hand from her body (which is shockingly then stained with blood) to keep as an "Amulet" or charm (Stoker 115-116). The Arabs are punished by what appear to be Tera's supernatural abilities. They meet strange, deadly fates in the next few days including falling from a cliff, being killed by a "lion of the desert" (Stoker 116), suffering strangulation by a sevenfingered hand, and being stabbed in the back by one's own knife.

When Trelawney and Corbeck raid the tomb more than 200 years later in 1884 (retrieving Tera's sarcophagus and other objects), their Bedouin traveling companions also meet untimely deaths. Some who tried to steal artefacts during the night are found dead in the morning. Tera's sarcophagus is discovered empty after a violent sand storm (the power of Tera or her Egyptian gods?) and Trelawney and Corbeck decide to return to the tomb in their search. There they find the bodies of several of the Arabs each with blackened faces, stained from blood having burst from their orifices, and seven-fingered handprints on their throats. Interestingly, neither van Huyn nor the Britons are immediately harmed, even though van Huyn has stolen Tera's sacred seven-pointed jewel and the others had stolen her body-twice. At first glance, it seems that Stoker is condemning the Arabs' widespread theft and desecration of Egyptian tombs; however, his contemporary Western Egyptologists meet similarly horrifying ends and are thus criticized, as well. 
Trelawney and his assistant Eugene Corbeck not only raid tombs, taking their stolen treasures back to England for private collection (as opposed even to a museum), but they also engage in mummy unwrappings and unethical procurement of objects. Trelawney, a wealthy collector without formal education in areas related to archeology, is undisturbed by his actions; however, Corbeck, a highly-educated ${ }^{73}$ Egyptologist, displays some moments of guilt and uncertainty. Corbeck admits to Ross that many of Trelawney's artefacts "he has procured through me, either by my exploration or by purchase—or—or—otherwise" (Stoker 81). This disclosure indicates theft or possibly extortion. Corbeck's unease is implied again later when he mentions the "treasures which we had—ah!- taken from the tomb" (Stoker 137). Trelawney matter-of-factly acknowledges his imperialistic passion for acquisition: "I went into the tomb from curiosity; and I took away what I did, being fired with the zeal of acquisitiveness which animates the collector (Stoker 211). Corbeck wonders aloud about the "superstitious feeling" he and Trelawney have about Tera: "Will it be any wonder if it go down to the grave with us at the appointed time? If, indeed, there be any graves for us who have robbed the grave!" (Stoker 135).

Their unwrapping of Queen Tera's mummy is particularly disconcerting because her body has been perfectly preserved (she appears alive) and she and Trelawney's daughter are nearly identical in appearance (the only difference seems to be that Margaret has normal hands/feet). Thus, under bright light, in front of several other men, Trelawney slowly strips naked what appears to be his own sleeping daughter. Margaret strongly objects to this unwrapping: "'Just think, Father, a woman! All alone! In such a way! In such a place! Oh! it's cruel, cruel!' Her cheeks were flaming red, and her eyes were full of indignant tears" (Stoker

\footnotetext{
${ }^{73}$ Corbeck is a "Master of Arts and Doctor of Laws and Master of Surgery of Cambridge; Doctor of Letters of Oxford; Doctor of Science and Doctor of Languages of London University; Doctor of Philosophy of Berlin; Doctor of Oriental Languages of Paris" and holds other degrees, as well (Stoker 80).
} 
230). She sees the act as a "horrible indignity to a Queen, and a woman" (232). Her father, undeterred, claims that she is "Not a woman, dear; a mummy!" (230) and that the unwrapping is for scientific and educational purposes conducted by "grave men" (231). Hughes notes that Tera's "status as artefact" trumps "respect accorded to her as woman" and the presence of a medical doctor (Dr. Winchester) reminds us that living women were also "exposed to similar indignities within the permitted spaces of medicine and science" (Beyond Dracula 40) ${ }^{74}$ Of the four men present, only Ross (who is courting Margaret) appears to feel embarrassment or reservation about the unwrapping; he refuses to assist in the process but is not above watching it happen. He feels "low-spirited, and miserable, and ashamed" about unwrapping the mummy but admits that as Tera is unwrapped, "I grew more and more excited" (Stoker 233). Upon seeing the queen "completely nude before us", however, he "felt a rush of shame sweep over [him]" and thought it "indecent" and "almost sacrilegious" (Stoker 235). ${ }^{75}$ Senf argues that in Trelawney's search for knowledge, it is likely that "he is more interested in control than in understanding"; for example, the unwrapping of Tera "is more voyeuristic than scientific" (Science 80). Given that Trelawney, Corbeck, and Winchester die in terror at the end of the novel, Stoker suggests that concerns about the propriety and respect of such unwrappings are legitimate. The story reveals the complex relationship between power, control, sex, and knowledge—one that is reflected in the larger project of empire.

While a pure, "unhybridized" discipline of archeology—one without theft, sexualization, trivialization, sensationalization, and other ethical lapses-is not fully possible, the practices of

\footnotetext{
${ }^{74}$ Notably, this is especially visible in the forced inspection of "suspected prostitutes" under the Contagious Diseases Acts (Senf, Science 80).

${ }^{75}$ Wynne contends that it is revenge for the "imperial voyeurs" that leads to the men's deaths; Ross is supposedly saved because he is outside the room during the Great Experiment and thus does not see Tera's naked body revivify (72-73). However, given that Margaret dresses Tera in her "Bridal" robe after the unwrapping and before the Experiment (Stoker 237), this is a less convincing interpretation; perhaps it is Ross's refusal to participate that aids him.
} 
Trelawney (as well as the Arabs) would still have been regarded by many of Stoker's early $20^{\text {th }}$ century readers as exploitative, even immoral. Collectors (such as Trelawney, Corbeck, and even van Huyn) were clearly acquiring artefacts for personal gain and assemblage, not for the ostensible larger benefit of knowledge/education that might conceivably be offered by a museum contribution. Artefacts were typically stolen and the fact that high numbers were taken over the years reasserts the superfluous nature of mummy-raiding. (How much knowledge could truly be gained after the unwrapping of a hundred mummies? Two hundred?) Senf notes this criticism in her discussion of Trelawney's "amateur" Egyptologist status. The unwrapping of Tera is unnecessary and "unscientific," she argues, and the current research during Stoker's time "indicates that they would have learned very little from the endeavor because unwrapping mummies was commonplace by the time Jewel was published" (Science 81). Hebblethwaite notes that in addition to museum procurements, mummies were especially popular for unwrapping ceremonies for the wealthy during the 1830s and 1840s; tea was sometimes made from the cerements for the viewers' consumption afterwards.

The 1890s, however, saw a professionalization of archeology, at least for those most serious about the discipline as scientific and educational, and the zeal for unwrappings decreased significantly (Hebblethwaite xvii). Senf references John Worthham's ${ }^{76}$ history of British Egyptology to further note that archeologists of the time would have already been utilizing new technology such as X-rays to study mummies without destroying them and notably, Trelawney mentions X-rays but does not make the connection (Science 81). Even if we argue that Tera does indeed offer new insight on mummy preservation as her body so clearly lacks decomposition, this incites new objections: if Tera is uncorrupted by death and is expected to reanimate back

\footnotetext{
${ }^{76}$ See John David Worthham's The Genesis of British Egyptology 1549-1906, Norman: University of Oklahoma Press, 1971.
} 
into living form through Trelawney's experiment, is not her unwrapping even more invasive? Trelawney knows of Tera's previous experimentation with suspended animation when she lies for a month, swathed and entombed, thousands of years ago before emerging unharmed (Stoker 129), which makes his decision to unroll her all the more unseemly. The "hybridization" of Egyptology as archeology and freak show/striptease thus illustrates the adverse connotations of such an amalgamation.

The negative repercussions of desecrating or pillaging Egyptian tombs and artefacts are also reflected in the Britons' attempted appropriation of Egyptian secret knowledge. Trelawney believes his work may allow him to "learn things that have been hidden from the eyes and the knowledge of men for centuries" benefitting "science, and history, and philosophy" (Stoker 163). He believes a new, hybrid epistemology will emerge, inspired by "a learning greater than our own" from ancient Egypt: "many new phases of old wisdom will appear in the light of fresh discovery, and afford bases for new reasoning" (Stoker 186). He views ancient knowledge not as inferior but merely different (Ballam 158). "Ancient, foreign and spiritual," asserts Hebblethwaite, "no more means antiquated, ignorant and irrational than modern, Western and scientific means advanced, correct and educated" (xxxii). However, even when Trelawney believes he has accurately interpreted Queen Tera's wish and plan to reanimate herself, the tragic ending of the book reveals anxiety about the search for and attempt to adapt or appropriate the secret knowledge of the foreign or ancient Other. Notably, Stoker's recurring theme of occult power vs. modern science and technology is especially pessimistic in this novel. ${ }^{77}$ While Stoker

\footnotetext{
${ }^{77}$ Such reservations are not unique to Jewel among Stoker's oeuvre; for example, even though the vampire hunters succeed in saving Mina and defeating Count Dracula in part by their utilization of modern Western knowledge, science has nonetheless been viewed as a "source of helplessness and confusion in the face of supernatural forces" (Byron, "Bram Stoker's" 49). They also make use of Catholic ritual and holy paraphernalia to defeat the vampires. Byron attributes this ambivalence to "science's unstable relationship with transgression" (49).
} 
was generally "optimistic" about science (Holterhoff 138), because most of the characters die in the experiment, it appears that modern science is not enough to combat the powers of ancient knowledge_-particularly from Egypt (or perhaps if modern science does have such a capacity, even apparent experts remain ignorant of it). Senf argues that Stoker's works usually end happily and thus celebrate the "power of the modern scientific and technological age" but Jewel does not; furthermore, "Tera's ghost haunts even the revised, supposedly happy ending" (Bram Stoker 110). Thus, even if we read Trelawney's work as noble and well-intentioned, it proves to be dangerous.

Trelawney believes he understands much of ancient Egyptian beliefs. He interprets the hekau or "word of power" (much like a curse holds power through language) engraved on Tera's Jewel that could command the "Lords of the Upper and Lower Worlds" (Stoker 172). He delineates the various aspects of human beings as the ancient Egyptians understood them (paraphrasing from Budge's work) such as the Ka (“double," or personality), the Ba (soul), Kho (spirit), and Khat (physical body). He describes the notion of the astral body; while utilized later in Buddhism, he claims that it originated in Egypt: "the gifted individual can at will, quick as thought itself, transfer his body whithersoever he chooses, by the dissolution and reincarnation of particles" (174). He links the idea of the Ka with the theosophist concept of the astral body, something addressed extensively by Helena Blavatsky and groups such as the Golden Dawn. Astral projection is Trelawney's explanation for much of Tera's movements, interference, and violence, including the injuries done to him while he is unconscious and to the seven-fingered strangulation marks on various murdered Arabs.

Trelawney's belief in Egyptian mythology and the power of their ancient gods is a clear challenge to traditional Judeo-Christian theology. In the novel, "pagan beliefs claim a validity 
customarily reserved for the Christian and the scientific" (Hughes, Beyond Dracula 37). To emphasize the religious investigation and juxtaposition of old, Eastern gods and the "newer" Western one ${ }^{78}$ Stoker incorporates aspects such as the symbolic number seven, themes from the Biblical book of Revelation, and the idea of resurrection. Trelawney explains that believing in the "old Magic" of Egyptian mythology is not so different from the supernatural elements presented in the Bible (165). He asserts that "the Bible is not a myth" and references the sun standing still from a human's command (Joshua), the speaking of a donkey (Balaam), and the Witch of Endor's ability to summon the spirit of Samuel (165). Trelawney's belief in (at least parts of) the Christian Bible as well as the supernatural power of Egyptian gods reflects a blended religious view similar to ones held by many throughout the Victorian period. As with other forms of hybridity, however, it worked to challenge the authority of the traditional practice of the West's dominant religion, Christianity, and is therefore somewhat threatening.

Stoker's novel makes much of the number seven. It is considered to be Tera's special symbol: she is born in the seventh month with seven fingers on one hand and seven toes on one foot; the aerolite (meteorite) that hits earth at her birth contains the titular ruby Jewel: "the light of it shone from seven stars, each of seven points, as clearly as though the stars were in reality there imprisoned" (Stoker 114); the "magic coffer" made from the aerolite is seven-sided; Tera's ("Familiar") pet cat has seven toes, as does Margaret's cat Silvio; there are seven stars in Tera's favorite constellation known in Britain as the Plough (and in the US, the Big Dipper); her sarcophagus is seven-sided; her reanimation apparatus includes seven lamps to be lit in the shape

\footnotetext{
${ }^{78}$ While the existence of the Judeo-Christian God is interpreted by believers to be the oldest (Creator of the earth/universe), the deity of Jesus emerges thousands of years later to initiate the contemporary Christian worldview espoused in many Western cultures. The Bible insists on a 6,000 year old earth; however, anthropological (and geological, etc) research both in the $19^{\text {th }}$-century and today suggests that the world is much older than this and provides evidence of religious cultures older than Judeo-Christianity.
} 
of the Plough; and even Trelawney chooses a seven-lettered combination for the safe in which he keeps the Jewel of Seven Stars. As Hebblethwaite notes, the number seven is significant in a variety of religions: the seven-branched candelabrum of Judaism ${ }^{79}$, the Seven Spirits of God in Christianity's Revelation, Islam's belief in seven heavens and seven earths, the seven sages of Hindu mythology, and Buddha's walking seven steps at his birth (xxxi). Stoker apparently draws quite a bit from Revelation for his novel. John the Apostle describes a vision sent to him by the Holy Spirit which he records and disperses to seven churches. In his vision, he sees "seven standing lamps of gold" and Jesus himself, who held seven stars in his right hand. Jesus asserts that "I am the living one; for I was dead and now I am alive" and that "the seven stars are the angels of the seven churches, and the seven lamps are the seven churches" (New English Bible, Rev. 1.13-20). Revelation thus contains not only the theme of seven, but also of resurrection. David Seed adds that in Revelation, a "book is held closed by seven seals which, as each is opened, release monstrous creatures" (195). A beast with seven heads also appears in chapter 13 of Revelation, supposedly representing a global political system near the end of days. However, rather than alluding to the apocalypse, Seed believes that Stoker is "drawing on The Revelation more subtly to disperse the relevant symbolism beyond the limits of Egyptology into the modern world of London" (195). Yet given the horrifying ending —and the potential release of a vengeful Egyptian monster into Britain - the apocalyptic theme of Revelation still resonates, at least with Stoker's original version of the book.

Other aspects of Revelation influence the novel. In the Book of Life, the names of those who are saved are recorded; not being named, then, essentially leads to the damnation and eventual destruction of one's body and soul. The corrupt priests of Tera's day, affronted mostly

\footnotetext{
${ }^{79}$ The seventh day of rest (the Sabbath) outlined in the Ten Commandments is also important to Judaism and some denominations of Christianity.
} 
by her refusal to conform to gender roles and threatened by her knowledge and potential power, worked to remove her name and any record of her from their culture. To deny her potential resurrection, they also associated the memory or history of her with terrifying consequences and put a kind of "curse" on the rocks of her tomb: "Hither the Gods come not at any summons. The 'Nameless One' has insulted them and is for ever alone. Go not nigh, lest their vengeance wither you away!" (Stoker 124). Suppressing her name was a cruel revenge, explains Trelawney, as "without a name no one can after death be introduced to the Gods, or have prayers said for him" (130). When van Huyn reaches the Valley of the Sorcerer, the Egyptian fellaheen "could not give the name [of the Sorcerer], persisting to the last that there was no name; and that anyone who should name it would waste away in life so that at death nothing of him would remain to be raised again in the Other World" (111). Hebblethwaite notes that the Christian concept of a Day of Judgment mirrors the principle of ancient Egypt in which a "divine trial" is held to decide whether to grant people entrance into the kingdom of Osiris (xxxi). Osiris himself was resurrected (in part by the efforts of his sister/wife Isis) in Egyptian lore after being murdered by his brother, and the Christian God's son was also resurrected, linking together these two theologies in the novel. Further, both cultures believe in a resurrection for believers after judgment. Rather than a mere metaphoric allusion for literary effect, however, the novel subverts the authority of Jesus's resurrection by its (ostensibly Christian) British characters' overt belief in, attempt at, and at least partial success in the resurrection of Queen Tera via her Egyptian power and knowledge.

Hughes's discussion of "Theology, Morality, and Popular Fiction" in the works of Stoker emphasizes the religious implications of The Jewel of Seven Stars. The tenets of Christianity-as well as the authority of empirical science-would not be affected by the failure of the Great 
Experiment; however, its success would challenge the supremacy of Christian doctrine as the proposal of Tera's resurrection is an "action striking at the unique nature of Christ's redemptive sacrifice" (Beyond Dracula 43). The flawless state of Tera's body is remarkable, unlike any Egyptian mummy or the decomposed bodies of most other deceased humans ("believer" or not). She is thus likened - uncomfortably — to the uncorrupted state of Jesus's body several days after death when he is resurrected. While Hughes does not mention this, Tera also is potentially likened to Lazarus (brother of Martha and Mary — who had anointed Jesus's feet with oil and dried it with her hair), who was after four days resurrected by Jesus. By the power of the JudeoChristian God, Lazarus was in a perfectly-preserved condition. The book of John notes that the "dead man came out, his hands and feet swathed in linen bands, his face wrapped in a cloth" (John 11.44), thus reminiscent of the mummy wrappings of Queen Tera. In this allusion, Trelawney would be uncomfortably aligned with Christ himself as the resurrector.

Tera has murdered a number of people and has surely committed other "sins" for which she should be judged. "If permitted to rise from the dead," notes Hughes, "Tera will be neither Saved in the Christian sense, innocent, nor judged at her resurrection" and if she "escapes judgment... the whole notion of Christ's Kingdom is, effectively, proved false" (Beyond Dracula 43). Such concerns are not merely subtle in Stoker's novel, but addressed overtly by Ross in chapter 16, "Powers-Old and New." He believes that the experiment is "foolish" (Stoker 184) and recognizes that it relies in part on the supernatural powers of ancient Egypt and its gods. "If there were truth at all in the belief of Ancient Egypt then their Gods had real existence, real power, real force," Ross states. He continues, "If then the Old Gods held their forces, wherein was the supremacy of the new? Of course, if the Old Gods had lost their power, or if they never had any, the Experiment could not succeed" (185). If there was "room in the Universe for 
opposing Gods", non-Christian forces would "tend to the weakening of His own teaching and designs" (185). Ross "dared not follow" (185) the subject as he recognizes the potential discrediting of his fundamental religious beliefs. Crucially, this chapter of the novel was the only one removed in the later 1912 edition. Hughes argues that the removal of Ross's "ontological speculation deflects attention away from the suggestion of competing gods and back onto the human participants"; the new version (with an ostensibly "failed" experiment and lack of resurrection) therefore focuses on individual transgression rather than a broader questioning of religious theology itself (Beyond Dracula 46). The original version of the novel was likely too subversive to hegemonic Christian doctrine to survive a new edition.

In addition to blending supernatural or religious knowledges, Stoker's novel also posits the idea that much of Egyptian "magic" might be interpreted in scientific terms, which then challenges the epistemological demarcations between what is "science" and "occult" in the same way that hypnotists and groups like the SPR sought to scientize the supernatural (with varying degrees of success). A conundrum emerges early in the novel and is the basis for gathering the various characters together: Trelawney's four-day-long mysterious trance state from which he cannot be awakened (and during which repeated, unexplained violent attacks are directed against him). Several doctors and brain specialists assemble at his bedside but remain stunned. At first, Doctor Winchester thinks that amongst the vast Egyptian curios in the room is "some substance or liquid which may have the effect we see" or that Trelawney has taken a drug (21). Later, he still cannot find a medical explanation for Trelawney's state. He explains that his patient's "unconsciousness does not resemble any of the many cases of hypnotic sleep which I saw in the Charcot Hospital in Paris" (30). This reference to Parisian doctor Jean-Martin Charcot (1825- 
1893) reflects Stoker's knowledge of contemporary medical establishments and discourse in the emerging field of neurology. ${ }^{80}$

When those watching over Trelawney begin falling into trance-like states themselves, they think it may be due to some influence associated with the strong mummy smell. Ross contemplates this possibility and notes that even after thousands of years, odors remain and "their secrets are unknown to us" (36). He feels the effects of the odor: "The Egyptian smell had seemed to get on my nerves—on my memory—on my very will" (36). The impact on his "will" and "memory" imply a power greater than a typical chemical compound. Interestingly, however, Ross buys a respirator and although it does not entirely keep him from feeling the Egyptian influence in Trelawney's room, it does work to a certain degree (Stoker 37). This confounding information is recognized by Dr. Winchester who struggles to make sense of the "two lines" of "Fact" and Fancy" which continually pull "in opposite directions" (69-70). "That respirator of yours," he tells Ross, "is the only thing that seems to have a bearing on the 'fact' side of the affair" (71). He also notes that Margaret is, inexplicably, the only person who remains unaffected by the trance-inducing influence.

Stoker incorporates a variety of characters who espouse differing views to highlight his theme of epistemological uncertainty. Notably, those who are more "scientifically" or "empirically" minded remain unenlightened at the end of the novel, but alive and unharmed. Brain specialist Sir James Frere does not "take much account of mysteries- except those of science" (57) and thus stipulates that Trelawney must be removed from the bedroom (filled with archeological artefacts and mummies) if he is to assist in his medical case. He argues that the

\footnotetext{
${ }^{80}$ Charcot established the period's best neurological clinic in Europe at Salpêtrière Hospital in Paris in 1882. Sigmund Freud studied under Charcot in 1885 and it was Charcot's utilization of hypnosis to "discover an organic basis for hysteria that stimulated Freud's interest in the psychological origins of neurosis" ("Jean-Martin Charcot").
} 
"assemblage of horrors" exhale a "mephitic" (or poisonous) odor and despite Trelawney's wishes not to be moved, he would require it to remain on the case. He claims that a "good daughter" would focus on her father's "health and sanity" rather than his whims or "penny dreadful" mysteries: "The day has hardly come yet, I am glad to say, when the British Museum and St Thomas's Hospital have exchanged their normal functions" (58). Winchester appreciates his rationale but recognizes that Frere "does not understand that there is something odd about this special case" (58). Winchester's open-mindedness keeps him on the case and he later tells Ross, "I have exhausted all human and natural possibilities of the case, and am beginning to fall back on superhuman and supernatural possibilities" (102). He is open to the power of Egyptian knowledge and tells Corbeck that Trelawney's "disease" or "condition" must be "in some way connected with Egypt" and to aid him, needs information concerning "Egyptian matters, language, writing, history, secrets, medicines, poisons, occult powers" (106). Winchester's curiosity and dedication will eventually lead him to the fatal room of the Great Experiment, however.

Sergeant Daw, the detective on the case, holds an epistemology like Dr. Frere's. His reliance on logic and natural law create frustration in Trelawney's case and begin to shake his beliefs. "You see," he explains, "I am not one who believes in magic and such things. I am for facts all the time; and I always find in the long-run that there is a reason and a cause for everything" (101). After increasingly inexplicable events, Trelawney awakens from his trance and Daw can abandon the case, thankful: "I verily believe I was beginning to get dotty over it all. There were too many mysteries, that aren't in my line, for me to be really satisfied as to either facts or the causes of them. Now, I'll be able to... get back to clean, wholesome, criminal work" (156). Still confounded but needing to move on, Daw asserts that he must "keep a check on 
[him]self" or else he will ponder the mysterious case when he should not be distracted (157).

Bowing out of the mystery without answers, Daw nonetheless is spared the horrors of the Great Experiment.

Ross, an educated barrister, does not understand the mysteries of the case either but stays on, largely due to his budding romance with Margaret. When initially confronted with the proposal of the Great Experiment, he contemplates what its success might mean as far as subversion of Christian beliefs in the "Powers-Old and New" chapter. He quickly claims, however, that the "subject was too vast," "full of strange surmises," and he "dared not follow it!" (185). Later, his inability to understand the implications of the Great Experiment supposedly absolves him of any objection or moral outrage in his complicity: "The question of the moral aspect of the case, which involved the religious belief in which I had been reared, was not one to trouble me; for the issues, and the causes that lay behind them, were not within my power even to comprehend" (204). Ignorance is bliss, but only temporarily. Like his precursor van Huyn, Corbeck is also open-minded about the power of the Other, particularly after his experience with Queen Tera's mummy during his expedition with Trelawney. However, he has had more time than Ross to digest the implications not only of gods potentially more powerful than the Christian one, but also the consequences of the unethical practices of archeology, as discussed above. Corbeck admits that the clearly supernatural events surrounding his excavation in Tera's tomb (the mysterious movement of the mummy, the unexplained seven-fingered strangulation marks on the Arabs, etc) challenged his beliefs. "Such strange things have happened regarding this mummy and all around it," he tells Ross, "that there is a necessity for new belief somewhere. It is absolutely impossible to reconcile certain things which have happened with the ordinary currents of life or knowledge" (131). Corbeck does not shy away from his obsession in 
Egyptology, however. Ross admires Corbeck and thinks "this man has learned the lesson of the Eastern bazaars; and with the Western intellect has improved upon his masters!" (87).

The character that is most flexible in his approach to differing epistemologies is Abel Trelawney. After he mysteriously awakens from his trance, he recommends to his entourage, "We must keep our eyes fixed on the scientific side, and wait for the developments on the psychical side" (181). Corbeck claims that Trelawney possesses a "rare knowledge" (81) and has great respect for him. Trelawney advises against any kind of epistemological dogma: "we must not go too fast, or believe too much in our present state of knowledge" (181). He attempts to explain his ideas about Egyptian magic and lost science to the group. Trelawney states: the Egyptians studied the properties of herbs and minerals for magic purposeswhite magic as well as black. We know that some of the wizards of old could induce from sleep dreams of any given kind. That this purpose was mainly effected by hypnotism, which was another art or science of Old Nile, I have little doubt. But still, they must have had a mastery of drugs that is far beyond anything we know. (Stoker 168)

His explanation implies that the hypnotic trance influence could be from either magic or a drug unfamiliar to the modern British. This kind of ambiguity or conflation of forms of knowledge is not uncommon for him. Trelawney believes that ancient Egyptians "knew sciences, of which today, despite all our advantages, we are profoundly ignorant" in areas such as Astronomy, acoustics, and the forces of light (Stoker 167). He explains that Astronomy originated in Egypt and "was developed to an extraordinary height; and that Astrology followed Astronomy in its progress. And it is possible that in the later developments of science with regard to light rays, we may yet find that Astrology is on a scientific basis" (167). J.D. Ballam argues that if Astrology is 
a "refinement" of Astronomy, Trelawney proposes that "the hard science of material properties exists as a means to enable the scientist to realize the unquantifiable forces inhering within those properties"; however, the secrets are only awarded to those who can both investigate with "analytical rigour, but also with an unsceptical desire to place their faith in the existence of things beyond those for which ordinary science can offer a rationale" (158). Such enlightenment may not be worth the effort, however, as Trelawney and his group discover.

Another speculation Trelawney makes is that the newly discovered metal radium ${ }^{81}$ may have been abundant in ancient Egypt and therefore known to its people. Having been pulverized from slabs of granite during the building of monuments, pyramids, and other structures, the radium particles may have settled on the ground. He suggests that the Egyptian choice of a "scarab as the symbol of life may not have been without an empiric basis" (189). "Might it not be possible," he asks, "that Coprophagi have power or instinct to seize upon the minute particles of heat-giving, light-giving — perhaps life-giving—radium, and enclose[e] them with their ova in those globes of matter which they roll so assiduously...?" (189). He hypothesizes in other areas, as well, such as when he considers how Tera's mummified corpse is maintained in perfect condition; he wonders whether paraffin, wax, or stearine were pumped into her veins (237). He thus attempts to consider the science behind the rituals and folklore of ancient Egyptian culture.

Tera herself embodies hybrid knowledges in her supernatural abilities and extensive learning. Born the only child of an $11^{\text {th }}$ dynasty King, Tera's father ensured she had comprehensive education and the support of the army behind her (especially because female monarchs were extremely rare and thus her authority was threatened by a potential shift in governance toward a priesthood "hierarchy"). She was taught statecraft, the "lore" of the priests

\footnotetext{
${ }^{81}$ Discovered in 1898 by Marie and Pierre Curie.
} 
themselves, scribing, art and hieroglyphs, and magic. This education gave her "power over Sleep and Will. This was real magic_-“black' magic; not the magic of the temples" which was harmless, white magic (128). An "apt pupil," she had "gone further than her teachers" and "won secrets of nature in strange ways" (128-9). She was "skilled in all the science of her time," including Astronomy, properties of light rays, acoustics, elements of physics, and so on (167, 170). Importantly, she also knew "Master Words" that had the power to "compel all the Gods, both of the Upper and the Under Worlds" (129). Tera's plan for her reanimation utilized supernatural knowledge; it required one of her hands to be left unwrapped and holding her talisman, the Jewel of Seven Stars. Trelawney explains that when her hand was exposed to the air, her "Ka could move," meaning that "her body could become astral at command, and so move, particle by particle, and become whole again when and where required" (130). It is through this astral projection that she is able to move on her own to return to her tomb when her sarcophagus was stolen, take revenge on various Bedouins who had desecrated her remains and artefacts, attack Trelawney in an attempt to take the key to his safe to retrieve her jewel, steal the magic lamps from Corbeck, and so on. Tera's wish for a "resurrection of the flesh" especially enraged the priesthood and gave them justification to erase the existence (past, present, and future) of "the one who had outraged their theories and blasphemed their gods" (169). Tera's hybrid knowledge was hence threatening and subversive to the dominant leaders of her culture. While it meant both empowerment and alienation for Tera, her unique set of knowledge did apparently offer a successful plan for the reanimation of her corpse after more than 4,000 years.

Trelawney calls Tera's reanimation the "Great Experiment," giving it a sense of the scientific and the empirical; however, it depends not only upon science and potentially lost "science" of ancient Egypt, but on Egyptian supernatural powers, as well. As in other novels by 
Stoker, this epistemological "hybridity" allowed him to explore the grey areas between new discoveries and accepted science of his day, and the occult or what was deemed by many to be pseudoscientific. Glennis Byron recognizes that Jewel portrays a more "radical challenge" to the lines between science and magic than Stoker's most famous novel, Dracula. Jewel presents an epistemological blending rather than science/technology and the occult in opposition to each other: "far from the old 'magic' being set against new 'science', the ancient sciences collaborate with the modern, powers old and new work together with the mutual goal of Tera's resurrection" (Byron, "Bram Stoker's" 56). Indeed, the Experiment is set in a cavern under Trelawney's old family estate in Cornwall, an area of England with its own ancient history. The cave is fully equipped with electricity "worked by a set of turbines moved by the flowing and ebbing tide, after the manner of the turbines at Niagara" (221) and contains a "pulley and a mass of strong tackle with multiplying blocks of the Smeaton order"82 (200). The cavern, decked out with ancient Egyptian relics, thus represents "both the old world and the new" (201). Even as Trelawney focuses on the science (and his own hypotheses of "lost science") of the Great Experiment, he also accepts that there may be inexplicable magical components to its success. He wishes to recover the lost sciences of Tera's day —-those of which she was knowledgeable (Stoker 167); however, he often slips into his recognition that the "lost" science of ancient Egypt may be, in fact, supernatural after all. His descriptions of the potential "mechanism" of the Great Experiment exhibit this tension.

Corbeck recounts Trelawney's initial epiphany (which was inspired by a dream and hence implies Tera's supernatural abilities in relation to dreams and sleep) about how the "Magic Coffer"-an essential component of Tera's resurrection—might be opened through an

\footnotetext{
${ }^{82}$ John Smeaton was an $18^{\text {th }}$-century civil engineer (Hebblethwaite 272).
} 
understanding of scientific properties. Trelawney had noted that the "translucent spaces" (139) of the coffer aligned with the constellation of the Plough and recalled that the Jewel and the coffer both came from an aerolite and thus may relate to the stars in some way. Tera's understanding of Astronomy is evident here; during her time, the "Pole star" was not the northern star of today. Trelawney states that "neither the stars in the Jewel nor the translucent places in the Coffer corresponded to the position of the stars in the Constellation as they then were!" (180). Whether Tera's reanimation required the modern alignment of the stars (not just the alignment of the lamps in the shape of the current Plough) remains unclear. Trelawney arranges the coffer under the starlight to coincide with the seven stars of the Plough and sees the box glow. He then tries electrical light in the same pattern but the coffer does not open, still merely emitting a glow. Considering that Tera's tomb would not have access to direct starlight, he then realizes that special lamps and oil would be needed to catalyze the mechanism. (This is rather implausible as starlight and burning lamps hold different properties and produce variant effects). He considers the relatively unknown area of the principles of light; he mentions the newly discovered qualities of Röntgen, Becquerel, and Cathode rays and suggest that "we may finally prove that there are different kinds and qualities of light, so we may find that combustion may have its own powers of differentiation; that there are qualities in some flames non-existent in others" (181).

When Trelawney places Tera's sarcophagus with her head to the West and feet to the East, "thus receiving the natural earth currents," he presumes that this arrangement corresponds with the force of "magnetism, electricity, or both" or perhaps from another source such as radium (218). The inclusion of radium in the Great Experiment - and its lethal effects to those in the room-give Stoker's original ending a particularly apocalyptic feel. While not entirely understood at the time, the radioactivity of the coffer effectively creates a "kind of magical 
nuclear device," argues Luckhurst (Mummy's Curse 174). Just emerging in scientific papers in 1902 and 1903, the work of nuclear physicist Ernest Rutherford and radiochemist Frederick Soddy was known to Stoker (Hebblethwaite xxix). They proposed the concept of the radioactive transmutation of elements (which, importantly, became known as the idea of radioactive halflife). Hebblethwaite makes an interesting connection between Tera's rebirth and radioactivity: rather than from one element to another, Tera is transmuted into a "new woman" through her possession of Margaret's body and soul $(\mathrm{xxx}){ }^{83}$

Among Trelawney's scientific musings, however, is his recognition of potentially supernatural powers at play. When he notes the Coffer's composition from an aerolite, he supposes that it may contain "some element unknown in our world" and in it "may be contained some mighty power which is to be released on its opening" (218, emphasis added). Even as he claims that the "box hides some great mystery of science," he admits that the light's effect may release "some greater power" (168). Similarly, while Trelawney believes that the successful reanimation of Queen Tera will allow history to "be set right" and the "teachings of science made veritable from their beginnings," it will also help restore the "knowledge of lost arts, lost learning, lost sciences" (212). He speculates that if "this resurrection can be accomplished, how can we doubt the old knowledge, the old magic, the old belief!" (213). Such a conflation of epistemologies is noted by Senf who states that Trelawney's "confusion of science, pseudoscience, and magic is evident in the fact that he sometimes characterizes the knowledge that he hopes to acquire as scientific knowledge, sometimes as magic" (Science 80). Stoker's (original) ambiguous ending to the novel reinforces the uncertainty about science, the occult, and

\footnotetext{
${ }^{83}$ Hebblethwaite notes early $19^{\text {th }}$-century radiochemists Rutherford and Soddy's theory of radioactivity as a "transmutation of elements" via nuclear reaction (xxx).
} 
the blurry boundaries between the two. It also indicates that these epistemologies are inevitably at odds and questions whether they can productively converge.

\section{Failed Reverse Mimicry, Reverse Colonization, Hybridity, and Menacing Mimicry}

Trelawney's attempts to carry out Tera's planned reanimation himself can be read as "reverse mimicry." This mimicry suggests that the Other's mysterious knowledge is far greater than our Western ones (whether Christian or scientific) and to attempt mastery is folly. Trelawney's study of Egyptian culture and history, as well as science and other areas, leads him to believe he can interpret the Egyptian artwork and hieroglyphs to create favorable conditions for Tera's resurrection; he thinks he can mimic her by doing what she had planned to do herself. While the postcolonial concept of mimicry is often considered to be a deliberate subversion of Western/colonial authority by the colonized, Trelawney — a kind of imperialist himself through his archeological pursuits and privileged British background-attempts mimicry without seeking to dismantle the authority of the colonizers. In fact, he is interested in appropriating secret knowledge of the colonized to bolster his imperialist nation's authority (the fact that his expedition to Tera's tomb occurs shortly after Britain's military action and colonization of Egypt as a protectorate is not incidental). Nonetheless, his mimicry also works to create undecidability in Western epistemology, particularly as his failure reveals an arrogant, exploitative, and rather selfish approach: his learned, Anglo-Saxon status does not afford him better mastery or application of knowledge.

Additionally, because Trelawney adapts the Great Experiment into a contemporary, Northern setting using modern technology, he problematizes the idea of a blended epistemological approach. Even if the Experiment succeeds, what will be its cost? Trelawney's foolishness arises less from his attempt at the Experiment itself than because he misjudges (or 
ignores) Tera's nature. Even though the evidence suggests that Tera detests others tampering with her body and prized possessions, Trelawney and Corbeck steal Tera's mummy and paraphernalia - more than once — and bring it all to England. Rather than gather the required materials (which have been stolen and disseminated around the world) in Tera's tomb for her reanimation in her own chosen time, they import them into Britain and choose a time and place of resurrection for her. They have personally seen the deadly, supernatural power held by Tera with the mysterious deaths of their Arab associates while on archeological expedition; likewise, they have read about her vengeful spirit from historical documents (including van Huyn's records). Yet, the men still believe that they can not only successfully carry out the Experiment, but also that the grateful Tera will charitably share her knowledge with them and wish them no harm. Given her experience with (and reaction to) patriarchy, this is a stretch. Stoker's decision to have the Experiment carried out in Britain (not in her tomb, which would make much more sense) thus highlights the theme of "reverse colonization" and the fear of injurious intrusion by the colonized and their mysterious objects, animals, occult powers, etc., into the motherland. ${ }^{84}$ Importantly, such "invasions" are brought on by the imperialists themselves.

The concepts of reverse colonization, mimicry, and hybridity are also present in the consistent doubling or duality of the characters of Margaret and Tera. Their uncanny connections are established from Margaret's birth: she is born just as Trelawney is raiding Tera's tomb (and mysteriously spends three days in a trance there). Margaret's mother dies giving birth. Trelawney, distraught from the news, associates the tragedy with his endeavors in Egyptology, particularly the "mysteries connected with the Queen," reports Corbeck. Trelawney's anxiety about his daughter's "existence seemed to wring his father's heart"; he finally admits to Corbeck

\footnotetext{
${ }^{84}$ This theme, emphasizing anxieties about the backlash of imperialism, is commonplace amongst late-Victorian Gothic tales for numerous writers such as Stoker, Doyle, Marsh, and Haggard.
} 
that Margaret is "unlike her mother; but in both feature and colour she is a marvellous resemblance to the pictures of Queen Tera" (Stoker 136). This "strange likeness" between the two is confirmed by others, including Ross (207). Ross's early descriptions of her (before he knows anything of Trelawney's interest in Queen Tera) note that she "seemed to rule all around her with a sort of high-bred dominance" and notes that she is "pale as snow," subtly likening her to the dead Queen Tera (11). He comments later on her queenly likeness (163) and her pride as that of "a veritable queen of Old Time" (160). Other characters also mention Margaret's royal (and here, beneficent) demeanor; housekeeper Mrs. Grant states that "the mistress is a Princess!" and Ross agrees, noting her "queenly figure" (64). He also describes her (with hints of Orientalization) as being fine-figured, with black hair "fine as silk," and "dark, straight-featured" with black eyes of "a mysterious depth" (28). He recalls a "great oriental traveller" who described "the effect of her eyes "as looking at night at the great distant lamps of a mosque through the open door"' (28). Margaret is typically dressed in Egyptian jewelry, including a lapis lazuli ornament in her hair and an antique bracelet celebrating Horus, son of Isis and Osiris $(64,258)$. The narrative also emphasizes Margaret's hand, that reflects the significance of Tera's hand (which has seven fingers, was left unwrapped in her sarcophagus, and was ripped from her body by an Arab wishing to procure it for a charm). Ross asserts that Margaret's "rare and beautiful hand" (11) "seemed to move from the wrist as though it had a sentience of its own" (29). When Margaret shows her wrist to Ross later in the novel, she reveals her birthmark: "a thin red jagged line, from which seemed to hang red stains like drops of blood" (160). Even Margaret's name includes an inversion of Tera, a constant reminder of their connection.

As the narrative progresses and Trelawney experiences further violent attacks during his "trance," Margaret becomes increasingly suspected as a potential perpetrator (particularly in this 
"locked room"-style plot which essentially excludes interference from persons outside the home). After one of the attacks on Trelawney, Ross finds Margaret kneeling beside her unconscious father, "her white nightdress stained with the blood in which she knelt" (40). Even after "the traces of blood" were washed from her hands, she trembles with a "ghastly white" face (41). What seems particularly inexplicable is that just as the knife was about the strike Trelawney's wrist (in an attempt to sever it and obtain the safe key attached to a steel bangle), "the blow had been arrested, for only the point of the knife and not the edge of the blade had struck the flesh" (40). This hesitation suggests that the attacker had a last-minute change of heart, or perhaps, Tera's influence over Margaret suddenly waned at just the right moment (the detective on the case believes her to be involved, reaffirming the strange connections between Tera's influence and Margaret). Margaret explains that she awoke suddenly with a "horrible feeling" that her father was in "great and immediate danger" and found him on the floor by the safe with new injuries. Shuddering, she reflects, "I must have gone mad for a moment" (42).

Indeed, Margaret begins to exhibit strange behavior as she is "hybridized," or at least begins to alternate between herself and the influence of Queen Tera. When Margaret and Ross are watching over her father, she appears to be in a partial trance as she "worked her hands in front of her, as though she was fending off something" invisible (52). She starts to break down and edges closer to a "state of collapse from nervousness" (56). She confesses that suddenly and increasingly, she has "hardly command of [her]self" (60) and Ross notices that she would sink into a "distraite" mood and then "would recover herself with a start" (195). She might enter a "new phase" such as when she fell into a "positive fury of passion" with eyes blazing and a mouth of "hard, cruel tension"; after Ross catches her eye, however, a "strange spasm came upon her" and she returned to her old self (201). Margaret thus enters a kind of dual or doubled state 
and continues to push Ross away. Phyllis Roth argues that as the Experiment nears, Margaret's spirit becomes less Ross's and more the queen's (68). Ross notes that Margaret's manner toward him becomes increasingly strange, with a "half shy half haughty" attitude (195). Sometimes this bizarre behavior causes even her adoring cat to cower away from her. "I never knew whether the personality present was my Margaret—-the old Margaret whom I had loved at the first glance—or the other new Margaret," he confesses (204). Sometimes it sounds as though she were "speaking parrot-like" and he laments the "mysterious veiling of her own personality" (213) as it creates an increasing barrier between them.

The creeping influence of Tera on Margaret also becomes evident in Margaret's new and uncanny knowledge. She makes bold claims such as her certainty that the stolen lamps would not be melted down and sold (Stoker 86) and that they would turn up, even as she admits she does not know where this confidence comes from (89). She explains to Ross that until her father's illness, she cared little for Egyptian artefacts but now "they grow and grow on me to quite an absorbing degree." She is surprised she has never felt such a curiosity before (90). When the lost lamps suddenly appear in a drawer at her home, her reaction upon seeing them confirms a special affection for Egyptian antiquities: Ross "could see by the heaving of Margaret's bosom that she was strangely excited" (96). Along with her increased interest in artefacts is a new extensive knowledge about them, an "unconscious" store of information that "many a scholar might have envied" (91). Her immunity from the effects of the "mummy smell" also align her more closely with ancient Egypt, its objects, and Queen Tera herself.

Another important aspect of the doubling between Tera and Margaret is their cats. Tera's pet cat (her Familiar) is mummified and buried in her sarcophagus. This cat had seven-toed paws just as Margaret's pet cat Silvio is seven-digited. When Trelawney suffers from scratches during 
his trance, Silvio is suspected. His seven-clawed scratch marks correspond with the wounds on Trelawney's arms (32). However, Margaret insists that Silvio is innocent. When the supernatural possibilities of the case are opened up and Trelawney is awake, he explains that the "Familiar of the Wizard Queen" is the mummied cat which could therefore act under the direction of Tera to scratch at his wrist in an attempt to steal his key (166). This delegation of power is confirmed later when they unwrap the mummy cat and see his mouth and claws covered in stains of recent blood (229). Margaret is especially distraught when Trelawney decides to incinerate the mummy cat just before the Great Experiment. Her sadness supposedly comes from place of empathy, but readers likely recognize that it feels more like Tera mourning the loss of her long-beloved pet.

As Tera's apparent power over Margaret becomes ever more pronounced, Ross finally faces what is a horrible possibility: that Margaret is merely an astral projection of Tera. "In such case," he considers, "Margaret would not be an individual at all, but simply a phase of Queen Tera herself" (206). Ross outlines the uncanny connections between the two women, including their physical likeness, the appearance of the stolen lamps in the house, Margaret's accurate prophecies, and her recent "strange dual existence" (207-8). He considers an additional possibility that Margaret is an individual but "in some occult way the Sorceress had power to change places" with her (207). When Margaret justifies Tera's use of deadly force to ensure her resurrection (the deaths of the Arabs), Ross hypothesizes that Tera's spirit is with Margaret to "animate her and suggest thoughts" (215). Interestingly, Trelawney is not disturbed by this prospect at all. He believes the spirit of his deceased wife is in his daughter and if there was also the "spirit of that great and wondrous Queen, then she would be no less dear to me, but doubly dear!" (215). Kate Holterhoff's examination of liminality and power in the novel justly criticizes Trelawney who is "willing to add another esteemed identity to the seemingly limitless vessel of 
Margaret's soul" (136). Despite Trelawney's enthusiasm, this "hybridity" of Margaret and Tera proves to be dangerous; in the original ending, Margaret misrepresents the queen's attitude and innocuousness, leading to the deaths of her father's cohort (and herself). In the revised ending, although Tera's mummy is not reanimated, her continued presence in Margaret is implied (and with it, her avenging spirit, which may strike unexpectedly).

Over the course of the novel, Margaret becomes increasingly assured of Tera's wishes, purpose, and character. While some critics argue that she is a "medium" for Tera (Seed 195, Glover 88), they offer little commentary about why Margaret is so apparently mistaken. Is it Margaret who is sincere but misled by the spirit of Tera, or is Tera speaking through Margaret and feigning sincerity so that she can reanimate and take her revenge, even on those who supposedly sought to aid in her plans? Several assurances made by Margaret on behalf of Queen Tera turn out to be dangerously false. The first of these is a monologue which stands out awkwardly in what Roth argues is "the weakest section of the novel" (73). In chapter 15, "The Purpose of Queen Tera," Margaret shares what she believes to be the queen's objective. With a "far-away" look and sounding like someone from "a new and strange world," Margaret captivates her "entranced" audience (178-79). She explains that the "dream of every woman's life," including "that sweet and lovely Queen," is of love (177-78). Notably, Tera seeks love in what sounds like an Edenic vision of the North as a land of plenty, away from persecution and a lack of natural resources. This vision implies not only a (reverse) colonization of Britain by an Egyptian, but an intercultural, interracial union with a Northerner (likely understood as a European). Margaret explains that Tera dreams of a "land under that Northern star, whence blew the sweet winds that cooled the feverish desert air. A land of wholesome greenery, far, far away. Where were no scheming and malignant priesthood... where there might be some one kindred 
spirit... whose being could merge with hers in a sweet communion of soul to soul" (178).

Notably, the gender of this sought lover is not indicated and perhaps the merging of souls is ultimately between Margaret and Tera. This connection between women is plausible (especially considering Victorian concepts of same-sex relationships as mimicking the binary of heterosexual coupling and via nomenclature such as "inversion" for homosexuals) given Tera's unconventional gender roles. Nonconforming gender expression was often linked by sexologists as indicative of "inversion" or homosexuality. Like Hatshepsut, Tera "claimed all the privileges of kingship and masculinity" and wore men's clothes (Stoker 129) and the revised edition of the novel particularly suggests a permanent (and welcomed) merging of the two women's souls. In the original novel, however, Tera's "innocent" search for love and prosperity in a new land is refuted by her apparently vengeful deception through Margaret to kill her unsuspecting revivers.

Tera's prospective colonization of Britain is preceded by her colonization of Margaret's soul (one that proves dangerously fatal in the original version of the novel). Through what Ross calls parroted speech (213), the sinister machinations of Tera are misrepresented as "noble words" (179) through Margaret's reassurances that Tera supports the actions of Trelawney et al and wishes them no harm. On the day of the Experiment, Margaret proclaims that there "will not be any trouble to-night. She will not wreck your arrangements for any cause. I would stake my life upon it" (193). When Ross advises prudence, ("Would it not be well to take every possible precaution, in case the Queen may not wish what we are doing...?"), Margaret insists, "she does approve! Surely it cannot be otherwise" (210). Margaret reasserts later that evening (more than once) that Tera "will offer us no harm" but Ross notices "something in her voice so strange to me that I looked quickly into her eyes. They were bright as ever, but veiled to my seeing the inward thought behind them as are the eyes of a caged lion" (215). This statement references 
both veils and lions, symbols of the Middle East and Africa. Margaret's actions and guarantees while under the "influence" of Tera can be viewed as a menacing mimicry. Tera (not exactly a colonized subject but still representing the newly colonized region of Egypt by late-Victorian Britain) appears to be purposefully feigning accord with the Northerners who have (likely disappointingly) recently used military force to ensure their colonial control of that ancient and foundational country of Egypt. (Tera's hostility toward the Arabs also mirrors the animosity between Arabs and Egyptians in Haggard's She). Postcolonial critics Ashcroft, Griffiths, and Tiffin explain the subversive power of mimicry which "is never very far from mockery, since it can appear to parody whatever it mimics" (139). Mimicry is inherently critical of colonial authority. Referencing Bhabha, Ashcroft, Griffiths, and Tiffin argue that the "copying of the colonizing culture, behaviour, manners and values by the colonized contains both mockery and a certain 'menace"' (140). Tera's menacing mimicry is projected through Margaret, a respectable, native-born Briton, and is thus particularly dangerous since she is largely free from suspicion.

The Jewel of Seven Stars's dual and doubling aspects of knowledges and the Margaret/Tera characters are reinforced by its structure. The novel blends genre categories of detective fiction, Gothic, travel narrative, and romance. There are two editions (without a clear consensus as to which is the "real" version ${ }^{85}$ ) and the ambiguity of both endings is also deconstructive or queer; they mirror Stoker's skepticism that we can truly know anything for certain. Ambiguous resolutions of the novel obscure Stoker's potential message/critiques, but their undecidability reinforces his obvious epistemological anxiety, particularly in regards to the

\footnotetext{
${ }^{85}$ The revised 1912 edition was utilized by most publishers for many decades after publication. The Penguin edition (2008) uses the original version with the new ending as an appendix. The Oakpast edition (The Collected Supernatural and Weird Fiction of Bram Stoker, 2009) uses the revised edition. Similarly, Project Gutenberg (offering online access) as well as the audiobook available on Audible (2006, narrated by Simon Vance) both use the revised 1912 edition. Critics typically discuss both versions of the novel, highlighting the uncertainty as to which is the preferred canonical edition.
} 
superiority or authority of Western sets of knowledge and their ability to understand and appropriate secrets from the ancient/foreign Other. Critics have widely commented on the two disparate endings and have, unsurprisingly, offered bleak interpretations of the novel's attitude toward the search for knowledge. Whether modern/Western science "succeeds," the endings are rather pessimistic. Hughes argues that in both versions of the novel, the Experiment "may be judged a failure" (Beyond Dracula 46) and likewise, Senf believes the science in the novel "is ultimately unsuccessful" (Science 82). Ballam notes that even if Tera is resurrected, the Experiment has been unsuccessful in providing "either comfort or insight" into how it worked (161). Byron argues that the Experiment may have been very successful in "achieving Tera's goal, resurrection" but the novel still "offers Stoker's most negative assessment of the sciences because here, rather than working to identify, control, and eliminate the transgressive and the monstrous, science works to release it" ("Bram Stoker's" 57).

In both endings of the novel, readers' anxieties stem mostly from Tera's aggressive, deadly actions and her supernatural strength and ability to destroy on a potentially grand scale. In the original edition, Ross waits outside the room to control the electric lights; when the Experiment starts to go wrong and smoke fills the room, he has seen a white-dressed figure moving about the room and hopes to rescue Margaret (both she and Tera are wearing white dresses) but mistakenly picks up the body of Queen Tera who, notably, is not inside her sarcophagus but rather on the floor of the room. Conspicuously (and jabbing at the supposed supremacy of modern technology), the lights fail entirely during the Experiment (243). As Ross carries the body of "Margaret" upstairs, the "weight that I bore seemed to grow less" (244). He places the body in the hall and searches for candles; when he returns, the body has disappeared but Tera's bridal robe and the Jewel of Seven Stars remain. All his companions, including 
Margaret, are dead in the cavern, "gazing upward with fixed eyes of unspeakable terror" (244). Helpless to aid his friends, his narrative ends abruptly, ambiguously, and bleakly after just a few more lines (his final words are "It was merciful that I was spared the pain of hoping," 244). Margaret's confidence in the peaceful success of the Experiment and Tera's nature are thus discredited and readers are left wondering whether Tera has dissipated after being (at least temporarily) revived or whether her vindictive spirit and body have merely moved elsewhere to wreak havoc on the rest of Britain. Tera's power to "compel all the Gods" (129), her "savage" and "remorseless" tendencies (Stoker 209, 211), and her record of murder leave many readers with a dark sense of pessimism.

The revised and superficially "happy" comedic ending of 1912 also exhibits anxiety about the looming power of the ancient/foreign Other and the ominous effects that hybridity and mimicry might have on imperial Britain. The night before the Great Experiment, Ross wonders about the "dual existence" of Margaret: "what might happen when the existences became one?" (216). Ross realizes that the "alternation" between the two spirits of Tera and Margaret might eventually coalesce into one, producing a hybrid, queered (and unpredictable, subversive) personality. In the novel's revised ending, the body of Queen Tera is gone but her jewels are found (not in her sarcophagus but on a couch in the room, again implying at least a temporary revival). The "physical annihilation" of Tera's mummy is suggested only by the "small patch" of dust found in the sarcophagus in the hall (250). However, Margaret herself indicates the enduring potential of Tera. She and Ross are married just a few months after the Experiment and she often wears Egyptian dress and jewelry. In a "far-away eloquent dreamy look," Margaret tells Ross, "Do not grieve for her! Who knows, but she may have found the joy she sought?" (250). Byron recognizes this ambiguity: "why should the assumption be that Tera, whose aim was to be 
resurrected within a new body, should be gone?" ("Bram Stoker's" 60). Supposedly, the argument (as outlined by Hughes) is that because Margaret's cat Silvio, who has served as a "spiritual index" (Hughes, Beyond Dracula 51) to indicate whether Margaret or Tera is controlling their body through his alternating affection and fear/revulsion, happily rejoins her at the end of the novel. However, it may be more likely that, instead of interpreting the finale as requiring a displacement of either Margaret or Tera, it offers a full hybridization of the two women. The complete amalgamation between Tera and Margaret is perhaps finally achieved by the Experiment and is so complete that Silvio no longer fears the "Tera" aspect of Margaret's personality. However, given the often antagonistic and vengeful spirit of Queen Tera, readers must sincerely question whether an integration of Tera and Margaret will truly lead to the meek and dutiful wife that Margaret appears to be shortly after her marriage to Ross. Impending disaster seems possible as Tera is known to be not only powerful and vengeful, but also "abiding of heart" or patient (174).

The Jewel of Seven Stars is ambiguous and bleak, reflecting the pessimism of the fin de siècle. The novel not only exhibits anxiety about the knowledge of the Other, but it is a cautionary tale regarding the attempted appropriation or hybridization of such knowledge. Stoker utilizes the nascent disciplines of Egyptology (and archeology more generally) to comment on the potential repercussions of exploitative and imperialist practices by the colonizers upon the colonized. These areas, much like their related philosophical fields of theosophy, theurgy, and the occult, adapted knowledges of foreign or ancient cultures but also hybridized them to adjust for Western practitioners and researchers. Despite the focus on empiricism and science, archeology nonetheless often encouraged the spread of rumors, doxai knowledge, and sincere belief in the powers of alternate religions and gods. This worked to destabilize hegemonic 
Western knowledges (both in supernatural or theological realms such as Christianity and in secular areas like empirical science). Egypt was especially viewed (and still is, by many people) as a place of particular wisdom, ingenuity, history, and spiritual power, a resonant "cradle of civilization." Disrespect toward such an authoritative culture could result in devastating consequences. The consistent destruction, desecration, and even literal consumption of the carefully preserved deceased through tomb-raiding and mummy unwrapping are harshly criticized through Stoker's narrative.

Trelawney's disastrous attempt to carry out Queen Tera's plans for reanimation reflects a failed "reverse mimicry." His obsession with Tera has allowed his only child to be possessed and eventually either destroyed or potentially amalgamated with Tera's spirit and influence. Tera exhibits a kind of "reverse colonization" in her influence over Margaret, which is fatal in the original version of the novel. While Tera is "mimicking" through Margaret, she falsely reassures Trelawney's group of experimenters that their plan and desire to resurrect Tera is innocuous and will be successful, both in the reanimation and their acquisition of esoteric knowledge; clearly, this kind of menacing is lethal. Tera's hybridization with Margaret is not only threatening in the original edition of the novel in which she leads her team to destruction, but also in the revised and ostensibly happy ending. The implied presence of Tera remains in Margaret, the seemingly submissive and doting wife of Ross, several months after the "failed" Experiment and thus retains tension in the novel as to whether-or perhaps when — the darker side of Tera will make its vengeful presence known. Stoker's undecidability about epistemology is reflected not only in the ambiguity of the endings, but also in their doubling. The uncertainty of exactly what really happens or what is the authentic ending mirrors the inability to know anything for sure, even the resolution of one's own fictional narratives. Whereas hybridity in the postcolonial sense often 
serves as a useful subversion to colonial or dominant authority, because Stoker is himself aligned with the colonizers, his novel's hybridity must ultimately undermine his own place of Western authority and supremacy. 


\section{Chapter 5}

"I couldn't define it to you, I only know I felt queer": The Great God Pan, Queer Knowledge, and the Horrors of a World Beyond Epistemology

Contemporary critical reviews of Welsh author Arthur Machen's ${ }^{86}$ The Great God Pan (1894) sometimes reflected a theme of the novella: certain knowledge can drive a person insane, particularly as it pertains to sexual deviancy. Appearing as part of a Keynotes series collection of Decadent works by the Bodley Head, ${ }^{87}$ The Great God Pan was condemned by the Westminster Review as a "nightmare incoherence of sex and the supposed horrible mysteries behind it, such as might conceivably possess a man who was given to a morbid brooding over these matters, but which would soon lead to insanity if unrestrained" (qtd. in Luckhurst, Late Victorian xxix). The Contemporary Review denounced the whole Keynote series as "morbid extravagances of hysterically neurotic and erotic imagination" and called Pan a "perfectly abominable story" with the harmful potential of "vitally affecting the public sphere" (qtd. in Karschay 87 ). ${ }^{88}$ While the novella avoids explicit discussion of sexuality, it utilizes a variety of elements to continually hint at the theme (focusing on $\operatorname{Pan}^{89}$ is one such obvious component) and uses what Eve Kosofsky Sedgwick recognizes as the Gothic tradition of fragmented and disrupted narration to illustrate "unspeakable" horror. In The Great God Pan, a doctor of "transcendental medicine" performs an experimental brain surgery on his ward, Mary, which will allow her to lift the "veil" and see beyond the material world to the spirit world —-what he calls "seeing the God Pan." The

\footnotetext{
${ }^{86}$ Born 1863 in Caerleon, South Wales and died 1947 in Beaconsfield, England.

${ }^{87}$ An early version of the first chapter appeared in The Whirlwind in 1890 but it was largely unknown until its publication in the Keynotes series, commissioned by John Lane, featuring Decadent artists and covers by Aubrey Beardsley (Lovatt 20).

${ }^{88}$ Interestingly, Machen took a particular pride in such harsh reviews, even including them in his Introduction to the reprinted edition of The Great God Pan in 1916 (Karschay 244).

${ }^{89}$ Stephan Karschay notes that by the 1890 s, Pan had been well-established as a "symbol of sexual prowess and unrestrained lechery" (110).
} 
experiment goes awry; Mary is driven mad, impregnated by the demonic Pan, and gives birth to Helen, a seductive yet monstrous femme fatale who has a devastating effect on those she encounters. In particular, she leads a series of London gentlemen to mysteriously commit suicide before her identity is finally discovered, she is caught, and chooses to hang herself.

While Machen's fame has risen and faded periodically over the years, The Great God Pan is currently considered the "quintessential text of the late Victorian Gothic" by many critics (Luckhurst, Late Victorian xxix). The novella captures much of the culture and anxieties of the fin de siècle and reflects themes of decadence. Pan criticism over the past two decades has focused on the novella as illustrating degeneration anxiety and dangerous sexuality (Eckersley, Hurley, Navarette, Mighall), in relation to occult societies and Machen's biography (Luckhurst, Pasi), the New Woman and medicine (Sparks), Decadence (Lovatt), Pan as a queer Gothic monster (De Cicco), and through medical and sexological debates (Karschay, Hughes, Rebry). While critics have commented on the tale's fragmented nature, its "obfuscating rhetoric" (Hurley, Gothic Body 47), and its ability to question epistemological certainty, The Great God Pan does more than deconstruct or hybridize epistemologies. Seeing Pan reveals a "queer knowledge" without an epistemology—an emotional, sensory, corporeal one of absolute breakdown and chaos, a knowledge beyond rationality or language.

This "queer epistemology" is unlike what many other Gothic characters have been attempting (discussed in previous chapters), which has been seeking forbidden knowledge of the Other to coopt and domesticate such powers in order to control and utilize them. In Machen's novella, Dr. Raymond attempts such a venture in his occult science research and, while the experiment technically works, he is unable to access the spirit world of Pan in any useable way. Mary cannot relay what she has seen or felt. Those who see Pan directly are instantly turned 
mad, unable to share their new knowledge; those who see him indirectly through Pan's daughter Helen are similarly (though less severely) affected, driven to madness and suicide, unable to articulate what they have experienced. This epistemology is queered beyond intelligibility, then, and becomes rather a queer phenomenology. Mark De Cicco recognizes this possibility: Pan "functions as a disquieting figure that shatters accepted notions of civilized order and reorients those he encounters towards new, queer possibilities or orientations" ("Queer God" 51). Encountering Pan reorients the world in front of its characters and in turn reorients them, but they can merely exist under such conditions as there is no way of "knowing" or understanding. The concept of epistemology itself is thus interrogated. What irrupts in Machen's tale is the potentiality of a world beyond thinking — an irrational world of emotion, affect, sexuality, and the body that is not epistemological. The central anxiety of the novella, then, is the possibility that underneath our "civilized" selves and our various ways of thinking and knowing lies a chaotic, primal, irrational state that undermines any notion of knowing/rational comprehension; everything can get queered, even knowledge itself. Pan represents this ultimate queering and deconstructive potential and for a conservative fin de siècle British author like Machen, this queerness is portrayed as a horrifying, indescribable, deadly force.

How does a Greek god-one often represented over the centuries as an innocuous symbol of bucolic sublimity — come to represent such horror in the fin de siècle? Pan's mythological origins are somewhat obscure; a pastoral god from Arcadia, he is usually described as the product of Hermes and a wood nymph (Cartwright). He is portrayed as half-human, half-goat, with horns, goat hindquarters and feet (much like a faun or satyr). He is the god of wild spaces and nature, a guardian of flocks and shepherds, and is associated with rustic music. The word 
"panic" comes from Pan. ${ }^{90}$ During the Middle Ages, Pan's horned appearance and connection with unrestrained sexuality and "wild" music led to the "superimposition of the Christian Devil on to Pan" (De Cicco, "Queer God" 52). De Cicco reminds us, though, that Pan has always been "potentially terrifying" and discusses several examples of ancient writers (such as Herodotus) who portray Pan as threatening (52). He notes that Pan was incredibly popular in Europe and North America at the turn of the $20^{\text {th }}$-century, appearing in art, music, dance, advertisements, children's and adult literature (49). Pan's image had changed between the Romantics and the Victorians, however, and Machen's depiction reveals a particularly dark connotation. Poets such as Shelley, Keats, and Wordsworth used a more abstract and benign, gentle invocation of Pan (De Cicco, "Queer God" 52); like earlier depictions in English literature, the Romantics portrayed a more "invisible" concept of Pan as an "all-infusing spirit of the landscape, most often benevolently pastoral, occasionally heard, but almost never seen" (Merivale 76). Ronald Hutton's history of modern pagan witchcraft elaborates on the early $19^{\text {th }}$-century's use of Pan as "sublime, mysterious and awe-inspiring, benevolent, comforting, and redemptive. He was pitted directly against the perceived ugliness, brutality, and unhealthiness of the new industrial and urban environment and the perceived aridity and philistinism of the new science" (qtd. in Pasi 70).

Victorian poets returned Pan to the realm of action and concrete being and focused less on his "benevolent" presence and more on his power to terrify and cause panic (Merivale 76). By the middle of the century, Victorians saw Pan as a "tangible" goat-god whose image became

\footnotetext{
${ }^{90}$ The Oxford English Dictionary notes the origins of "panic": "Early 17th century: from French panique, from modern Latin panicus, from Greek panikos, from the name of the god Pan, noted for causing terror, to whom woodland noises were attributed."
} 
increasingly menacing (De Cicco, "Queer God" 53). Biographer Mark Valentine views

Machen's version of Pan as "influential in attaching to Pan a new mode," away from previous bucolic associations and toward sexual license and "cosmopolitan decadence" during the late Victorian and Edwardian periods (33). Marco Pasi suggests that the popularity of Pan amongst occultists and esotericists of the period (such as Algernon Blackwood, Florence Farr, Aleister Crowley, and Dion Fortune-all Golden Dawn members who published works dealing with Pan or fauns) was connected to the neo-pagan movement. The notion is that Pan represents the mysterious spiritual place beyond our materialist reality that "esotericists and mystics of all times have yearned to gain access" (Pasi 69). The esotericist portrayal of Pan thus moves once again toward the abstract.

Unlike such conceptions of Pan, however, Machen's depiction is particularly bleak and represents Pan as a concrete figure (though he is seldom seen). He is a "god of subversion" (Pasi 81), demon-like, a force that causes panic not only in the sylvan landscape, but everywhere he is invoked — even in high society London. Machen's Pan is queer, "disturbing psychologically, temporally, spiritually, and sexually," notes De Cicco, both a "harbinger of horrifying death and rebirth into new, queer possibilities" ("Queer God" 50). For Machen, however, these are not very distinguishable; Pan is more than a queering Gothic monster, as De Cicco argues. Rather than engendering a productive queer epistemology or phenomenology for those he encounters (something often viewed as positive and ethical today), Machen uses Pan to represent the anxiety of a world beyond epistemology, a world beyond knowing or comprehending one's surroundings. The "rebirth" for "queer possibilities," then, leads only to death and madness. Interestingly, Pan can be seen as a critique of modernity ${ }^{91}$ as he represents an ancient pagan

\footnotetext{
${ }^{91}$ De Cicco, for example, argues that Pan "projects onto the 'civilized' Victorian age an image of ancient chaotic forces that continue to shadow modern industrialized society" ("Queer God" 50).
} 
spiritual presence. He stands in opposition to the fin de siècle world thatfor is "civilized," industrialized, and urban and yet his ancient, pastoral, spiritual force is not to be emulated or even understood. His force is apparently even more devastating than the "decadent" world of the 1890s. Each tradition therefore seems as destructive as the other. ${ }^{92}$

\section{Queer/ing Knowledge and Epistemology: The Experiment}

The previous chapters have discussed various ways that Westerners of late Victorian Gothic tales (unsuccessfully) sought forbidden knowledge of the foreign or ancient Other. These men attempted to adapt or hybridize such knowledge into an enlightened, queered epistemology but ultimately found that they could not truly understand or utilize such knowledge. Dr. Raymond's experiment in The Great God Pan also reflects this theme of seeking forbidden knowledge and contemporary debates about blending epistemologies. His experiment attempts to hybridize epistemologies to become truly enlightened and see beyond the "dull," everyday material world. However, what he eventually uncovers goes far beyond his expectations of an amalgamated knowledge and indeed, further than what the previously discussed characters have encountered. The novella also deals with other forms of uncertain, hybrid, and queered epistemologies. These will be organized and discussed as they relate to the victims of Pan/Helen's influence, the "occult explorers" who witness certain events and/or serve as amateur detectives, and the central villain—demi-god and daughter of Pan, Helen.

The late $19^{\text {th }}$-century witnessed a variety of societies, scientific discoveries, and philosophical debates that actively challenged traditional forms of knowledge. This common interest (and its underlying anxieties) are frequently reflected in fiction of the period. As

\footnotetext{
92 One might consider, however, whether Machen is suggesting that the horror-induced madness and death brought on by Pan's presence is due to his actual embodiment of unrepressed id, chaos, or the Real, or if his devastating effect is because modern humans are too far removed from the primal and corporeal forces Pan represents (which are perhaps intolerable under our current "civilized" condition).
} 
discussed above, occult and theosophical societies as well as groups like the SPR were a central source of the period's attempted epistemological hybridizations. Blavatsky's Isis Unveiled not only pointed toward a potential blending of science and religion or spiritualism, but also borrowed from a variety of knowledge traditions, including ancient Egyptian, Indian mystic, and Buddhist. Peter Washington's discussion of Blavatsky and spiritualism notes that she hoped to "subsume those facts [presented by Victorian science] into a grand synthesis that makes religious wisdom not the enemy of scientific knowledge but its final goal" (qtd. De Cicco, "More than Human" 13). As we have seen, such ventures proved popular as they afforded not only alternatives to scientific materialism and traditional Christianity, but also provided a new frontier for exploration - one that combined the adventure of scientific discovery with the frisson of approaching powerful supernatural and occult forces.

A hybrid or queer knowledge-often one which "bordered on the knowable, science, religion, and the occult" (De Cicco, "More than Human" 5) - is what Dr. Raymond attempts in The Great God Pan's opening chapter titled "The Experiment." Raymond describes his research as "transcendental medicine," a phrase borrowed from Robert Louis Stevenson's Strange Case of Dr. Jekyll and Mr. Hyde (1887). The phrase's hybrid nature is obvious as "transcendental" relates to the spiritual or nonphysical realm, while "science" implies the study of the physical and natural world. Kelly Hurley describes this hybrid epistemology as one in which "supernatural phenomena are produced through scientific practice-by means of physiological manipulation, or chemical experimentation, rather than magical spells" ("British Gothic" 192). Like some other "mad scientists" of the Gothic genre (such as Frankenstein), Raymond has an interest and background in alchemy. He references $17^{\text {th }}$-century alchemist Sir Kenelm Digby 
(who wrote about the interdependence of the body and soul ${ }^{93}$ ) and tells his friend Clarke, who has come to observe the operation, about Oswald Crollius (an Elizabethan neo-Platonist and alchemist ${ }^{94}$ ) who "was one of the first to show me the way, though I don't think he ever found it himself" (Machen 186). Raymond also alludes to his continued research in modern Western science, including the "immense strides" made recently in the study of brain physiology and "Brown-Faber's discoveries," which Luckhurst believes is an allusion to Charles BrownSequard, a Victorian brain neurologist who studied and debated cerebral localization and function (Late Victorian 279). Raymond claims he is fifteen years ahead of contemporary "men of medicine," however, and that he knows the function of a "certain group of nerve cells in the brain" still baffling other scientists (185). Raymond believes that the components of the physical world we experience daily (mountains, stars, people, etc) are merely "dreams and shadows: the shadows that hide the real world from our eyes. There is a real world, but it is beyond this glamour and this vision... as beyond a veil"; lifting this veil was what the "ancients" called "seeing the god Pan" (184). He tells Clarke that a "microscopical alteration" of those nerve cells would raise this veil: the brain surgery would activate or "set free the current" to "complete the communication between this world of sense and-we shall be able to finish the sentence later on" (185). Interestingly, Raymond is never able to finish this sentence, despite the "success" of the experiment, because rational, comprehensible means of communication and language do not exist in Pan's realm.

That Dr. Raymond's experiment is a brain surgery especially reflects contemporary debates, particularly the notion of duality between the mind versus body, and the spiritual versus material or physical. Descartes believed in a fundamental distinction between the mind and the

\footnotetext{
${ }_{93}$ Luckhurst, Late Victorian 279.

${ }^{94}$ Luckhurst, Late Victorian 279.
} 
body. As many religious traditions continue to assert, such duality insists that the "soul" or "mind" is immortal and exceeds the body and material world. During the $19^{\text {th }}$-century, advances in neuroscience and psychology spurred many debates about the relationship between the body and mind, "the physiological basis of consciousness, and the nature of the will" (Rebry 12). The study of the "soul" by the fin de siècle, as William James asserted in 1890, was largely ignored by psychologists and other scientists (Rebry 12). After all, within a positivist, materialist epistemology, the "soul" could neither be located in the body nor studied through controlled conditions. Natasha Rebry notes that the soul was "no longer assumed to be the vehicle of consciousness or the vital principle presiding over the body" by the end of the century (12). The concept that had seemingly replaced the "soul" was the "will" (Rebry 17); however, science of the period also interrogated this concept.

Contemporary scientists such as Paul Broca and David Ferrier discovered that certain sections of the brain are directly linked with specific mental and physical functions; this became known as cerebral localization. Such connections were made by studying people with head trauma or brains of patients suffering from the same condition. ${ }^{95}$ Later in the Victorian period, scientists utilizing vivisection and electricity on animals found further evidence of specific connections between brain location and mental faculties. Such experiments were often inhumane, however, and received much public criticism. ${ }^{96}$ Rebry argues that perhaps what bothered the public more than the cruelty to animals, however, was how such experiments "demonstrated the fundamental physiological similarities between humans and other animals, and in part because of the ways they challenged belief in the human will, and by extension the

\footnotetext{
${ }^{95}$ In the 1860 s, for example, Broca found lesions in the left frontal region of the cortex which indicated that the patients' aphasia was linked to this part of the brain (Rebry 12).

${ }^{96} \mathrm{H}$. G. Wells's 1896 gothic/science fiction novel The Island of Dr. Moreau addresses the ethical questions of vivisection research.
} 
soul" (16). After all, separating the brain into distinct, individual components deconstructed the notion of a unified brain or soul leading a person's thoughts and actions. Laura Otis explains how the concept of the "will"- what many had sought as a replacement to the "soul"- -was especially deconstructed through such experiments. Using electric current on different sections of the brains of living animals showed that even when they did not wish to, say, move their leg, "electricity could replace a creature's will" and, given mammals' similar physiology to humans, this implied that "there was nothing sacred about the human will, not even human consciousness" (qtd. Lovatt 24). Some mental scientists of the era considered the will differently, though. William Carpenter, for example, acknowledged that the brain carries out certain functions automatically, but that the "power of the Will" (which represented a kind of "soul"the "spiritual self which was capable of guiding thoughts and directing actions," Rebry 17) could overcome reflexive and spontaneous brain function. Carpenter argued that a well-disciplined will could actually alter the physical structure of the brain, shaping and developing as one might strengthen muscles through exercise (Rebry 16-17).

Machen's use of the brain as central to the experiment in The Great God Pan responded to the displacement of the soul in scientific research as well as how the notion of the will was being debated in contemporary discourse. Like others in the Decadent movement, he critiques the notion of mind as separate from body in certain ways. Gabriel Lovatt notes that a central goal of Decadents was the "aesthetic expression of perception and cognition derived from embodied experience" (20) and argues that Machen "takes the growing knowledge about the embodied mind to its darkest limits, eradicating human consciousness through physiological manipulation" (24). By using the body (a surgical alteration in Mary's brain) to impact the mind (and soul/will), Machen seems to deconstruct this Cartesian duality. At the same time, he implies that a spiritual 
dimension is separate from our materialist one (and apparently not directly approachable) and that we do, in fact, have souls. Rebry argues that Machen views the brain as the "locus of a human spiritual self" and portrays it as a "permeable barrier between the worlds of spirit and matter that acts as a portal to other, often ancient dimensions" (10). Machen seems to want to hold onto the notion of a spiritual will or soul that guides us (thus critiquing much of the contemporary scientific materialist perspective) while also recognizing that the body and mind are not separate entities. That the experiment causes Mary to lose her self-awareness and mind/sanity, control of her body, her will power, and thus in a sense, her soul, suggests the interconnectedness of these components and more strongly indicts the unethical experiment undertaken by Dr. Raymond.

Apart from Dr. Raymond's experiment as occult science, its unethical nature also can be understood in the context of traditional modern science of the Victorian era. William Hughes's "Victorian Medicine and the Gothic" notes that the queering of "epistemological drives" between the roles of doctor and scientist is common in Gothic literature but represents a damaging irresponsibility to its victims. Scientists are focused more on the general, whereas doctors focus specifically on individual patients. When these approaches become blurred, a destructive and unscrupulous experiment often follows. Combining the generic and the individual, "when the doctor treats his patient not for his or her own disorder but as the facility from which a generalisation might be made or a theory tested," "characteristic difficulties arise that dissociate the doctor from his patient" (Hughes, "Victorian Medicine" 199-200). In such cases, the doctor/scientist tends not to cure or alleviate disease, but instead causes or exacerbates it; he also "distort[s]" the "culturally idealised image of altruistic professionalism," notes Hughes ("Victorian Medicine" 200). Raymond, too late, realizes his mistake. He finally admits to Clarke 
in the novella's final pages that it was "an ill work I did that night," "without knowing or caring what might pass forth or enter in"; "I had ruined the reason of a human being by a foolish experiment" and had forgotten that "no human eyes could look on such a vision with impunity" (Machen 232). He felt a "constant," "incarnate horror" around Mary's child and sent Helen out into the unsuspecting world after a few years (233). While Raymond eventually feels some guilt, Machen allows him to emerge from this disastrous endeavor essentially unscathed-a kind of impunity not afforded to most of the other characters.

\section{Queer/ing Knowledge and Epistemology: Victims of Pan}

As the epistemological structure of society is disrupted or queered, the various aspects of that society are influenced, too. The most negative impact of Pan is seen in what we might term his "victims" - those who either directly confront him or those who see him indirectly, through demi-god Helen. The first and most negatively impacted victim of Pan is 17-year-old Mary (from Britain, most likely Wales). Because of her youth, subservient and dependent workingclass female status, however, she is also a "victim" of Dr. Raymond and his dangerous experiment. When Clarke initially expresses concern about both the safety and ethics of the endeavor, Raymond replies, "I rescued Mary from the gutter, and from almost certain starvation, when she was a child; I think her life is mine, to use as I see fit" (186). Mary meekly agrees to be her guardian's test subject, Raymond anesthetizes her, performs his "minor" brain surgery, and the men wait for her to awaken and "see the god Pan." When she comes to, her eyes "shone with an awful light, looking far away, and a great wonder fell upon her face, and her hands stretched out as if to touch what was invisible" (189). Mary's first impression of Pan, then, seems to be a kind of wonderful enlightenment-something she orients herself toward as she reaches out to it. After a moment, however, what she experiences becomes unbearable: "the wonder faded, and 
gave place to the most awful terror"; her facial muscles were "hideously convulsed, she shook from head to foot; the soul seemed struggling and shuddering within the house of flesh. It was a horrible sight" and Mary falls from the chair, shrieking (189). The spiritual battle she undergoes is written on her body and the effects are devastating; after three days, Mary is only able to lie in bed, "rolling her head from side to side, and grinning vacantly," clearly insane (189-190). She becomes pregnant and gives birth nine months later to a daughter, who would be named Helen. Mary dies just days later, without ever regaining her sanity.

Mary has been exposed to a queer and unbearable knowledge, one that leads only to madness and death. Her destroyed mental state denies her the opportunity of describing what she has seen and experienced-if, indeed, it could be understood and articulated into words. She is clearly the victim of a cold and unethical scientist (his response to her madness is to "quite $\operatorname{cool}[1 \mathrm{ly}]$ " pronounce that "it is a great pity; she is a hopeless idiot. However, it could not be helped; and, after all, she has seen the Great God Pan" 190). Given Pan's reputation of wild, unrestrained sexuality and lasciviousness, Raymond should have foreseen (and forewarned her) of what might occur. Her pregnancy is evidently supernatural-a "spiritual" experience that is reflected in her body. Interestingly, her name implies a warped revision of the Christian "immaculate conception": this Mary, dressed in white (perhaps symbolizing her upcoming "marriage" to Pan) is raped and impregnated by a horned, goat-footed, demon-like pagan god in what might be termed an infernal conception. What she births is not a savior, but a destroyer of lives - what a fin de siècle audience likely interpreted as a spawn of Satan.

And yet Machen complicates Mary's status of "victim." In her brief exchange with Dr. Raymond, she repeatedly refers to him as "dear" and before the surgery begins, she states an imperative sentence: "Give me a kiss before you begin" (189). Although this sounds more like a 
conversation between spouses, it could be read as relatively harmless between a teen ward and her guardian. However, Raymond responds by kissing her on the mouth (and this is apparently expected and welcomed by Mary). Tabitha Sparks argues that Mary's forwardness works to sexualize her: Mary's demand for a kiss "asserts the impurity of her social caste" since late Victorians often believed that female desire, especially of the working-class, was a sign of "immorality and degeneration" (129). This request, then, "effectively moderates Raymond's transgressiveness" (129, emphasis Sparks); Raymond does not initiate the contact but is passive in this moment. Since Mary is complicit in their implied sexual relationship, this aligns her with her nefarious daughter Helen as Mary seems to possess "ambivalent signs of worth and perversion" (129). Sparks persuasively connects moments like these in Gothic texts of the period (particularly Stoker and Machen) to the medico-legal controversies surrounding sexuality and disease.

When the Contagious Diseases Acts were repealed in 1886, this reflected not merely the efforts of early feminists such as Josephine Butler, but also a shift in culpability of disease transmission from poor and working-class women (especially the prostitute) onto bourgeois men (Smith 95). Texts such as Pan then work to reclaim the power of men over women's bodies. Even when men are responsible for the women's "monstrosity"-women who are "transformed against their will" (such as Stoker's Lucy, Machen's Mary, or even Helen), the sexuality of these women justifies the horrible repercussions they face (including murder) in the name of protecting the public (Sparks 127). This message clearly opposes the repeal of the CDAs and instead argues that men can serve as heroes of redemption - even if they have been complicit in (or caused) the negative transformation of women - in order to serve the public and protect the British race. Even though structural forces of poverty and male lust are generally what drive women into 
prostitution and keep the trade alive, the women - who are often truly the victims - must pay the highest price. Mary's status as victim, then, is queered by Machen's narrative choices.

While Mary suffers the most devastating effects of any character due to her surgicallyenforced direct encounter with Pan, her demi-god daughter Helen continues to wreak havoc on the world as a kind of representation of and medium to Pan. When Helen is 12-years-old, Raymond sends her to board on a farm nearby in Wales where she may roam the woods all day and essentially do as she likes. Because she seemingly comes from money (the farmer is wellpaid), local families allow their children to play with her. Her closest companion is a girl of about 11 named Rachel. Their friendship is of a "peculiarly intimate character" (Machen 194) and their "intimacy" was encouraged by Rachel's parents (though they later regret it). The girls often spent all day in the woods and sometimes afterwards, Rachel had a "peculiar" manner: "she seemed languid and dreamy" and "different from herself" (195).

Machen's choice of the word "languid" is not incidental. While the word's denotative meaning is faint, listless, and lacking vigor, "languid" also had different connotations to a Victorian audience. Notably, the word "languid" is often applied to female vampires (and sometimes their victims); for example, it is used repeatedly in Stoker's Dracula (1897) and LeFanu's "Carmilla" (1872), both stories including female vampires. "Languid" connotes both an enervation/loss of blood (as when Lucy is becoming a vampire) as well as a kind of sexual satiation and exhaustion (LeFanu's Carmilla). Rachel's mother once finds Rachel in her room "lying, half-undressed, upon the bed, evidently in the greatest distress" (195). She asks her mother why she lets her go into the forest with Helen and Rachel's explanations of her distress ("a wild story") are left untold by the narrator, although he expresses great distress at what has been intimated (it is "too incredible, too monstrous," 195). Given Helen's connection with the 
hypersexual Pan, the girls' "intimate" relationship, Rachel's "languid" condition, her indications of distress and guilt, and the unspeakable nature of her experiences with Helen, a queer sexual relationship is strongly implied. Rachel continues this relationship that is both queer and queering: she is perceived as "different from herself" by her family. While some evidence exists that Rachel has been raped, she also seems to have difficulty separating herself from her companion and their sylvan adventures. Rachel eventually dies a "terrible death" (details are not provided) which also leads her parents to die from "grief and horror," caused by their daughter's demise and "what had gone before that death" (230). The influence of Pan thus illustrates a queering potential for sexual deviancy and dissolution of selfhood, even amongst children. Another child encounters Helen and Pan in the woods of Wales, a boy of 7 named Trevor. While out picking flowers, the young boy falls asleep and is awakened by a "peculiar noise, a sort of singing" (Machen 193). This noise/singing alludes to Pan's ancient association with wood noises, the panpipes, and his ability to cause panic. Trevor finds Helen "playing on the grass with a 'strange naked man," cries and runs away, screaming in terror. He is "unable to describe further" what he witnessed to his father (193). Although he experiences nightmares, he seems to be improving when he happens upon a particular ancient statue at a neighbor's home. A local gentleman had recently dug the foundations of his estate and displayed relics from the Roman period ${ }^{97}$ he had found. The "grotesque stone head" that terrifies Trevor is said to be a "faun or satyr," according to the "most experienced archaeologists of the district" (194). The sight is too much for the boy and he falls senseless to the ground, "his face contorted in terror," suffering from "shock" "98 and "violent hysteria." The lasting effects of the severe shock are a

\footnotetext{
${ }^{97}$ The Romans occupied the region now known as Wales in the $1^{\text {st }}-4^{\text {th }}$ centuries AD.

${ }^{98}$ Rebry discusses Machen's use of "shock" and how it stands in for the concept of psychological trauma (or what we might think of as PTSD today).
} 
"weakness of intellect" with "little promise of amending" (194). That Trevor's incurable state is catalyzed by the sight of a piece of ancient Roman architecture is rather intriguing within a Gothic tale. As explained in the introduction, a common conception of the Gothic (whether in relation to the term's origin, art and architecture, or within the literary genre) is that it stands in opposition to the ordered rationality of Greco-Roman classicism. The Goths were allegedly a "barbaric" tribe that helped effect the fall of the Roman Empire; they were viewed as antithetical to the "civilized" society of Rome. The Gothic generally refers to what is ornate, excessive, impractical, irrational, or superstitious and even Christian cathedrals that take on such designs are considered "Gothic" as they break from the relative simplicity of Greek and Roman architecture. In contrast, classical connotations of Greece and Rome are typically rational, ordered, practical, and logical. What Machen presents is a queer Gothic tale set on the border of Wales and England in an area once held by Romans; while the use of Wales in correlation with the mystical is unsurprising, ${ }^{99}$ Machen's choice of a Roman figure as the Gothic monster is less anticipated and thus in a sense, deconstructive.

When Helen is about 18-years-old, she moves to London in search of more victims. As her reputation becomes notorious, she periodically travels from place to place (including Buenos Aires and Florence, though she spends most of her time in London) and changes her identity frequently as she pursues young, wealthy, blithe gentlemen and leads them to insanity and suicide. The liaisons she forms with these gentlemen are not explicitly described, but there is ample textual evidence that points to sexually deviant relationships. This interpretation

\footnotetext{
${ }^{99}$ See Darryl Jones's "Borderlands: Spiritualism and the Occult in fin de siècle and Edwardian Welsh and Irish Horror" for a discussion on how Celtic authors invoked the rich mystical past of their ancestors while nonetheless Othering native Celts as monsters or subhuman within the gothic and Weird genres. He argues that the Celt was often figured as "pre-modern, pre-Enlightenment, superstitious, supernatural, magical, occult, irrational or prerational" (33-34).
} 
influences our understanding of what kind of "queer knowledge" these men acquire, how it impacts their epistemology, their bodies and appearance, and how onlookers are queered by their attempts to read their physiognomy. That the men willingly sexually engage with Helen also complicates their status as victim. Helen's hypersexuality and deviancy are not unexpected, given who her father is. Her childhood hinted at a sexual nature, as well (e.g., her "play" with the "strange naked man" in the woods, her intimate relationship with languid Rachel). Helen's intimate relations with gentlemen are hinted in a variety of ways. The men are often witnessed leaving her house very late at night (which surely signified an inappropriate relationship to a Victorian readership). For example, one unnamed man is found dead outside her house very early in the morning (one who apparently "died of fright," according to the inquest doctor); another named Crashaw was seen leaving her house at two o'clock in the morning. His face was "an infernal medley of passions" including "furious lust" (Machen 220). Another one of her men, artist Arthur Meyrick, has his sketchpad sent to his friend Austin after Meyrick's illness and death. The sketches feature "evil," dancing "Fauns and Satyrs and Ægipans" (212) across various landscapes. Occult explorer and "detective" Villiers later insists that the images "were not drawn from his imagination" (223). The collection also features a Latin quote by third century geographer Gaius Julius Solinus describing a Bacchic orgy near Mount Atlas with Ægipans and satyrs (Luckhurst, Late Victorian 279). Helen thus apparently has the ability to serve as a medium to connect gentlemen with her lustful and horrifying orgies; from Trevor's testimony, we can assume that Pan himself can take concrete form in the material realm through Helen.

The manner of the men's deaths also points toward sexual deviancy brought on by their queering experience with Helen/Pan. Many of the men die by strangulation. Lord Argentine's valet finds him his bedroom, "his body leaning forward at an angle from the bottom of the 
bed... [he] had tied a cord securely to one of the short bed-posts, and, after making a running noose and slipping it round his neck, the unfortunate man must have resolutely fallen forward, to die by slow strangulation" (215). Within three weeks, three additional men have died under similar circumstances. Lord Swanleigh is found "hanging from a peg affixed to the wall" of his dressing room, and two other gentlemen died in the exact manner as Lord Argentine (215). Crashaw also dies by hanging.

The recurring death due to strangulation led critic Stephan Karschay to investigate the connections between The Great God Pan, sexological discourse, Machen's life and writings, and deviant sexual practices of the late Victorian period. He connects the demeanor and actions of the novella's characters to sexology texts. For example, Richard von Krafft-Ebing's Psychopathia Sexualis discusses hyperaesthesia sexualis (or, nymphomania and satyriasis for women and men respectively) and Havelock Ellis's Studies in the Psychology of Sex talks about the "craving to be strangled," what we call asphyxiophilia today (Karschay 105-107). Depleted oxygen can "heighten the sensations of sexual excitement" and the danger of the practice can also contribute to the pleasure (Karschay 107). Ellis notes that erotic asphyxiation was a relatively common practice in brothels (107). Would Machen have known about this kind of sexual practice? Karschay believes so, as Machen translated thousands of pages of erotica during his lifetime and was "well known for his eccentric literary tastes and his profound knowledge of mystical and sexual arcana" (108). It is quite possible, then, that Machen alluded to this practice in The Great God Pan.

The sexual connotations of the novel thus queer the concept of the gentlemen as mere victims of Helen. The text suggests that the "potential for deviance and transgression lies as much in the normative male self as it does in the monstrous female Other," argues Karschay 
(111). Similarly, Glennis Byron sees human nature itself as threatening in the text. The queering force of Pan reveals that our natures are "potentially deviant and destructive when freed from the fetters of social and ethical taboos and codes of behavior" which are needed for stable individuals and society (Byron, "Gothic" 137). This vulnerability produced anxieties that extended widely and contributed to the doubt surrounding the superiority of the British "race" and the alleged "civilizing" mission of the imperial project.

The queering influence of Pan-one which seems to induce a complicity in sexual deviancy - also reveals a queer knowledge to those who encounter him/his daughter. This knowledge is brought forth through physical, sensory, and emotional means rather than through rational sign systems and language. This queer knowledge is often sexual in nature; it also has a queering force that challenges one's epistemology; it cannot be articulated or communicated to others through conventional means. The narrative is filled with omissions, obfuscations, and utter denial in representing exactly what this queer/ing knowledge entails. When a character does try to explain the horror associated with it, secondary readers/listeners experience symptoms of terror, nausea, and "queerness." In fact, the word "queer" (or a variation of the word) appears sixteen times over the course of this brief novel. While the term mostly connotes strangeness and unease during the fin de siècle, it also relates to the emerging association of "queer" with deviant or non-conforming sexuality and gender performance and works to reinforce the deconstructive, destabilizing verb use we see today.

As discussed above, Pan/Helen bring a queer knowledge that is physical and sensational - an irrational, primal one focused on sexuality and emotion. The basis for the encounters between mortals and Pan or Helen are evidently sexual and sometimes victims are lured through sensory means. For example, Herbert tells his old college friend Villiers how he 
met Helen and what drew him to her. At an evening party in London, Herbert overheard a young "English-Italian" woman from Florence (as she tells people) serenading her listeners. He heard "above the hum and babble of conversation a voice, which seemed to thrill my heart. She was singing an Italian song, I was introduced to her that evening, and in three months I married Helen" (Machen 198). Interestingly, siren-like singing is also a trope utilized by Marsh's The Beetle in which the "Woman of Songs" seduces Lessingham through her music. While this will not be discussed here, it may indicate the view that music can tap into a person's emotions or subconscious in a particular, effective way; however, it also suggests anxiety about the destructive power music can have on an audience, especially as it is linked to "foreign" women and sexuality.

Machen's novella is filled with instances of characters that cannot (or will not even attempt to) describe their experiences and newly acquired queer knowledge. While Gothic novels frequently use the trope of the unspeakable to allow readers to use their own imaginations to supply the terror, The Great God Pan is littered with such omissions. Hurley notes, "Narrators suffer aphasia and breakdown; the text and its interpolated texts are ruptured by narrative gaps, elisions, and outright refusals. There's a compulsion to represent, as the almost obsessive proliferation of interpolated manuscripts indicates, but at the same time the novel abjures utterance" (Gothic Body 48). While Hurley discusses this narrative strategy in terms of a psychoanalytic reading about Freud and hysteria, it can also be interpreted as an indication of Pan's knowledge as being unrepresentable through language. Such a force has the ability to interrogate the notion of epistemology: it reflects the anxiety that there are simply some forms of knowledge that we cannot approach or conceive of through our traditional epistemological methods - or even a hybrid version of them-whether those methods are scientific, occult, 
religious, modern, ancient, etc. In the end, ways of studying or thinking about knowledgeepistemology—are necessarily based on text and language.

When Villiers first hears about Helen after running into his friend Herbert begging on the street (Helen has stolen her husband's fortune and disappeared), Herbert is unable and unwilling to fully describe his story. He mentions his wedding night and Helen on the bed talking: "she spoke in a beautiful voice, spoke of things which even now I would not dare whisper in blackest night" (Machen 198). Herbert asserts that Villiers "can have no conception of what I know" [...] of what I have heard—and seen. Yes, seen; I have seen the incredible, such horrors" (198). He declines to tell Villiers more as "you would never know a happy day again" and would be a "haunted man" (199). Herbert infers that Helen is not human ("Only human beings have names") and ends his story abruptly: "I can't say any more. Good-bye" (199).

Likewise, Meyrick is unable to speak about his experiences with Helen in Buenos Aires; instead, he relies on his artwork to portray his experiences and queer knowledge. The doctor treating him tells Austin that Meyrick never spoke about what caused his illness (and eventual death) (227). Villiers tells Austin about a man from Soho ${ }^{100}$ (where Helen had previously lived and continues to visit). He was "no great Puritan" and "shuddered and grew sick in telling me of the nameless infamies which were laid to her charge" (223). The reader is unable to tell to what extent the man could reveal details of the "nameless infamies" (or what role the man may have played in them), but evidently Villiers is unable or unwilling to describe them to Austin (or the reader); he only suggests examining Meyrick's drawings, which seem to confirm the existence of Bacchic orgies, including satyrs, as part of Helen's "entertainment." A doctor who witnessed Helen's death transformation similarly cannot fully reveal what he has witnessed in the presence

\footnotetext{
${ }^{100}$ Soho was generally considered to be at the lower end of the social scale in London at the time; it was known for its slums, immigrant population, and was often associated with crime, debauchery, and general immorality.
} 
of Pan's queering power. Dr. Matheson's manuscript contains multiple moments where "[Here, the MS is illegible]" and other instances that he "will not further describe" (229). Karschay argues that the pattern of unspeakability seen in the narrators (particularly those bachelor gentlemen with whom Helen has had sexual relations) recurs because to speak of them would "make[] the gentlemen complicit in Helen Vaughan's crimes" (111). This potential culpability reaffirms the queering influence of Pan that complicates their status as "victim." The silences in the text, however, also represent how Pan/Helen provides a knowledge that is beyond rationality and epistemology themselves. Pan's knowledge is irrational, sensory, emotional, and physical; it cannot be truly understood or expressed in terms of language. It is, indeed, a horrifying world beyond epistemology.

\section{Queer/ing Knowledge and Epistemology: Occult Explorers}

"Occult explorers" (and/or occult scientists) found in $19^{\text {th }}$-century Gothic literature are described by De Cicco as "hybridized figures, practitioners and repositories of queer, liminal sciences and fields of knowledge," who, for example, seek queered epistemologies in unstable disciplinary positions such as between "alchemy and chemistry," "transcendental medicine" and neurosurgery, and "parapsychology and psychology" ("More than Human" 8). They "force readers to confront the same uncomfortable void between reason and faith, the rational and irrational, that as occult explorers they have attempted to bridge through supernatural means" (De Cicco, "More than Human" 8). While Dr. Raymond would be considered an occult explorer/scientist, he is discussed above in regards to the experiment; thus, the following will focus on Clarke and Villiers, educated London bachelor gentlemen who feel the allure of the occult and act not only as enthusiasts in occult matters, but also as amateur detectives on the hunt for the mysterious, destructive Helen. 
Machen's use of physiognomy regarding "occult explorers" (such as Clarke and Villiers) in The Great God Pan reflects a queering of epistemology. Since physiognomy involves reading a person's character or inner self by his outward physical appearance (especially his face), this concept connects Pan's victims to the occult explorers who attempt to read them. Robert Mighall notes the similarities between Pan and Oscar Wilde's The Picture of Dorian Gray (1890). Both fin de siècle Gothic texts utilize an "epistemological framework" that "relies heavily on physiognomy to represent moral meaning" (200). Mighall calls physiognomy the "privileged language" in these texts because what cannot be communicated through language is instead written on the body: the "victim's face serves as a locus of knowledge about [to quote Villiers in reference to his friend Herbert] 'scenes of evil beyond the power of words"' (200). While the horrifying encounters with Pan/Helen experienced by various characters do impact them physically, the queering, uncanny effects on the occult explorers attempting to read such bodies undermine the reliability of this way of knowing.

When Villiers happens upon Herbert begging, he initially describes a "face altered and disfigured by poverty and disgrace," a weakened man wearing "evil-looking rags" (196-97). As Herbert tells his story, Villiers realizes that it is not merely "poverty and disgrace" that have left their marks upon his body: it has been his association with Helen Vaughan, the woman he married and who has since left him destitute. Herbert alludes to the horrors he has seen and heard (and, by implication, experienced) with Helen which, within a year of marriage, left him a "ruined man, in body and soul,--in body and soul" (198). Villiers asserts that it was "not [Herbert's] poor rags or the marks which poverty had set upon his face, but rather an indefinite terror which hung about him like a mist" (199). Villiers also recognizes that Herbert is not a mere victim, but had actively participated in his own downfall: Herbert admitted that "he himself 
was not devoid of blame" as Helen had "corrupted him body and soul"; "Villiers felt that this man, once his friend, had been an actor in scenes evil beyond the power of words. His story needed no confirmation; he himself was the embodied proof of it" (199). Villiers thus uses Herbert's physical appearance as a way of knowing that which Herbert could/would not explicitly describe. Encountering Herbert also physically influences Villiers. He sees a hauntedness on Herbert's physiognomy that in turn haunts him: "when I looked in his face I knew he was speaking the truth. There was something about the man that made me shiver [...] when he was gone I gasped for breath. His presence seemed to chill one's blood" (204). His "presence" is therefore haunting and powerful and has apparently even turned his clothes "evil-looking." Pan/Helen's influence has also affected the physiognomy of other gentlemen. Villiers runs into Crashaw late one night emerging from Helen's (alias Mrs. Beaumont) house. When he looks at Crashaw's face, he turns and runs all the way home. He explains that Crashaw's face reflects "an infernal medley of passions" including "furious lust, and hate that was like fire, and the loss of all hope and horror that seemed to shriek aloud to the night, though his teeth were shut; and the utter blackness of despair" (220). Villiers asserts that Crashaw's eyes reflected "a lost soul" and even though his "outward form remained," "all hell was within it"; Crashaw "no longer belonged to this world; it was a devil's face that I looked upon" (220). Interestingly, Villiers interprets Crashaw as having been so corrupted that he is supernaturally transformed beyond the state of human: he is essentially described as being possessed by a demon. Within hours, Crashaw hangs himself. Another unnamed gentleman also exhibits physical signs of Pan/Helen's corrupting influence. Found dead outside Helen's home, a doctor at the inquest tells Austin that the victim "died of fright, of sheer, awful terror; I never saw features so hideously contorted in the entire course of my practice, and I have seen the faces of a whole host of dead" 
(202). Austin also notes the doctor's inability to speak on the subject further as he "couldn't get anything more out of him" (202). Witnessing the destructive influence of Pan on someone else leaves even the doctor at a loss for words.

These characters queer the distinction between body and soul (or mind or will) by their physical "embodiment" of what they have experienced; their internal feelings of terror and lust, for example, are visible on their faces. They have also been physically altered by their surroundings and interactions with Pan/Helen. This relates to Sara Ahmed's discussion of queer phenomenology. Ahmed argues for the usefulness and ethics of a "queer phenomenology," one in which a disorienting experience allows us to be reoriented by our surroundings and redirect "our attention toward different objects, those that are 'less proximate' or even those that deviate or are deviant" (3). Rather than an immediate attempt to reorient ourselves, such a phenomenology would actually "function as a disorientation device; it would not overcome the 'disalignment' and would instead allow new, oblique angles to emerge in our worldview"; it would encourage "those whose lives and loves make them appear oblique, strange, and out of place" $(172,179)$. While such an approach is considered liberating and even moral in the $21^{\text {st }}$. century, Machen's attitude toward such a "queer phenomenology" is clearly negative. The queer influence of Pan/Helen is lethal, contaminating, contagious, and destructive to society at large. Machen's approach to the physiognomy of his characters and how others read and react to such faces reflects his conservative Victorian viewpoint. Rather than conceiving of bodies as distinct from their environs, Ahmed notes how the body "is affected and shaped by its surroundings: the skin that seems to contain the body is also where the atmosphere creates an impression" (for example, goose bumps) (9). She argues, "Bodies may become orientated in this responsiveness to the world around them, given this capacity to be affected" and thus the body is not 
disconnected from "exterior" dwellings—it is shaped by them, too (9). Pan/Helen's victims are queerly oriented from their encounters but the impact is destructive and haunting; in turn, they also provoke negatively queering responses in those who try to read their bodies.

Karschay notes how occult scientists/detectives in texts such as Strange Case of Dr. Jekyll and Mr. Hyde and The Great God Pan attempt to utilize the "science" of physiognomy in their "detective quest for the degenerate Other"; however, instead of the attempt validating the practice as effective, it is proven "unproductive of epistemological certainty" (87-88). When they "read" Helen's face (as well as those of her gentlemen "victims"), the occult explorers feel an uncanny connection of "rapport" between "normative subject and the degenerate transgressor" (88). Karschay recognizes how they "register Helen's influence on the features of her victims"; nevertheless, while this may seem to be an effective epistemology in the absence of linguistic evidence, he disagrees with Mighall's proposal that physiognomy is an effective, "privileged language." Rather, the "sight/site" of the men's bodies does not "dispel the sense of ineffable terror" that Helen provokes and instead, "the story legibly written on these contorted faces merely augments the unspeakable mysteries at the heart of the novel and does nothing to account for the strangeness" of Helen's visage (Karschay 100). An epistemology based on physiognomy is thus queered here and made rather ineffectual in providing useful knowledge. The experiences and surroundings of those affected by Pan/Helen do impact their bodies, but this is unable to be properly read by others. Instead, it produces an uncanny feeling in the detectives; if they identify in certain ways with what they observe, reading the Other's body does not provide epistemological certainty as it reveals a connection or complicity in the viewer with the corruption being observed. 
Pan's queering influence also exerts itself through emotion and indescribable feelings for not only victims, but also for the occult explorers. This influence occurs through direct contact with Helen (or Pan himself) but also through indirect means such as when Villiers tours Helen and Herbert's (since abandoned) house in London. In turn, such encounters provoke a corporeal, visceral response. Villiers tells his friend (and fellow "occult explorer") Clarke that the house (described by one man as having "the most unpleasant physiognomy he had ever observed," 200) had a peculiar effect on him—one he struggles to relate. Upon entering, Villiers "noticed a queer, heavy feeling about the air of the house [...] I can't describe it to you, but it seemed to stop the breath"; there was "something strange" about the house and Villiers states, "I couldn't define it to you, I only know I felt queer" (205). One particular room—one that likely held the deviant orgies-felt "full of horror." Villiers feels he is about to faint: his teeth grind, "limbs tremble," and his "heart beat as if [he] were at the hour of death" (205). Villiers "couldn't stay in the room" as it was "overpowering" and when he emerges from the house, his staggering prompts onlookers to assert that he was drunk. Villiers is bed for a week and his doctor attributes his collapsing physical state to the result of "nervous shock and exhaustion" (205). Villiers explains to Austin that the house's influence was "more physical than mental. It was as if I were inhaling at every breath some deadly fume, which seemed to penetrate to every nerve and bone and sinew of my body. I felt racked from head to foot, my eyes began to grow dim; it was like the entrance of death" (209).

Clarke also exhibits a physical response to an ink portrait of Helen-particularly because he recognizes the resemblance to Mary, whose transformation he had witnessed. Her image evokes a memory of many years before (about 24 , based on Helen's age when she dies) of when Mary "saw" the god Pan. Clarke's "heart grew cold within him," his voice becomes "dry and 
hoarse," and he turns "white as death" (207). Clarke "shuddered before [the sketch] in his inmost soul," fell back in his chair and groaned. He later tells Villiers to burn the portrait and "never give it another thought $[\ldots]$ or you will be sorry" (209). He admits that his own knowledge is "horrible enough" and "beyond my knowledge there are depths and horrors more frightful still"; he will not pursue the inquiry any further (209). Such experiences (what Hurley would likely call "hysterical"101) reveal not just the affect and physical responses to Pan's force, but also the ways in which Pan's "knowledge"-what is behind the veil—is indescribable and beyond language. Thus, the possibility of an epistemology in relation to Pan, even a queered one, is challenged.

Remarkably, while Clarke shuns this particular occult pursuit (despite the significant damage Helen is causing not only in London, but also worldwide), he has been seduced by occult inquiries throughout his life. Since witnessing Dr. Raymond's disturbing experiment, Clarke explains that he had tried to avoid "all occasions of occult investigation" (190). Ultimately, however, he cannot avoid his obsession. He uses erotic terms to describe his passion for occult knowledge: "he still pined for the unseen" and soon "the old passion began to reassert itself" as the frightening memories of Mary fade. He claims that the "temptation to relax in the evening was too great," and he would soon find himself "casting glances of warm desire" toward the bureau which held his research. He admits, "lust always prevailed"; "his sole pleasure was in the reading, compiling, arranging, and rearranging what he called his 'Memoirs to prove the Existence of the Devil,' and engaged in this pursuit the evening seemed to fly and the night appeared too short" (191). This lust is perhaps not so different from the passions felt by Helen's "suitor" victims. Karschay argues that "Clarke's familiarity with secret transgressions exceeds

\footnotetext{
${ }^{101}$ See The Gothic Body, 46-49. She argues, "To assert that something is too horrible to be spoken of is the privileged utterance of the Gothic, but it is also the privileged utterance of the hysteric"; Freud's precondition of hysteria, she asserts, is a sexual disturbance "so intolerable that it must be repressed" and thus the "forces of repression at work ensure its unspeakability" (Hurley 48).
} 
the merely theoretical" (113). Clarke experiences a strange reverie while at Dr. Raymond's: he envisions a moment in the woods near his family's home during the heat of summer where, for a moment, "he stood face to face there with a presence, that was neither man nor beast, neither living nor dead, but all things mingled, the form of all things but devoid of all form" (Machen 187). (Notably, this scene foreshadows Helen's devolution later in the novella.) However, the reader is unable to tell whether this is merely a dream or is in fact a memory. Karschay thus argues that "Clarke's own past might harbour more dark secrets than the novel openly avows" and this potentially shady past functions to interrogate the "integrity" of the novella's

"supposedly normative characters" (113). Like the cold and unethical Raymond or Villiers-who buys a noose and effectively plans (and elicits) Helen's own suicide by locking her in a room with it - Clarke too is queered away from a singular status as hero, victim, or objective investigator.

\section{Queer/ing Knowledge and Epistemology: Helen, femme fatale}

In Machen's novella, the queering force of Pan is most frequently and visibly viewed through his demi-god daughter, Helen. Helen is not only queer herself (in multiple ways), but exhibits a disruptive influence on those around her; she deconstructs knowledge and epistemology, as well. Helen's queerness is affirmed very early in The Great God Pan when the reader learns of her (strongly implied) sexual relationship with young Rachel. We know that Helen has been seen "playing on the grass with a "strange naked man"” (193) in another rather ambiguous encounter with a seven-year-old boy. As Helen matures, she extends her sexual encounters beyond children and her "father" (if we read the naked man as Pan himself, an interpretation supported by the boy's horrified recognition of his countenance later in the Roman faun statue). She seduces young bachelors around the world and exposes them to various forms 
of sexual deviancy including, at the least, the Bacchic orgies of old that involved fauns, satyrs, and Ægipans, and 1,000-year-old wine (which "seems rather antiquated for a beverage, doesn't it?" remarks Austin, 211). Helen's sexual relations with male and female, child and adult, human and supernatural, and her sexually deviant and excessive practices within such liaisons mark her as particularly "queer."

Her liminality and hybridity also reflect her queerness. Her physical features are "of a very different type" than the other Welsh residents with the "strongly marked" face of a "somewhat foreign character" (192); her "olive skin" has an "almost Italian appearance" (195). Herbert describes her as "a girl of the most wonderful and most strange beauty" (198). Austin remarks that she is called "very handsome" yet "there is something strange about her face which I didn't like. The features are exquisite, but the expression is strange"; he also senses a "familiar" feeling of uncanniness (217). Helen is a hybrid subject: Hurley describes her as "a daughter of a human woman, a nonhuman force, and experimental neurosurgery" (Hurley, "British Gothic" 191) and De Cicco asserts that she is a "manifestation of Pan in human form" ("Queer God" 61). She is a demi-god, both of this world and otherworldly. Clarke recognizes this about Helen from reports of her childhood and in his "Memoirs to prove the Existence of the Devil," inscribes in Latin: "And the devil was made incarnate. And was made man" (196). ${ }^{102}$ She is both a product of forbidden knowledge and acts as a medium to that knowledge as she connects humans with Pan's supernatural world of unspeakable, irrational sexual excess and deviancy. Lovatt recognizes Helen's queering power: as "femme fatale, Helen is a catalytic figure, less of a stable archetype than a protean, dynamic element" (27). Additionally, Helen possesses elements of

\footnotetext{
${ }^{102}$ Luckhurst notes that this is a "blasphemous rewriting" of an early Christian proclamation: "By the power of the Holy Spirit he became incarnate from the Virgin Mary, and was made man" (Late Victorian 279). This reinforces Machen's inversion of the "immaculate conception" theme.
} 
androgyny and deconstructs traditional notions of gender/roles. She is "physically female, but imbibed with the dark powers of a male Pan" (De Cicco, "Queer God" 63) and "reveals in destructive form the New Woman's aim to seek masculine reward for masculine qualities" (Sparks 120).

Helen's shocking devolution into the abject after her suicide similarly reaffirms her queered, destabilized essence. Additionally, Marsh's Priestess of Isis/Beetle exhibits this metamorphic and essentially structure-less body. The Great God Pan, however, witnesses Helen's transformation into viscosity with much more detail. Dr. Matheson, who observes her devolution, describes it with horror and nausea: "the structure of the human body that I had thought to be unchangeable, and permanent as adamant, began to melt and dissolve" as "some internal force $[\ldots]$ caused dissolution and change" (228). He "saw the form waver from sex to sex, dividing itself from itself, and then again reunited" (228). Helen defies not only categories of gender, but also of species. Dr. Raymond is unsurprised by "the hideous form upon the bed, changing and melting before your eyes from woman to man, from man to beast, and from beast to worse than beast" (232). Hurley argues that the "admixed, fluctuating, abominable" abhuman Gothic body has the capability of "mimicking" the human form that further threatens the "integrity of human identity" ("British Gothic" 190). Byron suggests that Helen is not an absolute villain, however; after all, her mother's exposure to the "full force of the unconscious" indicates that "Helen seems to have been born without any social or psychic restraints upon her primitive desires" ("Gothic" 137). Helen is therefore a queered antagonist; her culpability is allayed by an inherited sense of amorality, as opposed to immorality. 
Helen has a queering effect on people (and objects ${ }^{103}$ ) around her. Onlookers often feel an inability to accurately characterize her: one man "positively shuddered as he tried to describe the woman, but he couldn't tell why" (Machen 202). "Every one who saw her at the police court," remarks Austin, "said she was at once the most beautiful woman and the most repulsive they had ever set eyes on" (202). De Cicco recognizes that in Helen's presence, "pigeonhole conceptions like beauty or ugliness lose significance" ("Queer God"63). Helen certainly provokes contradictory reactions within those she encounters; besides attraction and repulsion, she continuously evokes terror and desire. This might make her a quintessential representation of the Gothic by Halberstam's definition (which is to evoke fear and desire in the reader, Skin Shows 2). Helen's queering involves the "collapse of traditional modes of interpreting and regulating conceptions of time, species, gender, sexuality, the body, and human nature itself" (De Cicco, "Queer God" 62).

Helen's queering effect further extends to knowledge and epistemology. She evidently provides a queer sexual knowledge - an emotional, sensational knowledge beyond logic and language. Her deconstructive influence on traditional, rational forms of knowing are apparent throughout the novella as the text moves closer to "Fragments" (the title of the last chapter and a descriptor for its contents—bits of manuscripts and letters). De Cicco notes Helen's impact on sign systems: "rational comprehension and conventional means of communication, like speech and writing, break down in the face of transmutations" ("Queer God" 63-64). Hurley acknowledges that an epistemology like the one embraced by T. H. Huxley focused on materialism: "matter subjected, provisionally, to the contingency of forms" (Gothic Body 31). However, The Great God Pan deconstructs the binary associated with such a system, reversing

\footnotetext{
${ }^{103}$ For example, Herbert's clothing and her house on Paul Street.
} 
the hierarchy of form and matter. Because matter is "intransigent" and resists containment, form is "shifting, variable, revealing itself as 'structurality' (a tendency towards shape and meaningfulness) rather than structure (a stable ordering of things)" (Hurley, Gothic Body 31). Importantly, we never hear Helen's voice in Machen's tale (or any woman's, in fact), not even second hand or through a manuscript or letter. Victoria Margree and Bryony Randall posit that "the silence of the central female character is part of the text's misogyny" (which is a valid claim). However, it may also serve to reinforce the concept that she represents a queered epistemology beyond understanding and language.

Machen's Pan serves as the ultimate queer/queering force-one that is horrifying and destructive in an anxious fin de siècle Victorian world. His interpretation of Pan is exceptionally dark, dangerous, and chaotic, revising the more innocuous symbol of nature frequently adopted by the Romantics. Raymond's endeavor to "see" Pan-his quest for forbidden knowledgeresembles in many ways what other late Victorian Gothic authors such as Haggard, Stoker, and Marsh were addressing: epistemological undecidability and anxieties about the superiority of Western knowledges. Raymond's research blends the occult and science and queers epistemologies. For example, his experiment questions the Cartesian duality of individuals while also seeming to maintain the notion of a separate soul or spirit. Machen's Pan is subversive and destructive, disrupting everything it encounters. His "victims" are introduced to a queer knowledge - a physical and emotional one that exceeds rationality. Direct contact with Pan (effected by Raymond's neurosurgical method) leads to immediate insanity with death following shortly after. Indirect contact, initiated via demi-god Helen, also destructively alters a person, both psychologically and physically, although with less immediate force. Pan/Helen's power can change or mark the body but its uncanny effects undermine the ability for the viewer to rely on 
such an epistemology. The queering influence of Pan/Helen enervates bodies and leads people to suicide; there is also evidence that it may induce an affinity for risky sexual deviancy. Newly acquired paraphilias (particularly asphyxiophilia) tend to lead Machen's characters away from le petite mort and toward la mort grande.

Helen serves as the earthly version of Pan and his subversive potential. She is queer in virtually every way, the product of science and the supernatural, god and mortal, a kind of devil incarnate. She is liminal and hybrid, defying any kind of category or boundary. Her gender, race, nationality, sexuality, and species are all unfixed. Her instability, in turn, has a disorienting effect on others and complicates their capacity to comprehend and communicate experience. Confronting Helen produces aphasia. Whether a character is sleeping with Helen, observing or investigating her, or even exploring her "haunted" house, her queering force evokes a disorienting effect in which characters sense strong emotions/feelings. They may feel strangeness, uncanniness, nausea, terror, lust, or fury, but they lack the ability to understand their experiences or communicate them to others. Pan/Helen's influence produces a knowledge that is extra-discursive-beyond language. It is most often connected to a sense of fear and desire and may be akin to what Žižek refers to as the Real. Žižek reworks the "Lacanian concept of the Real as 'the irreducible kernel of jouissance that resists all symbolization' $[\ldots$,$] an experience of$ shattering that lies outside the field of representation," explains Benjamin Noys. Pan's queering essence is like the Real, the attractive but threatening ineffable which lies outside the Symbolic order of language and culture. Machen's characters who approach the Real are unable to bear it and suffer madness and death.

The Great God Pan suggests that Pan's queering force, which is hidden behind the veil, should be kept shrouded. Its power disrupts knowledge beyond comprehension and is in fact 
queered to essentially exceed the possibility of an epistemology. Such a knowledge cannot be rationally understood or analyzed; one can merely exist in such a world. What Pan does, then, is represent a queer phenomenology. His force disorients those who encounter it and reshapes their worldview. Such a disorientation, in Machen's world, does not offer the kind of positive outcomes Ahmed alludes to such as liberation, empowerment, or an openness to new and productive possibilities. In a $21^{\text {st }}$-century world, she advocates for queer/ing phenomenology and embracing "moments of disorientation." She argues that "if we stay in such moments then we might achieve a different orientation toward them; such moments may be the source of vitality as well as giddiness. We might even find joy and excitement in the horror" (4). Machen's fin de siècle viewpoint is extremely pessimistic, however, and thus his queered phenomenology has a dangerous effect not only on individuals, but also on society at large. Luckhurst argues that Machen "overloads the reader with materialist and extraordinary science, traditional and new forms of supernaturalism, using the Chinese-box structure of tales to undermine the certainty of any one system of meaning" (Invention 201). The Great God Pan does certainly illustrate epistemological anxiety. It questions the perceived hierarchy of knowledges and ways of knowing. However, it also implies a more fundamental threat: a terrifying world beyond language, beyond epistemology. It is a place where one exists without meaning, without even a sense of identity or orientation. While queerness today offers the possibilities of empowerment and an alternate, ethical worldview, Machen's 1894 novella can only envision the queer as producing horrifying chaos and devastation. 


\section{$* * * * * *$}

This analysis has attempted to delineate how the surface anxieties of late-Victorian Gothic texts— "reverse colonization" or "reverse mimicry," miscegenation, the New Woman and challenges to conventional gender norms, homosexuality and other sexual "deviancies," sexually transmitted diseases, the powerful knowledge held by the colonial or ancient Other, and so on—overlay a more fundamental anxiety about epistemology. While concerns about whether the West's knowledges were in fact superior and their values "universal" were not always visible (or even conscious), the Gothic provides a space to substantially explore and represent those underlying or subconscious anxieties. Victorians were troubled not only by the powerful knowledges held by other cultures and the Westerner's inability to understand or master such knowledge, but also by whether they (we) can know anything for certain. When met with alternative knowledges, particularly in a context of colonial cultural exchange, Westerners felt undecidability. For a culture so fixated on science, technology, and progress, even to the point of scientizing the occult and spirituality, a force beyond epistemology is what most deeply troubled late Victorians.

Rider Haggard's She: A History of Adventure delves into many kinds of esoteric knowledges ostensibly held by foreign or ancient Others. At the center of his novel is the search for immortality, exhibited by the Cambridge men's quest for Ayesha in Africa and her rare secrets and powers. Haggard also includes references to or motifs of reincarnation, mesmerism, telepathy, and reanimation. She portrays several anxieties about Western epistemology and the imperial mindset including whether positivistic or empirical epistemology is adequate for explanations to natural and philosophical inquiries, if the Other's knowledge may, in fact, supersede Western knowledge, and whether Europeans can even understand or coopt the 
powerful knowledge of the Other. Her unexpected destruction at the novel's climax illustrates the undecidability felt when Westerners-especially those in colonial contexts-encounter the power of the Other's knowledge (for Ayesha, this is the superior authority of Egypt, symbolized through a curse). Additionally, as suggested by John Lamb, Ayesha is a metaphor for Victorian epistemology. She is confident in her knowledge and is quite successful for a time, both in her mastery of the knowledge and her ability to apply it to an imperial context to retain authority. However, the limits of her epistemology are made painfully clear when she steps into the Pillar of Fire and rather than renewing her youth and immortality, her age ascends upon her and she perishes in humiliation. Thus, while she begins with an epistemological confidence, her certainty erodes, falls apart, and she ultimately meets destruction. ${ }^{104}$ The assuredness of an imperialist's knowledge, while displaced onto a somewhat "Orientalized" white femme fatale, is nonetheless revealed to be both arrogant and foolish.

The Beetle, by Richard Marsh, also challenges the superiority of not only Western knowledges, but also the supposed "inherent" rationality and logic of the standard British gentleman. Marsh's novel alludes to anxieties about sexually transmitted diseases being spread via prostitutes in colonized regions, particularly syphilis, a rather gruesome, debilitating, and incurable disease at the time. This affliction was sometimes utilized dramatically in fiction or popular culture because of its tendency to cause insanity in its latter stages. While the novel arguably advocates for the conservative enforcement of CDAs in colonial regions to "protect" the many British soldiers and tourists abroad, it also illustrates a deeper anxiety about undecidability and even hybridity. Communicable diseases, by their very nature, reiterate the uncertainty of boundaries: bodies, like other boundaries, are not impervious or stable. They are

\footnotetext{
104 John Lamb, in discussion with the author, April 10, 2017.
} 
porous and changing and Marsh represents this deconstruction through the interpenetrating experience of sexual exchange between Britons and Egyptian women (or supernatural Egyptian entities). Such encounters may lead to literal or imagined contamination, resulting in irrational states. The Beetle suggests that irrational conditions ensuing from such exposure reveal not only the dangers of consorting sexually with foreign peoples, but also the susceptibility of the Westerner's supposed superiority in terms of knowledge and logic. The lapses and ambiguities in the novel's plot, narrations, and ending are evidence of this concern about whether Westerners can truly understand, master, or refute the Other's knowledge and power (sexual or otherwise), and retain sanity and logical reasoning.

Bram Stoker's The Jewel of Seven Stars focuses on an "amateur archeologist" who specializes in Egyptology. Trelawney's research has led him to believe that he can carry out the wishes of an ancient Egyptian queen to be reanimated. He embarks on a "Great Experiment," which attempts to fuse science and technology with ancient Egyptian science and occult knowledge. The endeavor is ultimately disastrous (at least, in the original 1903 edition) as it kills those involved in the experiment (excluding the narrator). The "success" of resurrecting the queen remains unclear, however, as she is at least momentarily reanimated but soon disappears mysteriously. While this clearly warns against the Westerner's appropriation or "hybridization" of the foreign/ancient knowledge of the Other, it also reveals another anxiety for Victorians: the potentially subversive and dangerous influence of the colonized "mimicker." Trelawney's daughter Margaret is at least partially possessed by Queen Tera and she seems to urge Margaret to guide Margaret's cohorts to their downfall by carrying out the Experiment. While Trelawney's "reverse mimicry" (his attempts to master and utilize the doxai knowledge of ancient Egypt) is critiqued, the "reverse colonization" exhibited via Margaret's possession by Tera is also 
negatively portrayed. Tera's damaging control over Margaret (which leads to not only Margaret's death, but her father's and others') is a kind of menacing mimicry. Imperial contexts inevitably created such anxious situations in which subjugated colonized peoples attempting to support or imitate the colonizing rulers inevitably might be mistaken for "mocking," rather than genuinely "mimicking," their oppressors. Stoker shows that the "hybridization" of Margaret and Tera is dangerous not only in his original, bleak version of the novel, but also in his 1912 revised edition in which the Experiment "fails," nobody dies, and yet Margaret seems oddly influenced by and amalgamated with Tera's soul. The ambiguity of both endings reflects Stoker's anxiety about epistemology and knowing anything for certain. While hybridity is viewed rather differently and in a more positive context in contemporary postcolonial criticism today, Stoker's work suggests that hybridity ultimately subverts and is threatening to the West's authority and thus his novels' endings end in either absolute pessimism or a looming sense of potential mayhem.

The central characters in the first three novels discussed have been essentially attempting to acquire and utilize - perhaps through queering or hybridization with their own epistemologies - the knowledge of the foreign or ancient Other. Arthur Machen's The Great God Pan also initially attempts this endeavor through Dr. Raymond's surgical experiment. However, what Raymond and other characters discover is not only that the Other can possess a knowledge inaccessible to the contemporary Westerner, but also that the enlightenment attained via such quests for forbidden knowledge may engender a potentially lethal outcome. Even though Raymond's subject, Mary, "sees" Pan, she is immediately turned insane and cannot relay her knowledge through words or other sign systems. Her infernal daughter, Helen, also causes irrationality in those she surrounds herself with and leads many British gentlemen to madness 
and suicide. The "epistemology" of Pan has thus been queered beyond rationality and language and presents itself rather as a phenomenology. Pan's knowledge is based on chaos, irrationality, emotion, sexuality, and the body. Due to its clear danger and its lack of logic or language (also reiterated by the novella's frequent failure to speak and its "obfuscating rhetoric"), Machen suggests the late-Victorian fear of a world beyond epistemology itself. Here, it is not merely that another culture possesses a more powerful knowledge, but rather that a world beyond language and rationality exists. The disorienting power of Pan's queer phenomenology is not depicted as potentially empowering as it might be today; rather, Machen's pessimistic depiction displays a world without meaning, identity, or any kind of orientation. The queer and its queering abilities must be ultimately portrayed as threatening and a catalyst for chaotic destruction.

What the final chapter on The Great God Pan suggests, then, is not merely an anxiety about the superiority of Western epistemology or whether Westerners can, in fact, understand and/or coopt powerful knowledge of the foreign or ancient Other, but also about the limits of epistemology and encountering the Real. Even though Machen's novella is not ostensibly about $19^{\text {th }}$-century British imperialism, it nonetheless serves as an important text that overtly interrogates Britain's own cultural (Greco-Roman) tradition. If Egypt is the cradle of civilization, it is a significant culture but still somewhat distant to Victorian Britons (not least because of the Muslim Arab occupation that had begun centuries before in 641 A.D., which perhaps created a more substantial "barrier" in the minds of Europeans in terms of both religion and race). ${ }^{105}$ The focus on Greco-Roman history and mythology in Britain suggests a deeper interrogation, one closer to "home." What the motif of seeking-forbidden-knowledge-gone-awry in late-Victorian Gothic texts reveals is that Victorians were not merely anxious about the knowledge of women

\footnotetext{
${ }^{105}$ Interestingly, both Stoker and Machen set their experiments in Wales, the first "internal" region colonized by England in the $16^{\text {th }}$ century.
} 
or colonized peoples or ancient Egyptians or Greeks, etc., but what Lacan calls the "Real," a term reconceived by Žižek. Despite the surface anxieties and the concerns about epistemology, the foundational worry is that there is a residual Real that cannot be known. Psychoanalytic critic Ian Parker describes the Real as a "traumatic kernel of our being," the "limit of our representation of the world" (59), and when we "touch the real we come up against a limit to what can be said" (64). At the end of a science-focused century, the notion that Victorians may encounter something outside of knowledge and sign systems entirely is particularly disturbing; they fear that they have reached the limits of scientific positivism. The fact that all the "monsters" of these stories end in slime, dust, or apparition is significant. As recognized by Dennis Allen, for Žižek, the monster in horror fiction always represents the Real—the "Thing" that does not fit into reality or our typical Symbolic system; s/he is always threatening from the outside. We cannot truly see the monster because, by definition, it cannot be represented; the closest that we can come to a symbolic representation of the imaginary Real, for Žižek, is slime. ${ }^{106}$ Thus, this concept helps to explain the underlying anxiety exhibited by late-Victorian Gothic texts: not merely the fallibility of Western knowledge or Europeans' inability to master the Other's knowledge, but the existence of the Real buried underneath our Symbolic realm of language and rationality - a place beyond even the queer — one that lies beyond the veil of representation.

${ }^{106}$ Dennis Allen, in discussion with the author, April 18, 2017. 


\section{Works Cited}

Addy, Shirley M. Rider Haggard and Egypt. Accrington, England: AL Publications, 1998. Print.

Ahmed, Sarah. Queer Phenomenology: Orientations, Objects, Others. Durham and London: Duke UP, 2006. Print.

Altick, Richard. Victorian People and Ideas. New York \& London: Norton, 1973. Print.

Angelides, Stephen. A History of Bisexuality. Chicago \& London: U of Chicago P, 2001. Print.

Arata, Stephen. Fictions of Loss in the Victorian Fin de Siècle: Identity and Empire. Cambridge and New York: Cambridge UP, 1996. Print.

Ashcroft, Bill, Gareth Griffiths, and Helen Tiffin. Post-Colonial Studies: The Key Concepts. London and New York: Routledge, 2000. Print.

Auerbach, Nina. Woman and the Demon: The Life of a Victorian Myth. Cambridge: Harvard UP, 1982. Print.

Ballam. J.D. "'Science as the Base of Wonders': Rational Enquiry in Bram Stoker's The Jewel of Seven Stars and The Lair of the White Worm." Restoring the Mystery of the Rainbow: Literature's Refraction of Science, vol. 1. Eds. Valeria Tinkler-Villani and C.C. Barfoot. Amsterdam and New York: Rodopi, 2011. 151-166. Print.

Bhabha, Homi. "Signs Taken for Wonders: Questions of Ambivalence and Authority under a Tree Outside Delhi, May 1817." Critical Inquiry 12 (1985): 144-165. Print.

The Bible. New English Version with the Apocrypha. Oxford UP and Cambridge UP, 1970. Print.

Bloom, Clive. Gothic Histories: The Taste for Terror, 1764 to the Present. London and New York: Continuum, 2010. Print.

Botting, Fred. Gothic. London and New York: Routledge, 1996. Print. 
Brantlinger, Patrick. "Mummy Love: She and Archaeology." She: Explorations into a Romance. Ed. Tania Zulli. Rome: Aracne, 2009. 37-57. Print.

------. Rule of Darkness: British Literature and Imperialism, 1830-1914. Ithica and London: Cornell UP, 1988. Print.

------. Victorian Literature and Postcolonial Studies. Edinburgh: Edinburgh UP, 2010. Print.

Bridges, Meilee D. "Tales from the Crypt: Bram Stoker and the Curse of the Egyptian Mummy." Victorians Institute Journal 36 (2008): 137-165. Print.

Bristow, Joseph. Empire Boys: Adventures in a Man's World. London: HarperCollins Academic, 1991. Print.

Bulfin, Ailise. "The Fiction of Gothic Egypt and British Imperial Paranoia: The Curse of the Suez Canal.” English Literature in Transition, 1880-1920 54.4 (2011): 411-443. Print.

Burdett, Carolyn. "Romance, Reincarnation, and Rider Haggard." The Victorian Supernatural.

Ed. Nicola Bown, Carolyn Burdett, and Pamela Thurschwell. Cambridge and New York: Cambridge UP, 2004. 217-235. Print.

Byron, Glennis. "Bram Stoker's Gothic and the Resources of Science." Critical Survey 19.2 (2007): 48-62. Print.

-----. "Gothic in the 1890s." A Companion to the Gothic. Ed. David Punter. Oxford: Blackwell, 2000. 132-141. Print.

Cartwright, Mark. "Pan." Ancient History Encyclopedia. 14 Feb. 2013. Web. 23 Feb. 2017.

Chrisman, Laura. "The Imperial Unconscious? Representations of Imperial Discourse." Critical Quarterly 32.3 (1990): 38-58. Print.

Colla, Elliott. Conflicted Antiquities: Egyptology, Egyptomania, Egyptian Modernity. Durham and London: Duke UP, 2007. Print. 
Cox, Simon and Susan Davies. An A to Z of Ancient Egypt. Edinburgh and London: Mainstream, 2007. Print.

Deane, Bradley. "Mummy Fiction and the Occupation of Egypt: Imperial Striptease." English Literature in Transition, 1880-1920 51.4 (2008): 381-410. Print.

De Cicco, Mark. “'More than Human': The Queer Occult Explorer of the Fin-de-Siècle.” Journal of the Fantastic in the Arts 23.1 (2012): 4-24. Print.

------. "The Queer God Pan: Terror and Apocalypse, Reimagined." Monsters and Monstrosity from the Fin de Siècle to the Millennium: New Essays. Eds. Sharla Hutchison and Rebecca A. Brown. Jefferson, NC: McFarland, 2015. 49-68. Print.

Delgado, Anne. Cosmic Plots: Occult Knowledge and Narratives of Belief. Diss. Indiana University, 2011. Print.

Doyle, Arthur Conan. The Mystery of Cloomber. 1889. London: Hesperus, 2004. Print. Driss, Hager Ben. "Closed to Oriental Heroines: Ethos of the Colonial Text." Middle East Studies Association Bulletin 36.2 (2003): 164-188. JSTOR. Web. 14 Nov. 2015.

Edwards, Justin. Postcolonial Literature. Houndmills, Basingstoke, Hampshire and New York: Palgrave Macmillan, 2008. Print.

Ellis, Havelock. Studies in the Psychology of Sex, Volume II: Sexual Inversion. 1897. Bibliobazaar, 2006. Print.

Feigl, Herbert. "Positivism." Encyclopedia Britannica. Encyclopedia Britannica Inc., 14 Mar. 2016. Web. 12 Apr. 2016.

Frankfurter, David. "Curses, Blessings, and Ritual Authority: Egyptian Magic in Comparative Perspective." Journal of Ancient Near Eastern Religions 5.1 (2005): 157-185. Print. Freccero, Carla. Queer/Early/Modern. Durham and London: Duke UP, 2006. Print. 
Garnett, Rhys. "Dracula and The Beetle: Imperial and Sexual Guilt and Fear in Late Victorian Fantasy." Science Fiction Roots and Branches. Eds. Rhys Garnett and R.J. Ellis. New York: Palgrave Macmillan, 1990. 30-54. Print.

Gilbert, Sandra. "Rider Haggard's Heart of Darkness." Reading Fin de Siècle Fictions. Ed. Lyn Pykett. London and New York: Longman, 1996. Print.

Gilbert, Sandra and Susan Gubar. No Man's Land: The Place of the Woman Writer in the Twentieth Century. New Haven: Yale UP, 1989. Print.

Glover, David. Vampires, Mummies, and Liberals: Bram Stoker and the Politics of Popular Fiction. Durham and London: Duke UP, 1996. Print.

Gordon, Joan and Veronica Hollinger, eds. Blood Read: The Vampire as Metaphor in Contemporary Culture. Philadelphia: U of Pennsylvania P, 1997. Print.

Graves, Benjamin. "'Signs Taken for Wonders': Hybridity and Resistance." Political Discourse: Theories of Colonialism and Postcolonialism. Brown University, 1998. Web. 18 Nov. 2014.

Greenblatt, Stephen, ed. "Empire and National Identity." The Norton Anthology of English Literature. $9^{\text {th }}$ ed. New York and London: W.W. Norton, 2012. Print.

Haggard, H. Rider. She. 1886. Ed. Daniel Karlin. Oxford and New York: Oxford UP, 1991. Print.

------. Ayesha: The Return of "She.” New York: Dover Publications, 1978. Print.

-----. Wisdom's Daughter: The Life and Love Story of She-Who-Must-Be-Obeyed. London: Hutchinson, 1923. Print.

Haggerty, George E. Queer Gothic. Urbana and Chicago: U of Illinois P, 2006. Print. Halberstam, Judith. Female Masculinity. Durham and London: Duke UP, 1998. Print. 
------. Skin Shows: Gothic Horror and the Technology of Monsters. Durham and London: Duke UP, 1995. Print.

Hall, Donald E. Fixing Patriarchy: Feminism and Mid-Victorian Male Novelists. New York: New York UP, 1996. Print.

------. Queer Theories. New York: Palgrave Macmillan, 2003. Print.

Harris, W.C. and Dawn Vernooy. "'Orgies of Nameless Horrors': Gender, Orientalism, and the Queering of Violence in Richard Marsh's The Beetle." Papers on Language and Literature 48.4 (2012): 339-381. Print.

Harrison, Robert T. Gladstone's Imperialism in Egypt: Techniques of Domination. Westport, CT and London: Greenwood Press, 1995. Print.

Hebblethwaite, Kate. "Introduction." The Jewel of Seven Stars by Bram Stoker. London: Penguin, 2008. Print.

Heller, Tamar. "The Unbearable Hybridity of Female Sexuality: Racial Ambiguity and the Gothic in Rider Haggard's She." Horrifying Sex: Essays on Sexual Difference in Gothic Literature. Ed. Ruth Bienstock Anolik. Jefferson, NC and London: McFarland \& Co., 2007. 55-66. Print.

Hinz, Evelyn J. "Rider Haggard's She: An Archetypal 'History of Adventure." Studies in the Novel 4.3 (1972): 416-431. Print.

Holterhoff, Kate. "Liminality and Power in Bram Stoker's Jewel of Seven Stars. ” From Wollstonecraft to Stoker: Essays on Gothic and Victorian Sensation Fiction. Ed. Marilyn Brock. Jefferson, NC and London: McFarland, 2009. 132-143. Print.

Hornung, Erik. The Secret Lore of Egypt: Its Impact on the West. Ithica and London: Cornell UP, 2002. Print. 
Hughes, William. Beyond Dracula: Bram Stoker's Fiction and its Cultural Context. London: Palgrave Macmillan, 2000. Print.

-------. "Victorian Medicine and the Gothic." The Victorian Gothic. Eds. Andrew Smith and William Hughes. Edinburgh: Edinburgh UP, 2014. Print.

Hughes, William and Andrew Smith, eds. Queering the Gothic. Manchester: Manchester UP, 2009. Print.

Hurley, Kelly. The Gothic Body: Sexuality, Materialism, and Degeneration at the Fin de Siècle. Cambridge: Cambridge UP, 1996. Print.

-------. "The Inner Chambers of all Nameless Sin': The Beetle, Gothic Female Sexuality, and Oriental Barbarism." Virginal Sexuality and Textuality in Victorian Literature. Ed. Lloyd Davis. New York: SUNY P, 1993. 193-213. Print.

------. "The Victorian Mummy-Fetish: H. Rider Haggard, Frank Aubrey, and the White Mummy." Victorian Freaks: The Social Context of Freakery in Britain. Ed. Marlene Tromp. Columbus: Ohio State UP, 2008. 180-199. Print.

Hyam, Ronald. Empire and Sexuality: The British Experience. Manchester and New York: Manchester UP, 1990. Print.

"Jean-Martin Charcot." Encyclopcedia Britannica. Encyclopedia Britannica Inc., 27 July 2006. Web. 7 Aug. 2016.

Jones, Darryl. "Borderlands: Spiritualism and the Occult in Fin de Siècle and Edwardian Welsh and Irish Horror." Irish Studies Review 17.1 (2009): 31-44. Print.

Judd, Denis. The World's First Superpower: The Rise and Fall of the British Empire from $1497-$ 1901. The Modern Scholar Series. Recorded Books, 2008. Audiobook.

Kaplan, Robert. "Syphilis, Sex, and Psychiatry, 1789-1925: Part 2." Australasian Psychiatry 
18.1 (2010): 22-27. Print.

Karschay, Stephan. Degeneration, Normativity and the Gothic at the Fin de Siècle. Houndmills, Basingstoke, Hampshire and London: Palgrave Macmillan, 2015. Print.

Ledger, Sally and Roger Luckhurst. The Fin de Siècle: A Reader in Cultural History c. 18801900. Oxford and New York: Oxford UP, 2000. Print.

LeFanu, Sheridan. In a Glass Darkly. 1872. Ed. Robert Tracy. Oxford and New York: Oxford UP, 1999. Print.

Levine, Philippa. The British Empire: Sunrise to Sunset. Harlow, England: Pearson Education Limited, 2007. Print.

-----. Gender and Empire. Oxford and New York: Oxford UP, 2004. Print.

-----. Prostitution, Race, and Politics: Policing Venereal Disease in the British Empire. New York and London: Routledge, 2003. Print.

-----.. "Public Health, Venereal Disease and Colonial Medicine in the Later Nineteenth Century." Sex, Sin and Suffering: Venereal Disease in European Society since 1870. Roger Davidson and Lesley Hall, eds. London and New York: Routledge, 2001. Print.

-----. "Rereading the 1890s: Venereal Disease as 'Constitutional Crisis' in Britain and British India." The Journal of Asian Studies 55.3 (1996): 585-612. Print.

Lovatt, Gabriel. "From Experiment to Epidemic: Embodiment in the Decadent Modernism of Arthur Machen's ‘The Great God Pan' and 'The Inmost Light.'” Mosaic 49.1 (2016): 19-35. Print.

Luckhurst, Roger. The Invention of Telepathy: 1870-1901. Oxford: Oxford UP, 2002. Print.

-------. "Knowledge, Belief, and the Supernatural at the Imperial Margin." The Victorian Supernatural. Eds. Nicola Brown, Carolyn Burdett, and Pamela Thurschwell. Cambridge: 
Cambridge UP, 2004. 197-214. Print.

------, editor. Late Victorian Gothic Tales. Oxford and New York: Oxford UP, 2005. Print.

-----.. "The Mummy's Curse: A Genealogy." Magic, Science, Technology, and Literature,

Book 3. Eds. Jarmila Mildorf, Ulrich Seeber, Martin Windisch. Stuttgart: VIT Verlag, 2006. 123-138. Print.

-. The Mummy's Curse: The True History of Dark Fantasy. Oxford: Oxford UP, 2012.

Print.

-------. "Trance-Gothic, 1882-97." Victorian Gothic: Literary and Cultural Manifestations in the Nineteenth Century. Eds. Ruth Robbins and Julian Wolfreys. London and New York: Palgrave Macmillan, 2000. 148-167. Print.

Machen, Arthur. "The Great God Pan." Late Victorian Gothic Tales. Ed. Roger Luckhurst. Oxford and New York: Oxford UP, 2005. 183-233. Print.

Margree, Victoria. "'Both in Men's Clothing': Gender, Sovereignty and Insecurity in Richard Marsh's The Beetle." Critical Survey 19.2 (2007): 63-81. Print.

Margree, Victoria and Bryony Randall. "Fin-de-siècle Gothic." The Victorian Gothic. Eds. Andrew Smith and William Hughes. Edinburgh: Edinburgh UP, 2014. Print.

Marsh, Richard. The Beetle. 1897. Toronto: Broadview, 2004. Print.

Masters, Bruce. The Arabs of the Ottoman Empire, 1516-1914: A Social and Cultural History. New York: Cambridge UP, 2013. Print.

Matikkala, Mira. Empire and Imperial Ambition: Liberty, Englishness and Anti-Imperialism in Late-Victorian Britain. London and New York: I.B. Tauris, 2011. Print.

Mazlish, Bruce. “A Triptych: Freud's The Interpretation of Dreams, Rider Haggard's 
She, and Bulwer-Lytton's The Coming Race." Comparative Studies in Society and History 35.4 (1993): 726-745. Print.

Merivale, Patricia. Pan the Goat-God: His Myth in Modern Times. Cambridge: Harvard UP, 1969. Print.

Mighall, Robert. A Geography of Victorian Gothic Fiction: Mapping History's Nightmares. Oxford and New York: Oxford UP, 1999. Print.

Monsmon, Gerald. H. Rider Haggard on the Imperial Frontier: The Political and Literary Contexts of His African Romances. Greensboro, NC: ELT, 2006. Print.

-----. "Who is Ayesha? An Allegory of Isis Unveiled." She: Explorations into a Romance. Ed. Tania Zulli. Rome: Aracne, 2009. 15-35. Print.

Murphy, Patricia. "The Gendering of History in She." Studies in English Literature, 1500-1900. 39.4 (1999): 747-772. Print.

Mustafa, Jamil. Mapping the Late Victorian Subject. Diss. U of Chicago, 1999. Print.

Navarette, Susan J. The Shape of Fear: Horror and the Fin de Siècle Culture of Decadence. Lexington: UP of Kentucky, 1998. Print.

Noys, Benjamin. "The Horror of the Real: Žižek's Modern Gothic." International Journal of Žižek Studies 4.4 (2010): n. pag. Web. 28 Feb. 2017.

van Onselen, Charles. The Fox and the Flies: the World of Joseph Silver, Racketeer and Psychopath. New York: Walker, 2007. Print.

Oppenheim, Janet. The Other World: Spiritualism and Psychical Research in England, 18501914. Cambridge: Cambridge UP, 1985. Print.

Owen, Alex. The Place of Enchantment: British Occultism and the Culture of the Modern. Chicago and London: U of Chicago P, 2004. Print. 
Parker, Ian. Slavoj Žižek: A Critical Introduction. London and Sterling, VA: Pluto Press, 2004. Print.

Parramore, Lynn. Reading the Sphinx: Ancient Egypt in Nineteenth-Century Literary Culture. New York: Palgrave MacMillan, 2008. Print.

Pasi, Marco. “Arthur Machen's Panic Fears: Western Esotericism and the Irruption of Negative Epistemology." Aries 7 (2007): 63-83. Print.

Pearson, Richard. "Archaeology and Gothic Desire: Vitality Beyond the Grave in H. Rider Haggard's Ancient Egypt." Victorian Gothic: Literary and Cultural Manifestations in the Nineteenth Century. Eds. Ruth Robbins and Julian Wolfreys. New York: Palgrave, 2000. 218-244. Print.

Petrey, Sandy. Speech Acts and Literary Theory. New York and London: Routledge, Chapman and Hall, 1990. Print.

Poller, Jake. "The Transmutations of Arthur Machen: Alchemy in 'The Great God Pan' and The Three Imposters." Literature and Theology 29.1 (2015): 18-32. Print.

Punter, David, editor. A Companion to the Gothic. Malden, MA and Oxford: Blackwell, 2000. Print.

------. The Literature of Terror: A History of Gothic Fictions from 1765 to the Present Day. Vol. I. London and New York: Longman, 1996. Print.

Punter, David and Glennis Byron. The Gothic. Malden, MA and Oxford: Blackwell, 2004. Print. Rebry, Natasha. "'A Slight Lesion in the Grey Matter': The Gothic Brain in Arthur Machen's The Great God Pan." Horror Studies 7.1 (2016): 9-24. Print.

Rigby, Mair. “'Do You Share My Madness?': Frankenstein's Queer Gothic.” Queering the 
Gothic. Eds. William Hughes and Andrew Smith. Manchester: Manchester UP, 2009. Print.

Rodgers, Terence. "Restless Desire: Rider Haggard, Orientalism and the New Woman." Women: A Cultural Review 10.1 (1999): 35-46. Print.

Roth, Phyllis, A. Bram Stoker. Boston: Twayne Publishers, 1982. Print.

Sedgwick, Eve Kosofsky. The Coherence of Gothic Conventions. New York: Arno P, 1980. Print.

Seed, David. "Eruptions of the Primitive into the Present: The Jewel of Seven Stars and The Lair of the White Worm." Bram Stoker: History, Psychoanalysis, and the Gothic. Eds. William Hughes and Andrew Smith. New York: St. Martin's, 1998. Print.

Senf, Carol. Science and Social Science in Bram Stoker's Fiction. Westport, CT: Greenwood, 2002. Print.

------. Bram Stoker. Cardiff, U of Wales P, 2010. Print.

Showalter, Elaine. Sexual Anarchy: Gender and Culture at the Fin de Siècle. New York and London: Viking, 1990.

-----. "Syphilis, Sexuality, and the Fiction of the fin de siècle." Reading Fin de Siècle Fictions. Ed. Lyn Pykett. London and New York: Longman, 1996. Print.

Smith, Andrew. Victorian Demons: Medicine, Masculinity and the Gothic at the Fin de Siècle. Manchester and New York: Manchester UP, 2004. Print.

Sparks, Tabitha. The Doctor in the Victorian Novel: Family Practices. Aldershot, UK: Ashgate, 2009. Print.

Spooner, Catherine and Emma McEvoy, editors. Routledge Companion to the Gothic. London and New York: Routledge, 2007. Print. 
Stauffer, Andrew M., ed. "Introduction." She: A History of Adventure. 1886-87. Toronto: Broadview, 2006. 1-26. Print.

Stevenson, Robert Louis. The Strange Case of Dr. Jekyll and Mr. Hyde. 1886. Ed. Martin Danahay. $2^{\text {nd }}$ ed. Ontario: Broadview, 2005. Print.

Stoker, Bram. Dracula. 1897. Ed. Glennis Byron. Toronto: Broadview, 2000. Print.

------. The Jewel of the Seven Stars. 1903. Intro. Kate Hebblethwaite. London: Penguin, 2008. Print.

Stott, Rebecca. The Fabrication of the Late-Victorian Femme Fatale: The Kiss of Death.

Houndmills, Basingstoke, and Hampshire England: Macmillan, 1992. Print.

"Syphilis-CDC Fact Sheet." Center for Disease Control and Prevention. 19 Oct. 2014. Web.

12 Aug. 2012.

Thompson, Jason. A History of Egypt: From Earliest Times to the Present. Cairo and New York: American U in Cairo P, 2008. Print.

Vanci-Osam, Ülker. “’May You Be Shot with Greasy Bullets': Curse Utterances in Turkish.” Asian Folklore Studies 57 (1998): 71-86. Print.

Vuohelainen, Minna. "You Know Not of What You Speak": Language, Identity, and Xenophobia in Richard Marsh's The Beetle: A Mystery (1897)." Fear, Loathing, and Victorian Xenophobia. Eds. Marlene Tromp, Maria Bachman, and Heidi Kaufman. Columbus: Ohio UP, 2013. 312-330. Print.

Warwick, Alexandra. "Vampires and the Empire: Fears and Fictions of the 1890s." Cultural Politics at the Fin de Siècle. Eds. Sally Ledger and Scott McCracken. Cambridge, New York, and Melbourne: Cambridge UP, 1995. 202-220. Print.

Wilde, Oscar. The Picture of Dorian Gray. 1890. Ed. Camille Cauti. New York: Fine Creative 
Media, 2003. Print.

Willburn, Sarah. "The Savage Magnet: Racialization of the Occult Body in Late Victorian Fiction." Women's Writing 15.3 (2008): 436-453. Print.

Wolfreys, Julian. "Introduction." The Beetle. By Richard Marsh. 1897. Ontario: Broadview, 2004. Print.

Worthham, John David. The Genesis of British Egyptology 1549-1906, Norman: U of Oklahoma P, 1971. Print.

Wynne, Catherine. Bram Stoker, Dracula and the Victorian Gothic Stage. Houndmills, Basingstoke, Hampshire and London: Palgrave Macmillan, 2013. Print.

Young, Shannon. "She: Rider Haggard's Queer Adventures." Nineteenth Century Literature in English 10.1 (2006): 245-266. Print.

Žižek, Slavoj. The Sublime Object of Ideology. London and New York: Verso, 1989. Print.

Zulli, Tania. "Between Body and Soul: She and the Aporia of Science and Religion." She: Explorations into a Romance. Ed. Tania Zulli. Rome: Aracne, 2009. 77-94. Print. 
Student Name: Davis Kristen $\frac{\text { (First) }}{\text { (Last) }}$ Janelle

Student ID \#: $\quad 700-97-4640$

Degree:

Document Type:

Document Title:

$$
\frac{{ }^{\prime} B}{b}
$$

I hereby certify that, if appropriate, I have obtained and attached hereto a written permission statement from the owners of each third party copyrighted matter to be included in my thesis, dissertation, project report, or other research material, allowing distribution as specified upon deposit.

I hereby grant to West Virginia University and its agents the non-exclusive license to archive and make accessible, under the conditions selected upon deposit, my above mentioned document in whole or in part in all forms of media, now or hereafter known. I retain ownership rights as specified in the WVU copyright policy to the copyright of the abovementioned document. I also retain the right to use in future works (such as articles or books) all or part of this abovementioned document.

\section{Review and Acceptance:}

The above mentioned document has been reviewed and accepted by the student's advisory committee. The undersigned agree to abide by the statements above, and agree that this Signature Form updates any and all previous Signature Forms submitted heretofore.

Signed:

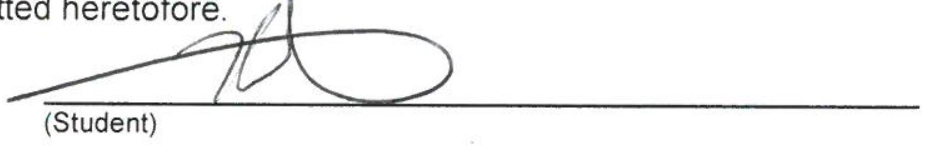

Committee:
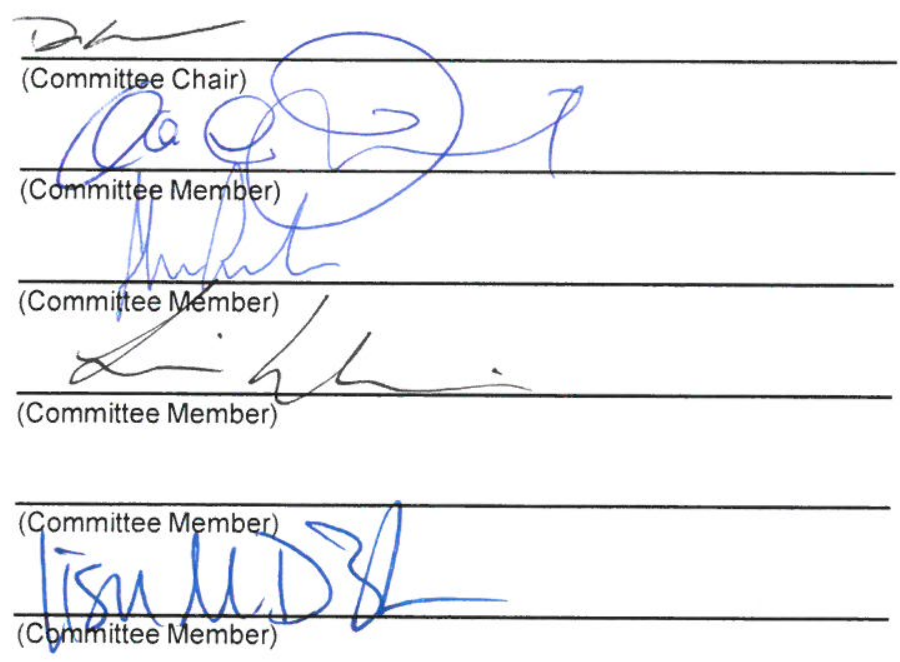

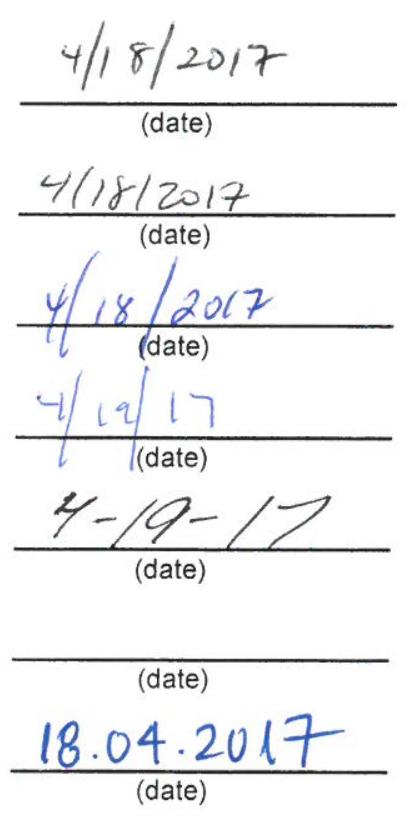

